Florida International University FIU Digital Commons

3-24-1997

\title{
An organizational learning approach to expatriate cross-cultural adjustment, organizational commitment, and job satisfaction
}

Meredith Downes

Florida International University

DOI: $10.25148 /$ etd.FI15101222

Follow this and additional works at: https://digitalcommons.fiu.edu/etd

Part of the Business Administration, Management, and Operations Commons

\section{Recommended Citation}

Downes, Meredith, "An organizational learning approach to expatriate cross-cultural adjustment, organizational commitment, and job satisfaction" (1997). FIU Electronic Theses and Dissertations. 3328.

https://digitalcommons.fiu.edu/etd/3328 
FLORIDA INTERNATIONAL UNTVERSTTY

Miami, Florida

\begin{abstract}
AN ORGANIZATIONAL LEARNING APPROACH TO EXPATRIATE CROSS-CULTURAL ADJUSTMENT, ORGANIZATIONAL COMMTMMENT, AND JOB SATISFACTION
\end{abstract}

A dissertation submitted in partial satisfaction of the

requirement for the degree of

DOCTOR OF PHLLOSOPHY

IN

BUSINESS ADMINISTRATION

by

Meredith Downes 
To: Harold E. Wyman

College of Business

This dissertation, written by Meredith Downes, and entitled An Organizational Learning Approach to Expatriate Cross-Cultural Adjustment, Organizational Commitment, and Job Satisfaction, having been approved in respect to style and intellectual content, is referred to you for judgment.

We have read this dissertation and recommend that it be approved.

Richard M. Hodgetts

Mary Ann Von Glinow

Michael R. Mullen

Anisya S. Thomas, Major Professor

Date of Defense: March 24, 1997

The dissertation of Meredith Downes is approved.

Dean Harold E. Wyman

College of Business

Dr. Richard L. Campbell

Dean of Graduate Studies

Florida International University, 1997 


\section{CCOPYRIGHT 1997 by Meredith Downes}

All rights reserved 
This dissertation is dedicated to my husband Frank ... for too many reasons to mention here. 


\section{ACKNOWLEDGMENTS}

My first round of thanks goes to a handful of the university faculty with whom I have worked over the past few years. In addition to successful end products, these relationships have resulted in my greater appreciation for collaborative research.

I wish to thank Dr. Galen Kroeck for his faith in my abilities from the onset. His willingness to undertake a time-consuming research endeavor, while still serving as Doctoral Program Coordinator, will not be forgotten. Together we brought to fruition some of Dr. Kroeck's innovative ideas for assessing the market for international careers. Special thanks also goes to Dr. Kannan Ramaswamy, under whose direction I was able to publish as a sole author for the first time. While his door was always open and his feedback continuous, his reticence to seek recognition for this effort is to his credit.

I am thankful to Dr. Karen Paul, who has treated me like a colleague for as long as I can remember. She fosters a team spirit among students, through a process of delegation and participation, and, while her new role as Associate Dean keeps her preoccupied, she is never too busy to give advice when it is sought. I would also like to extend my gratitude to Dr. Sherry Moss, who agreed to coach me through some of my preparation for comprehensive exams. Our sessions together were instrumental as a means to a successful end. 
I look forward to continued friendships and professional alliances with my fellow doctoral colleagues: Lori Zalka has been an ideal co-author and travel companion throughout my time in the program; Kevin Lowe, who, as both a study partner and co-author, represents the epitome of patience when the "going gets rough"; and Shawnta Friday, who joined us a year later as part of a cohort that met regularly to talk openly about anything and everything.

I am particularly grateful to my family, for enduring the various levels of accomplishment and anxiety that I have experienced during my doctoral tenure. I have shared my trials and tribulations with my Aunt Gerrye, Uncle Lenard, and my sister P.J., and now I wish to share with them my achievements. Perhaps most understanding have been both my mother and my husband Frank - my mother, who worries when I worry and rejoices when I rejoice, and Frank, who, after three years into the program, married me anyway. Frank and I have been a two-member team in earning this degree. I only hope to make him as proud of me as I am of him.

My next round of thanks goes to Dr. Paulette Johnson and Dr. Stephen Mueller, whose insights led to major breakthroughs in my dissertation analyses.

Last, but by no means least, I am indebted to my committee members, each of whom contributed to an ultimately successful defense. I will strive throughout my career to live up to the faith they have bestowed upon me.

I sincerely thank Dr. Richard M. Hodgetts, for his graciousness and understanding during the "restructuring" of my committee. He continued to 
welcome my office visits and frequent phone calls and provided me with constructive feedback at all stages of the process.

Dr. Mary Ann Von Glinow likewise has been influential to my academic career. Her concern for the entire doctoral cohort did not preclude her from giving this dissertation a great deal of attention. Since her arrival at the university, her role as our "liaison to the community" has led to some fruitful relationships and ideas about the practical application of my research.

I would also like to take this opportunity to thank Dr. Michael Mullen for agreeing to represent our partner institution, Florida Atlantic University, on my dissertation committee. He frequently devoted both university and conference time to methodological concerns and guided me through the organization of a rather large data set.

I am now left with the formidable task of finding the words to express my gratitude to Dr. Anisya S. Thomas. She has been more than a dissertation chairperson, offering selflessly of her time to train me as a teacher and a researcher and to provide insights into pursuing an academic career. She has been my ally and my harshest critic. She has also been my friend. Early on, we agreed that her role would not be to pat me on the back, but rather to tell it like it is. She has certainly lived up to that responsibility, and it is now my turn to live up to mine. Dr. Thomas has taught me how to teach, but perhaps even more importantly, she has taught me how to learn. And this skill I will now pass on to my own students. This 
dissertation is the first on which she has served as chair, and I hope that this experience will lead her to serve on others in the same capacity. 
ABSTRACT OF THE DISSERTATION

AN ORGANIZATIONAL LEARNING APPROACH TO

EXPATRIATE CROSS-CULTURAL ADJUSTMENT,

ORGANIZATIONAL COMMITMENT, AND JOB SATISFACTION

by

\section{Meredith Downes}

Florida International University, 1997

Professor Anisya S. Thomas, Major Professor

The purpose of this study was to investigate the relationship between organizational learning and expatriation in overseas subsidiaries as well as in organizations as a whole. In doing so, two issues were addressed -- (i) the use of expatriation as firms internationalize, and (ii) the significance of various factors to expatriate success as firms gain international experience. The sample of companies for this study was drawn from U.S. Fortune 500 multinational corporations (MNCs) in two sets of related industries -- computers/ electronics and petroleum/chemicals. Based on the learning that takes place within organizations as they increase their involvement overseas, a positive relationship was expected between international experience and expatriation when internationalization was low, and a negative relationship was expected when internationalization was high. Results indicate a significant positive relationship between country experience and the proportion of expatriates in that subsidiary when subsidiaries were relatively young, and a negative relationship, however not significant, for more mature subsidiaries. The relationship 
between overall firm degree of internationalization (DOI) and the proportion of expatriates in the firm as a whole was negative regardless of stage of internationalization, but this relationship was significant only for highly internationalized firms. It was further suspected that individual, environmental, and family-related characteristics would have a significant effect on the success of expatriates whose firms were low on internationalization, and that organizational characteristics would play a significant role in highly internationalized firms. Support for these hypotheses was received with respect to certain outcomes and some determinants of success. The preponderance of support was found for those addressing the effects of both environmental and family-related characteristics on the cross-cultural adjustment of expatriates in firms with little international experience. Considerable support was also found for those hypotheses addressing the impact of organizational characteristics on the job satisfaction levels of expatriates assigned to mature subsidiaries. The relevant literatures on organizational learning and expatriation are reviewed, and a model is developed underlying the logic of the hypotheses. Research methods are then described in full detail, results are reported, and implications for theory and for management are discussed. 
CHAPTER

I. INTRODUCTION 1

The Research Study $\quad 2$

Literature Review $\quad 8$

Methods $\quad 8$

Results 9

Discussion $\quad 10$

II. LITERATURE REVIEW

$\begin{array}{ll}\text { Introduction } & 12\end{array}$

The Importance of Expatriation $\quad 12$

Expatriation Defined 12

Advantages of Expatriation $\quad 14$

Theoretical Background and Hypotheses 17

$\begin{array}{ll}\text { Organizational Learning } & 17\end{array}$

$\begin{array}{ll}\text { Organizational Learning Defined } & 17\end{array}$

Individual v. Organizational Learning $\quad 17$

Types of Learning 18

Organizational Learning and Strategic
Competitiveness

The International Transfer of Knowledge $\quad 22$

Market-Specific Knowledge 23

General Knowledge 24

Expatriation as a Means of Transferring

Knowledge 25

Hypotheses $\quad 27$

The Use of Expatriates as Firms Internationalize $\quad 27$

The Determinants of Expatriate Success as Firms 29

$\begin{array}{ll}\text { Internationalize } & 29 \\ \text { Expatriate Success } & 32\end{array}$

Cross-Cultural Adjustment $\quad 39$

Individual-Level Determinants of Adjustment $\quad 40$

Organizational-Level Determinants of Adjustment 41

Environmental-Level Determinants of Adjustment 43

Family-Related Determinants of Adjustment 43 
Organizational Commitment 44

Individual-Level Determinants of Commitment $\quad 45$

Organizational-Level Determinants of Commitment 46

Job Satisfaction $\quad 47$

Individual-Level Determinants of Satisfaction $\quad 48$

Organizational-Level Determinants of Satisfaction 49

Environmental-Level Determinants of Satisfaction 50

Summary of Expatriate Success Research 51

III. METHODS 54

Introduction $\quad 54$

Sample and Setting $\quad 54$

Data Collection $\quad 56$

Primary Sources $\quad 56$

Packages $\quad 57$

Package A $\quad 57$

Package B 58

Secondary Sources $\quad 59$

Measures $\quad 59$

Primary Sources $\quad 59$

Expatriate Success $\quad 59$

Cross-Cultural Adjustment $\quad 59$

Previous Measures 59

Current Study 61

Organizational Commitment 62

Previous Measures 62

Current Study 63

Job Satisfaction 63

Previous Measures 63

Current Study 65

Proportion of Expatriates 65

Determinants of Expatriate Success 65

Individual-Level Determinants $\quad 65$

Age 65

Firm Tenure $\quad 66$

Previous Overseas Experience $\quad 66$ 
Organizational-Level Determinants $\quad 66$

Role Ambiguity \& Role Discretion $\quad 66$

Career Development Practices $\quad 66$

Environmental-Level Determinants 67

Cultural Familiarity $\quad 67$

Family-Related Determinants $\quad 68$

Spousal Cross-Cultural Adjustment $\quad 68$

Country Experience $\quad 68$

Secondary Sources 69

Degree of Internationalization $\quad 69$

Determinants of Expatriate Success $\quad 70$

Environmental-Level Determinants $\quad 70$

Geographic Proximity 70

Level of Development 71

Risk 71

$\begin{array}{ll}\text { Analysis } & 72\end{array}$

Response Rates $\quad 72$

Respondent Profiles 73

Reliability and Validity of Measures $\quad 77$

Expatriate Success $\quad 77$

Cross-Cultural Adjustment $\quad 77$

Organizational Commitment 81

Job Satisfaction $\quad 82$

Determinants of Expatriate Success $\quad 83$

Role Ambiguity \& Role Discretion 83

Career Development Practices 83

Spousal Cross-Cultural Adjustment $\quad .84$

Variables and Correlations $\quad 85$

$\begin{array}{ll}\text { Differences Among Means } & 87\end{array}$

IV. RESULTS 91

The Use of Expatriates as Firms Internationalize

Expatriation and Country Experience 91

Expatriation and Degree of Internationalization 94

The Determinants of Expatriate Success as Firms Internationalize 98

The Determinants of Expatriate Cross-Cultural Adjustment 98 Country Experience 102

Young Subsidiaries 102

Mature Subsidiaries 103 
Degree of Internationalization $\quad 104$

Low DOI 104

High DOI 106

The Determinants of Expatriate Organizational Commitment $\quad 106$

Country Experience 110

Young Subsidiaries $\quad 110$

Mature Subsidiaries 110

Degree of Internationalization $\quad 110$

Low DOI 110

High DOI 111

The Determinants of Expatriate Job Satisfaction 111

Country Experience 114

Young Subsidiaries $\quad 114$

Mature Subsidiaries $\quad 114$

Degree of Internationalization $\quad 116$

Low DOI 116

High DOI 116

The Relative Importance of Individual, Organizational,

Environmental, and Family-Related Characteristics 117

Expatriate Cross-Cultural Adjustment 117

Country Experience $\quad 117$

DOI 121

Expatriate Organizational Commitment 121

Country Experience 121

DOI 121

Expatriate Job Satisfaction $\quad 122$

Country Experience $\quad 122$

DOI 122

Summary of Results 122

$\begin{array}{ll}\text { V. DISCUSSION } & 124\end{array}$

$\begin{array}{ll}\text { Introduction } & 124\end{array}$

Hypothesis 1: The Use of Expatriates as Firms Internationalize 125

Implications 126

Theory 126

Practice 127

Limitations $\quad 129$

Suggestions for Future Research $\quad 130$ 
Hypotheses 2, 3, and 4: The Determinants of Expatriate

Success as Firms Internationalize

Implications

Theory

132

Practice

Support of the Model Based on Outcome

Support for Individual, Organizational,

Environmental, and Family-Related

Characteristics

The Role of Overall Firm Internationalization

Limitations

v. Specific Country Experience

Suggestions for Future Research

Overall Implications and Contributions

Conclusion

\section{APPENDIX}

Appendix A: Summary of Expatriate Cross-Cultural

$$
\text { Adjustment Literature }
$$

Appendix B: Summary of Expatriate Organizational Commitment

$$
\text { Literature }
$$

Appendix C: Summary of Expatriate Job Satisfaction Literature

Appendix D: Letter to HR Manager (limited participation)

Appendix E: Letter to HR Manager (full participation)

Appendix F: HR Manager Survey

Appendix G: Letter to Expatriates

Appendix H: Expatriate Survey

Appendix J: Index of Abbreviations 


\section{LIST OF TABLES AND FIGURES}

Table 1: Cross-Cultural Adjustment Hypotheses for Country Experience and Degree of Internationalization

Table 2: Organizational Commitment Hypotheses for Country Experience and Degree of Internationalization

Table 3: Job Satisfaction Hypotheses for Country Experience and Degree of Internationalization

Table 4: $\quad$ Summary of Empirical Studies on Expatriate Success

Table 5: $\quad$ Fortune 500 Companies

Table 6: $\quad$ Respondent Profiles

Table 7: $\quad$ Factor Structures for Dependent Scales

Table 8: $\quad$ Factor Structures for Independent Scales

Table 9: $\quad$ Correlations, Means, and Standard Deviations for All Variables

Table 10: Means and Standard Deviations by Country Experience and Degree of Internationalization

Table 11: Differences Among Means for the Dependent Variables

Table 12: Results of H1: The Use of Expatriates as Firms Internationalize

Table 13: Results of H2: Cross-Cultural Adjustment Models with Country Experience and Degree of Internationalization as Moderators

Table 14: Cross-Cultural Adjustment Models with Country Experience and Degree of Internationalization as Moderators: Significant Variables Only

Table 15: Results of H3: Organizational Commitment Models with Country Experience and Degree of Internationalization as Moderators 
Table 16: Organizational Commitment Models with Country Experience and Degree of Internationalization as Moderators: Significant Variables Only

Table 17: Results of H4: Job Satisfaction Models with Country Experience and Degree of Internationalization as Moderators

Table 18: Job Satisfaction Models with Country Experience and Degree of Internationalization as Moderators: Significant Variables Only

Table 19: Standardized Beta Coefficients for Significant Variables:

Expatriate Cross-Cultural Adjustment

Table 20: Standardized Beta Coefficients for Significant Variables:

Expatriate Organizational Commitment

Table 21: Standardized Beta Coefficients for Significant Variables:

Expatriate Job Satisfaction

Figure 1: A Dynamic Model of Organizational Learning and Expatriation

Figure 2: A Depiction of Knowledge Transfer in Multinational Corporations: The Role of Expatriates

Figure 3: The Impact of International Experience on Expatriate Success

Figure 4: Scatter Plots of the Relationship Between Country Experience and Proportion of Expatriates in the Subsidiary

Figure 5: $\quad$ Scatter Plots of the Relationship Between Degree of Internationalization and Proportion of Expatriates in the Firm 


\section{Chapter I \\ Introduction}

Intellectual capital, the knowledge resident in the human resources of an organization, is becoming a vital element in the global competitive arena. This asset, which consists of a firm's capability to extract the best solutions from its people; also defines its ability to learn and continuously expand its base of knowledge. In the era of the knowledge economy, effective organizations are those that can successfully recruit, enhance, and retain this intellectual capital. This study explores the link between organizational learning and expatriation effectiveness among multinational organizations. By investigating the determinants of successful expatriation experiences over time, prescriptions for effectively managing this expensive human resource can be developed.

Firms establishing subsidiaries abroad are faced with three staffing alternatives -(i) PCNs, or parent-country nationals, who are sent on assignments overseas for an average of three to five years, (ii) HCNs, or host-country nationals, who are recruited from the host country, and (iii) TCNs, or third-country nationals, who are recruited from a location that is neither the home nor the host country. While both PCNs and TCNs may be referred to as expatriates, as they are essentially foreigners in the locations to which they are assigned, it is typical in the literature to use "expatriates" and "PCNs" interchangeably. This study will do the same, reserving the term "TCNs" for third-country nationals.

Expatriation represents the most expensive staffing strategy for the multinational corporation (MNC), averaging approximately three times the executive's home-country 
salary. The literature indicates that expatriates often return from these assignments prematurely, increasing these costs exponentially. Nonetheless, expatriation remains a viable method for facilitating coordination among subsidiaries, for establishing relationships with host governments and other interest groups, and for increasing the firm's overall understanding of international operations.

While organizations may perceive expatriation as an attractive method for accumulating foreign market knowledge, the enormous investment involved in this type of strategy challenges the organization to select, retain, and successfully repatriate the most appropriate individuals. Thus factors contributing to the successful expatriation experience are of significant interest to MNCs as well as to academics eager to provide theoretical explanations for the phenomenon of expatriation and to aid in predicting its outcomes.

\section{THE RESEARCH STUDY}

The purpose of this study is to examine the role of expatriate managers in the learning process that firms undergo as they increase their international involvement. To accomplish this, two issues are addressed -- (i) the use of expatriation as firms internationalize, and (ii) the significance of individual, organizational, environmental, and family-related factors to expatriate success as a company gains international experience.

For the first research question, it was expected that as firms internationalize, they will gradually increase their expatriate populations in order to expand their international knowledge bases, but that the use of expatriation will diminish as international experience 
is gained, and that this is due to the "learning-by-doing" and subsequent expansion of both the market-specific and the general knowledge base. Thus hypotheses are tested for both the extent to which the firm has had experience operating in a specific country and for the overall firm degree of internationalization (DOI).

The hypotheses put forth in this study to address the second research question contend that the learning experienced through internationalization influences desirable expatriate outcomes. It was expected that individual, environmental, and family-related characteristics would have a significant effect on the success of expatriates whose firms are low on internationalization. And, in contrast, organizational characteristics would have a significant effect on the success of expatriates whose firms are highly internationalized. As the firm gains international experience and organizational learning occurs and is institutionalized, the necessary training and knowledge may be transmitted to the expatriate pool about how to embark on the overseas assignment. In this regard, the organization has entered a zone of higher learning, building on its prevailing resource base. By undertaking training, establishing standard operating procedures, and clearly defining the expatriate's organizational role, the organization is able to buffer the executive from the external environment, diminishing the importance of individual and environmental factors, as well as those associated with the family.

The logic of the study is diagramatically depicted in Figure 1, which illustrates the learning and transfer of knowledge over the course of an organization's internationalization experience. In the early stages of firm internationalization, when a new subsidiary is established, expatriation is an important vehicle for the transfer of 


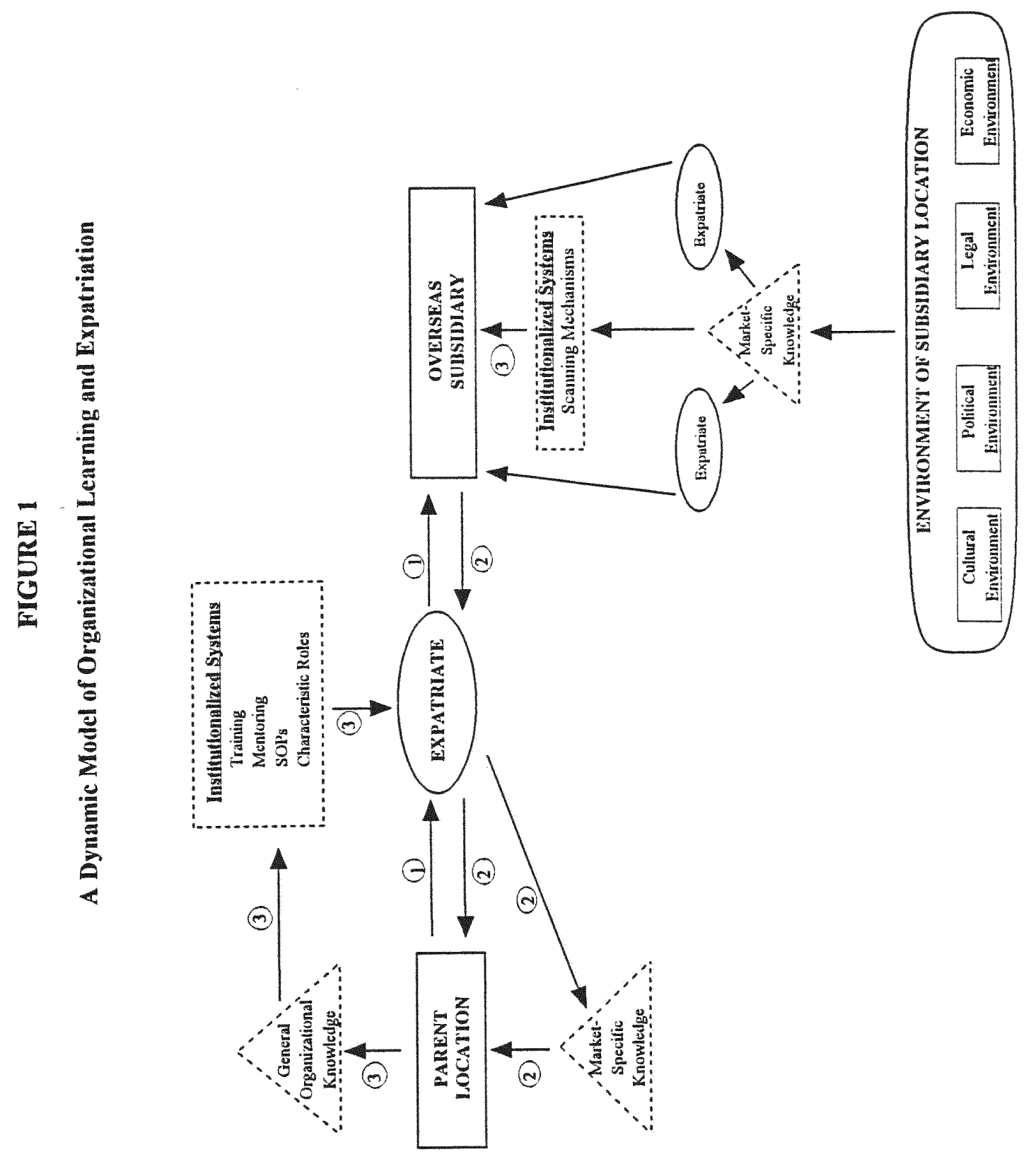


headquarters' philosophy, culture, and strategy from the parent to the subsidiary (Path 1). As the subsidiary becomes established and the transfer is largely completed and institutionalized, the need for expensive expatriates is reduced. At the subsidiary, the home-country expatriate serves as a symbolic and physical link to the parent in interactions with the local business community and government. Given the organization's relative inexperience with foreign environments, the success of the expatriation experience is largely dependent on the competencies of the individual and the hostility or benignness of factors in the host-country environment. Over time, however, as the new subsidiary gains experience, knowledge of market-specific factors begins to accumulate. This knowledge, gained through the expatriate's interactions with various sectors of the environment and/or through other scanning mechanisms, is transferred back to the parent (Path 2) in the home country. As the organization as a whole gains greater international experience, it can become more effective at gathering such data from its various subsidiaries. This data in turn is integrated with the existing knowledge base to create institutionalized systems such as predeparture training, mentoring, and role definitions, all intended to improve the expatriation experience. Thus, eventually the organization, both at the parent as well as subsidiary locations, can buffer the expatriate from environmental factors. In doing so, the importance of individual adaptive capabilities as well as the nature of the host environment is diminished. In other words, as the organization learns from subsequent international experiences, it can systematically introduce mechanisms to improve the expatriation experience (Path 3). This overall model is broken down into Figures 2 and 3, which represent the logic of expatriation as a staffing mechanism and the determinants of 


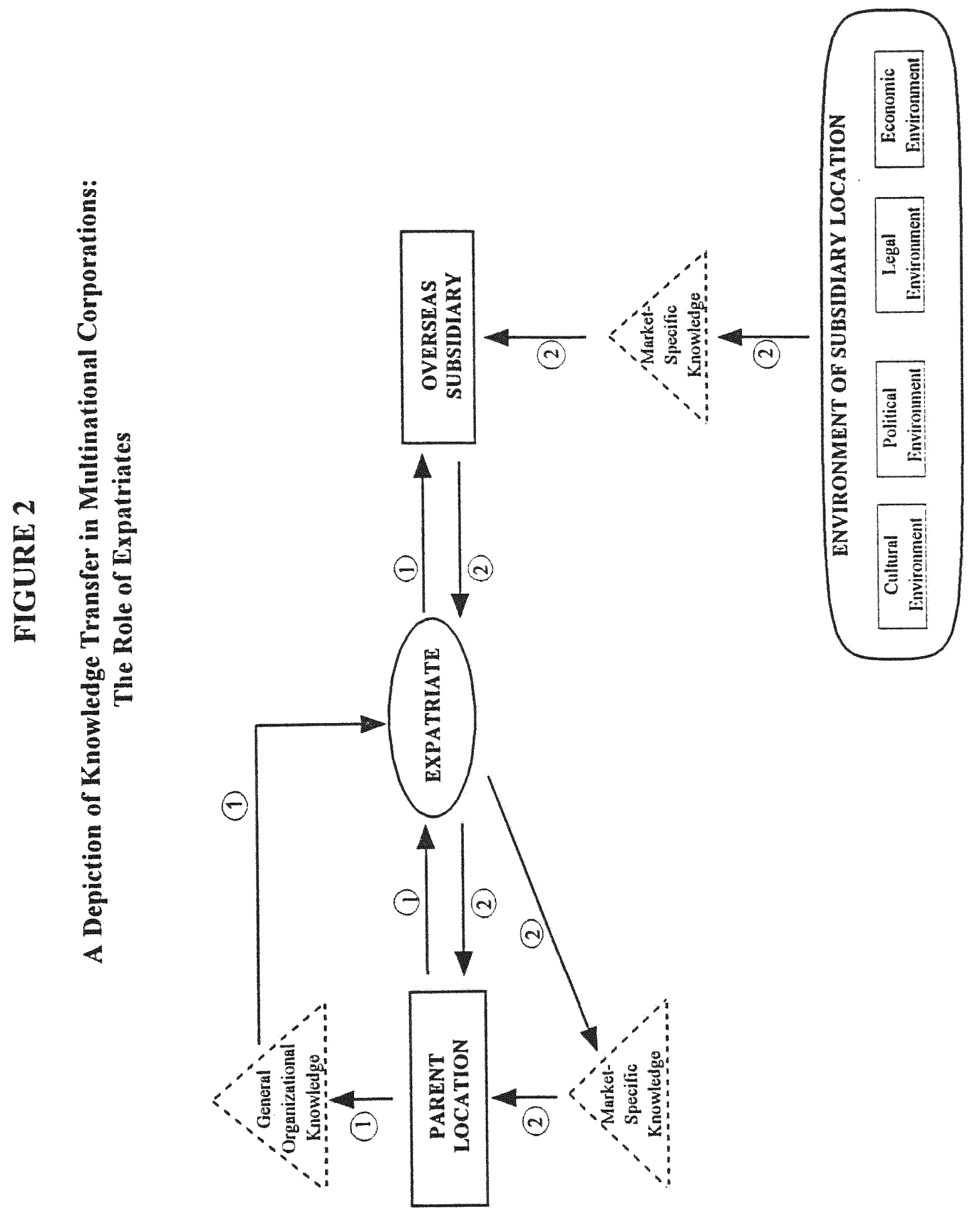



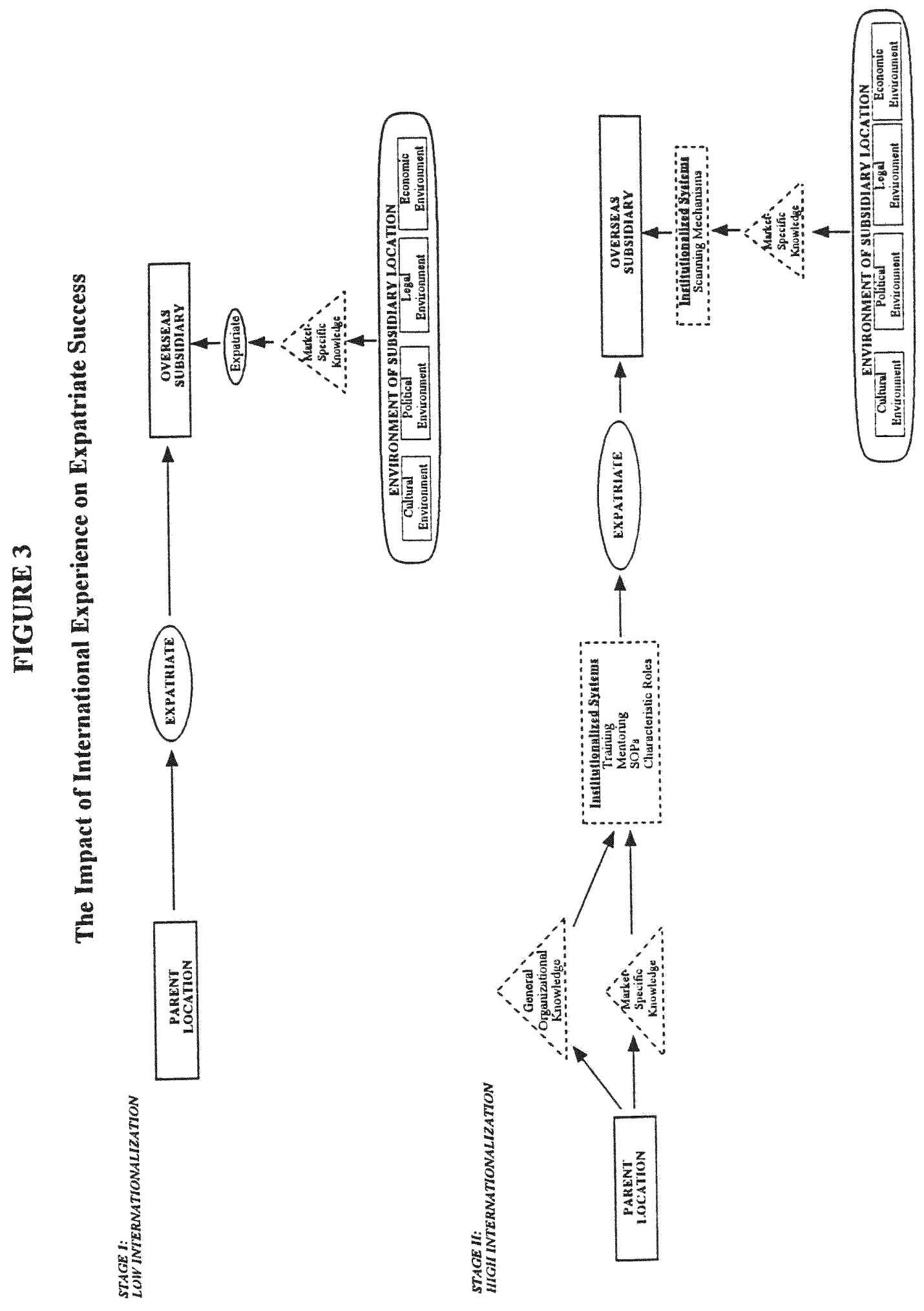
expatriate success, respectively. The next section briefly outlines the structure and content of the remaining chapters which provide greater detail on the development and test of the theoretical model.

\section{Literature Review}

Chapter II provides the foundation for this research, laying the groundwork for the model to be tested. Upon establishing that intellectual capital is essential to the long-term survival of the MNC, it is shown how firms nurture and expand their resident bases of knowledge through the continuous transfer of core competencies (the capabilities which form the basis of competitive advantages), a process known as organizational learning, most specifically through expatriates on assignment abroad. The literature on organizational learning is reviewed and two sets of hypotheses are offered to test the research questions. The literature on expatriate effectiveness is then reviewed and synthesized in justification of those variables selected to represent expatriate success and its determinants.

\section{Methods}

A detailed description of the research methods used in this study are provided in Chapter III. Highlights of this chapter include a description of the research setting and the use of both primary and secondary data collection techniques. The sample of companies for this study was drawn from U.S. Fortune $500 \mathrm{MNCs}$ in two sets of related industries -computers/electronics and petroleum/chemicals -- due to their maximally different international histories. Within these industries, data was collected at three levels of analysis via questionnaires completed by human resource managers and expatriates 
currently on assignment abroad. The chapter provides a description of the samples representing usable data - expatriates, subsidiaries, and firms. The use of secondary data is also addressed, where published sources were tapped for macro-level, host-country information, as well as for financial information relevant to participating organizations. The chapter then describes the measurement of each variable for the purpose of the study. Finally, results of some preliminary analyses are offered, including the reliability and validity of measurement scales, the correlations among all variables, and tests for differences among means.

\section{Results}

Results of the study are presented in Chapter IV. The first set of hypotheses stated that (i) there will be a positive relationship between international experience and expatriation when there is relatively little experience in a host country as well as in the overall international arena, and (ii) this relationship will be negative when there is considerable experience at the country level and when the firm is highly international overall. Two sets of multiple linear regression models were run -- one using country experience and one using degree of internationalization (DOI) -- as the independent variable. A significant relationship emerged between country experience and proportion of expatriates in a given subsidiary, but only when there was considerable experience in that host environment. This relationship is negative, indicating that, after a certain level of experience is gained in a host country, firms tend to reduce their expatriate populations in subsidiaries located there. A significant, positive relationship emerged between DOI and proportion of expatriates in the firm, for those firms with little international experience. 
While this relationship was negative for highly internationalized firms, it was not significant. Thus each hypothesis is partially supported. Scatter plots display the distribution of expatriate employment along the internationalization continuum.

The second set of hypotheses addressed the determinants of expatriate success as firms internationalize. Specifically, it was expected that individual, environmental, and family-related characteristics would have a significant effect on the success of expatriates whose firms were low on internationalization, and that organizational characteristics would play a significant role for highly internationalized firms. Again, multiple linear regression models were run separately when either country experience or DOI was used to moderate the relationships between the independent variables and the success measures. Hypotheses were partially supported, either with respect to certain outcomes or independent variables, or with respect to whether internationalization was measured at the subsidiary level or for the company as a whole. The preponderance of support was found for those hypotheses addressing the effects of environmental and family-related characteristics on the cross-cultural adjustment of expatriates in firms with little international experience. Considerable support was also found for those hypotheses addressing the impact of organizational characteristics on the job satisfaction levels of expatriates assigned to mature subsidiaries.

\section{Discussion}

Chapter $\mathrm{V}$ reviews the empirical findings for the two research questions and discusses the implications of these findings for both IHRM theory and practice. It is 
suggested that a significant relationship between subsidiary age and expatriation when country experience is limited has the potential to advance the field of IHRM by providing a theoretical explanation --organizational learning - for why expatriation remains in wide use among MNCs. Additional insight is offered as to why the strategy of expatriating home-country nationals is reduced over the international life of the subsidiary.

Implications from the models of the determinants of expatriate success are also addressed in Chapter V. The model integrates paradigms from IHRM and Organizational Development by linking the internationalization process to organizational learning theory. From a practical perspective, in an effort to enhance expatriate adjustment, firms may choose to emphasize environmental, host-country characteristics, perhaps through the strategic selection of operation sites, when international experience is low, and to place greater emphasis on task-related factors as experience is gained, which is shown to increase expatriate job satisfaction in more mature subsidiaries. These and other issues are addressed in greater detail in this final chapter, followed by potential limitations from both a theoretical and methodological perspective and some suggestions for proceeding with this line of research. The chapter closes by synthesizing the implications of both sets of research questions and offering some concluding remarks on international human resource management in general and on expatriation in particular. 


\section{Chapter II \\ Literature Review \\ INTRODUCTION}

In this chapter, the impetus and foundation for the current study are explained. Additionally, reasons for firms to pursue an expatriate strategy are delineated in order to emphasize the importance of expatriating key personnel abroad. The chapter explains how intellectual capital is developed through the continuous transfer of core competencies, a process known as organizational learning. Relevant literature on organizational learning is reviewed, and hypotheses are approached via the role expatriates may play in this learning phenomenon. Subsequent to offering a set of research questions, in the form of testable hypotheses, literature on expatriate effectiveness is reviewed and synthesized.

\section{THE IMPORTANCE OF EXPATRLATION}

\section{Expatriation Defined}

Expatriation refers to the practice by multinational corporations (MNCs) of sending home-country nationals to overseas locations. For example, when General Motors, a U.S. MNC, sends an American executive to China to manage its subsidiary there, the manager is a U.S. expatriate in China. Similarly, when Royal Dutch Shell sends a Dutch national to Saudi Arabia to head up its Middle East operations, the individual is a Dutch expatriate in that country.

According to the U.S.-based Employee Relocation Council, the average annual cost to send an employee overseas is US $\$ 200,000$ to $\$ 250,000$, which is roughly three 
times the executive's home-country salary (O'Boyle, 1989). However, if the expatriate fails to complete the overseas assignment, these costs are exacerbated (Bird \& Dunbar 1991; Black, 1988), particularly if the person is replaced with another expatriate.

The expatriation literature indicates that premature returns from expatriate assignments are a persistent problem for U.S. companies, fluctuating between 25 and 40 percent on the average (Bird \& Dunbar, 1991; Black, 1988; Henry, 1965; Tung, 1981; Zeira \& Banai, 1987). Direct costs of such early returns include salary, training, and relocation allowances (Mendenhall \& Oddou, 1985). In addition, indirect costs associated with an incomplete assignment may include strained relations with host-government officials and/or key clients, which in turn may result in loss of market share (Harvey, 1983).

An alternative to expatriation is the use of either host-country nationals ( $\mathrm{HCNs}$ ) or third-country nationals (TCNs) in overseas affiliates. To illustrate, GM may select a local Chinese executive (an $\mathrm{HCN}$ ) to manage its operation in China or may opt for someone from yet a third country ( $\mathrm{TCN}$ ), such as a British national.

Advantages of locally-hired managers include a better understanding of the cultural, political, and economic context of the host environment (Copeland \& Griggs, 1985). Thus, HCNs are often more in tune with subtle changes in consumer buying habits, customer complaints, and government regulations on the local front (Kobrin, 1988).

In contrast, advantages associated with staffing overseas subsidiaries with TCNs (or those who are recruited from a location that is neither the home nor the host country) include a more comprehensive search for the best candidate. Since recruitment is not 
restricted by nationality, the search is open to the most qualified candidate anywhere in the world. Furthermore, employing TCNs, especially in conjunction with home- and hostcountry nationals, enhances the diversity of the subsidiary work force and the experiences that are brought to the table.

Despite the apparent advantages of employing $\mathrm{HCNs}$ and TCNs in overseas affiliates, firms continue to expatriate due to the unique value associated with sending parent-country nationals abroad. For example, International Business Machines (IBM) maintains a base of approximately 700 U.S. expatriates among its population of 1,800 on foreign assignments.

\section{Advantages of Expatriation}

The fact that expatriate assignments remain in wide use among U.S. MNCs may be attributed to the value that they can add to both the subsidiary and to the organization as a whole. Among these value-added contributions are the potential to:

(i) facilitate the communication process between the parent location and its subsidiaries, as well as across subsidiaries (Boyacigiller, 1991; Rosenzweig, 1994).

(ii) enforce and protect the company's interests (Bird \& Dunbar, 1991; Dowling, Schuler, \& Welch, 1994).

(iii) aid in establishing country linkages (Boyacigiller, 1990).

(iv) increase the firm's understanding of international operations (Boyacigiller, 1991).

Expatriate assignments may facilitate intersubsidiary communication and coordination (Boyacigiller, 1991; Rosenzweig, 1994) by transferring overall corporate 
philosophies and the company vision along with the expatriate. Having worked for the company in its home location, it is likely that the expatriate has "bought into" the corporate culture through assimilation and socialization, and would therefore communicate goals and objectives in the manner in which they were intended. As a result, subsidiary objectives, policies, and procedures are more likely to comply with those at the corporate location.

Furthermore, when foreign market conditions are uncertain, especially when there are host-country pressures to protect domestic businesses, home-country nationals are more likely than local managers to look out for the company's interests. If put in a position to negotiate with local contingencies, whether they be the host government, suppliers, or distributors, there will be less concern about the expatriate's loyalties.

The use of expatriates in overseas subsidiaries may also aid in forming linkages with other nations (Boyacigiller, 1990). On-going relationships with host-country governments, domestic businesses, and other interest groups can enhance the competitiveness of firms operating abroad. As these firms compete for access and for market share in the international arena, the "first-mover advantages" associated with government concessions and establishing efficient channels for distribution may be critical to long-term success. When expatriates, as opposed to $\mathrm{HCNs}$, are involved in those activities, the organizational ties to the host country are stronger due to the manager's ultimate repatriation.

Finally, the practice of employing expatriates may be a strategic move on the part of an MNC to increase the international experience and knowledge base of present and 
future managers (Boyacigiller, 1991). GM, for example, expatriates key personnel as a means of "transferring some very specific technology abroad", (J. McClure, personal communication, 1995) with the expectation that knowledge and skills will also be acquired and transferred back to the home country upon repatriation.

A significant advantage of expatriation, then, is the organizational learning that is facilitated by the expatriate's experiences overseas. Thus expatriation is a tool by which organizations can gather and maintain a resident base of knowledge about the complexities of international management. This knowledge in turn provides for competitive advantage by creating a cadre of cosmopolitan executives sensitive to international opportunities. According to Boyacigiller (1991):

If high-potential individuals are carefully selected and trained for overseas positions, they will not only facilitate the maintenance of an international network of operations in the short term but should be allowed to continue providing informational support upon their return to the U.S. The international education that future executives could acquire in these types of assignments cannot be replicated in any classroom.

In the following sections, the literature on organizational learning is reviewed as a step toward deriving a dynamic model describing the determinants of successful expatriate assignments, and hypotheses are offered to test these notions. The chapter concludes with a review of the current base of literature relevant to successful expatriate assignments. 


\section{THEORETICAL BACKGROUND AND HYPOTHESES}

\section{Organizational Learning}

\section{Learning Defined}

\section{Individual y. Organizational Learning}

The dictionary defines learning as "the acquiring of knowledge" (Webster's II New Riverside University Dictionary, 1984). It encompasses both the acquisition of "knowhow", which implies the physical ability to produce some action, and the acquisition of "know-why", or the ability to articulate conceptual understanding of an experience (Kim, 1993). Learning requires some conscious acquisition of knowledge or insight on the part of an individual (Argyris \& Schön, 1978), but if this knowledge is unrelated to organizational action or decision-making, it is relevant only to individual learning and not to that of the organization (Miller, 1996).

Analogous to individual learning, organizational learning is defined as "the acquisition of new knowledge by actors who are able and willing to apply that knowledge in making decisions or influencing others in the organization" (Prahalad \& Hamel, 1990). However, the learning process is fundamentally different at the organizational level (March \& Olsen, 1975), in that it must impart intelligence and learning capabilities to a nonhuman entity without anthropomorphizing it ( $\mathrm{Kim}, 1993)$, or without losing something in the translation. Organizational learning capability entails the ability to move the lessons learned from experience across boundaries (Ulrich, Von Glinow, \& Jick, 1993), in order to both generate and generalize ideas with impact. While individuals learn by acquiring tacit knowledge through education, experience, or experimentation, this learning need not 
be shared. Organizational learning, on the other hand, occurs as individual learning is shared and transferred to new individuals, whether across boundaries of space, time, or hierarchy.

Organizational learning may be thought of as an aggregation of the learning of an organization's individual members (Marsic \& Watkins, 1990). Throughout the learning process, a culture is created that becomes a repository for collective learning (Schein, 1992). Such learning may manifest itself in the establishment of core competencies (Prahalad \& Hamel, 1990) or in the transfer of competencies between generations of employees (Van Maanen \& Schein, 1979), a process known as socialization. As socialization takes place, organizations develop the capability to translate historical inferences into routines that guide behavior (Levitt \& March, 1988).

In the early stages of existence, an organization consists of a small group of people and therefore has minimal structure. Hence, organizational learning remains synonymous with that in the individual case. The distinction becomes pronounced as the organization grows and a system evolves for capturing the learning of its individual members (Kim, 1993), whereby information is somehow stored and reasonably retrievable -- in the minds of individuals, in computer memories, and in written reports, for example.

\section{Types of Learning}

The literature on learning methods is somewhat fragmented, ranging from behavioral/strategy level learning (Duncan, 1974) to habit-forming/discovery (Hedberg, 1981) to reactive/proactive learning (Miles, 1982). However, the majority of learning 
theories tend to converge on the distinction between single- and double-loop learning processes, as introduced by Argyris and Schön (1978).

Single-loop learning, also referred to as learning at the procedural (Miller, 1996) or lower level, focuses on influencing behavioral outcomes such as the steps necessary to complete a particular task. This know-how is captured in routines, such as filling out forms, operating a piece of machinery, or handling a switchboard. These standard operating procedures (SOPs) accumulate and, in turn, change routines.

Double-loop learning, which may be thought of as conceptual (Kim, 1993) or higher-level learning, aims to create new insight, heuristics, and a collective consciousness within the organization (Fiol \& Lyles, 1985). Conceptual learning has to do with thinking about why things are done in the first place, challenging the nature or existence of prevailing SOPs (Kim, 1993), and it often produces specialization and highly differentiated organizational designs that in turn promote non-routine behavior (Levitt \& March, 1988).

Although many typologies are available for understanding how learning occurs, Miller's (1996) integrative framework allows for the distinction between lower and higher orders of learning as well as between learning at the individual and organizational levels, and is therefore helpful in laying the foundation for the current study. Miller (1996) identified and categorized six modes of learning, as described below, on the basis of two dimensions -- methodological and emergent.

Methodological inquiry is analytical and deals with objective facts. It is systematic and often tests notions deductively. Facts are gathered and evaluated in an orderly way and with explicit purpose (Ansoff, 1965). In contrast, emergent rationality is spontaneous 
and intuitive, and it centers on instincts and impressions. Intuitive managers learn tacitly and inductively, and choices might be made quite unconsciously (Miller, 1990; Mintzberg, 1989).

\section{Methodological}

- Analytic

- Experimental

- Structural

\section{Emergent}

- Synthetic

- Interactive

- Institutional
Intensive analysis due to careful environmental scanning

Similar to analytic learning, except that action sometimes precedes analysis in the learning cycle (Weick, 1979), implying "learning by doing".

Codification of prior learning by specifying how to carry out tasks and roles efficiently. This is learning via routines or SOPs.

Combines pieces of knowledge so that the whole is greater than the sum of the parts and is characterized by harmony, consistency, and fit (Mintzberg, 1989).

Learning by doing, but the learning is less systematic (than with experimental learning). It is impulsive and implicit, achieved, for example, by bargaining with each other and with external stakeholders (Cohen, March, \& Olsen, 1972).

Learning by a very large group, so that knowledge is widely diffused, by establishing organizational myths and legends, harmonizing the values of the leader or some other organizational constituent.

As we can see, some of these methods can be experienced by individuals, such as analytic, experimental, and interactive. Structural, synthetic, and institutional learning, on the other hand, must be experienced at the group level by definition. Furthermore, it is easy to see that the methodological modes resemble those of procedural learning and that 
the emergent modes are our higher-order, conceptual experiences. This makes for a clear distinction for the purpose of this paper and is therefore revisited later on. It is first necessary, however, to develop an appreciation for the collective learning that takes place in organizations, which manifests itself in a strong resource base and leads to a more sustainable competitive position.

\section{Organizational Learning and Strategic Competitiveness}

The concept of intellectual capital introduced earlier may be a source of core competency for the organization. In fact, achieving strategic competitiveness and aboveaverage profits (an implicit goal of any for-profit organization), requires that such intellectual capital be rare, valuable, imperfectly imitable, and non-substitutable. Prahalad and Hamel (1990) suggest that a core competence is based on collective learning in the organization and that firm strategy should be learning-driven. In fact, competitive success will be based less on how strategically physical and financial resources are allocated, and more on how strategically intellectual capital is managed, from capturing, coding, and disseminating information, to acquiring new competencies (Bontis, 1996). We may conclude, then, that core competencies are developed from organizational learning. Furthermore, for core competencies to be effective, they must be perpetually evolving via continuous organizational learning (Lei, Hitt, \& Bettis, 1996). 


\section{The International Transfer of Knowledge}

In the case where an organization expands overseas, it undergoes the learning process on a worldwide scale. Organizations typically enter foreign markets via exporting and increase their involvement through licensing and joint venture agreements, eventually establishing wholly-owned subsidiaries abroad. This increase in the level of involvement and commitment to foreign markets is known as internationalization (Bilkey \& Tesar, 1977; Johanson \& Vahlne, 1977; Johanson \& Weidersheim-Paul, 1975).

The notion that skills become the basis for a core competence is especially important for global firms because of their opportunity for creating a sustainable competitive advantage by investing in invisible assets such as the transfer of capabilities (Lei et al., 1996). According to Hendry (1996), this "going international" is about translating domestic competitive strengths into international markets. Dunning (1988) emphasizes these "ownership-specific advantages" as one of the main reasons for firms to engage in foreign direct investment in the first place. Similarly, Porter's (1990) theory for competitive advantage rests on the premise that leveraging domestic resources and competencies provides a starting point for international competitiveness.

Chang's (1995) Sequential Investment Theory suggests that firms sequentially approach foreign entry with learning gained from past entry experience. Results from Japanese electronics manufacturers show that they first enter businesses in which they have strong competitive advantages in order to reduce the risk of failure. The learning from earlier entry experience enables firms to build organizational capabilities to operate overseas and to launch further entries into areas where they have less strong competitive 
advantages. As firms internationalize, their intrinsic disadvantages in a foreign market may disappear or be substantially diminished because their capabilities improve through accumulating knowledge (Chang, 1995). Therefore, the logic underlying Organizational Learning Theory would also apply as organizations expand internationally. As a result, we would still expect the experiential "learning-by-doing" to increasingly shape the aging and growing firm.

It is possible to distinguish between two directions of internationalization -(i) increasing involvement of the firm in the individual foreign country, and (ii) successive establishment of operations in new countries (Johanson \& Vahlne, 1977). Accordingly, both national and corporate culture are transmitted via institutionalized practices, such as decision-making procedures and corporate policies (Brown, Rugman, \& Verbeke, 1989; Shenkar, 1992) and are manifested in market-specific knowledge and in general knowledge, respectively.

\section{Market-Specific Knowledge}

Each new market entry may be regarded as an unprecedented case, where environmental threats and opportunities presented are handled in their contexts and where commitments to other markets are not explicitly taken into consideration (Johanson \& Vahlne, 1977). Such market-specific knowledge "relates to present and future demand and supply, to competition and to channels for distribution, to payment conditions and to the transferability of money, and those things vary from country to country and from time to time" (Carlson, 1974). This type of knowledge is characteristic of the national market, 
its business climate, cultural patterns, structure of the market system, and, most importantly, individual customers and suppliers.

Research further suggests that MNCs develop the capacity to reduce barriers to operating abroad through a good bargaining position vis-à-vis host governments (Fagre \& Wells, 1982; Lecraw, 1984; Ruygrok \& van Tulder, 1993), substantiated by the fact that longevity of acquisitions is positively influenced by prior entries of an organization in the same country (Barkema, Bell, \& Pennings, 1996). Hence, there are positive "learning-bydoing" effects associated with operating in a given market.

\section{General Knowledge}

Over time, firms may learn from previous globalization efforts and reduce the barriers that prevent them from freely tapping cheap labor, new technology, and foreign product markets. This knowledge, which is concerned with marketing methods and common characteristics of certain types of customers, irrespective of their geographical location, is also a case of "learning-by-doing", and is a critical resource since the knowledge needed to operate in any country cannot easily be acquired. Further, the creation of foreign production facilities is predicated on the knowledge that has been accumulated previously (Barkema et al., 1996). While market-specific knowledge is gained mainly through experience in the market, general knowledge can often be transferred from one country to another. At the time of initial entry, the market-specific type does not exist, whereas the general type might.

The ability to leverage core competencies across geographic units helps the firm to achieve economies of scale and scope, which represent two of the primary benefits of 
global diversification (Hitt, Hoskisson, \& Ireland, 1994). Such meta-learning and dynamic core competencies help firms internalize the knowledge available in such environments and reduce the costs of entering new geographic markets, by reducing uncertainty and unpredictability (Lei et al., 1996). In fact, this higher-order learning, as suggested by Fiol and Lyles (1985), is more prevalent in firms with diverse environmental contexts, such as MNCs.

\section{Expatriation as a Means of Transferring Knowledge}

The expatriation literature frequently cites the need to transfer resources abroad as a primary reason for expatriating home-country nationals to foreign affiliates (Dowling et al., 1994). However, the process of expatriation, as well as its effectiveness, remains void of any deeper theoretical explanation. The above discussion, together with practitioner viewpoints, suggests that there is a link between the processes of organizational learning and expatriation.

The internationalized firm must continually develop its intellectual capital, through a variety of functions, businesses, and countries. Initially, international activity lacks the critical mass necessary to operate effectively, and the MNC breeds "ethnocentric" tendencies (Heenan \& Perlmutter, 1979) emanating from the parent location. As international activity grows, however, this activity will tend to acquire momentum as firms gain both market-specific and general knowledge through their expatriates.

As firms set up facilities overseas, expatriates become a vehicle for transferring technical expertise and managerial know-how, as well as company philosophy and culture 
to its affiliates. To illustrate, IBM considers its exempt staff, or those who bring a specialty or skill needed in a particular location, as viable candidates for expatriation. This suggests that these expatriates are used for the purpose of resource transfer and will thus be unnecessary once the transfer is complete. Similarly, as GM sets up new facilities overseas, there is an immediate need for an expatriate population. But, as the company gains a presence in a particular country and remains there over a certain period of time, there is a trend away from expatriates in favor of locals nationals. From 1982 to 1995, the company's subsidiary in Spain, GM España, drastically reduced its use of expatriates. According to Pre-Assignment Training Coordinator Joseph McClure, GM's expatriate policy is summed up as follows: "bring in your expatriates, develop the business and then move on out and let local management do the job."

Such corporate agendas suggest a deliberate purpose, that of resource transfer, in expatriating key personnel abroad. In essence, this transfer process is cyclical, with the subsidiary location as the recipient of general knowledge during expatriation and the corporate location as the recipient of market-specific knowledge upon the manager's return. In this study, the first set of research questions addresses this issue. The second set of hypotheses put forth are concerned with organizational learning, as it occurs through structural, synthetic, and institutional modes, and how it bears on the overall effectiveness of expatriate assignments. 


\section{Hypotheses}

\section{The Use of Expatriates as Firms Internationalize}

Aldrich and Pfeffer (1976) suggest that organizations are evolving towards bureaucratic structures over time. Starbuck (1965) found from his review of research that organizations become formalized as they grow older -- that is, they develop characteristic roles into which individuals settle, patterns of behavior stabilize, and standard operating procedures are established. He concluded that "the formalization process is fundamentally an adaptive process: As an organization gets older, it learns more and more about coping with its environment and with its internal problems of communication and coordination." Similarly, according to Chandler (1977), once managerial hierarchies have been formed, these hierarchies themselves became sources of permanence, power, and continued growth. The learning process is officially enforced when processes which emerge are sanctioned and fixed in job descriptions, organizational handbooks, or planning systems (Cangelosi \& Dill, 1965). Therefore, in addition to the reduced role that one individual will play in the organization at large, the external environment becomes less of an issue to the firm as it learns through experience to deal with the multitude of outside influences.

The above suggests that throughout the organization's evolution, it will inevitably learn at the lower level, by virtue of "learning by doing", but that conscious effort must be made to learn at the higher level. Johanson and Vahine (1977) assert that the less structured and defined the activities, the more important this experiential learning will be, and further that it is particularly important in connection with activities that are based on relations to other individuals, such as management and marketing activities. Applied to 
MNCs, learning is occurring with each successive international endeavor. So, this study rests on the premise that internationalization inherently breeds a certain degree of learning. It is expected that as firms internationalize, they will gradually increase their expatriate population in order to expand their international knowledge base, but that the use of expatriation will diminish as international experience is gained, and thus the following hypotheses are offered:

H1a: When international experience is low, there will be a positive relationship between internationalization and expatriation.

$H 1 b$ : When international experience is high, there will be a negative relationship between internationalization and expatriation.

Due to the "learning-by-doing" and subsequent expansion of both the market-specific and the general knowledge base, $\mathrm{Hla}$ and $\mathrm{Hlb}$ are tested at two levels:

HIa-CE: When there is little country experience, there will be a positive relationship between country experience and the proportion of expatriates in that country's subsidiary.

H1b-CE: When there is extensive country experience, there will be a negative relationship between country experience and the proportion of expatriates in that country's subsidiary.

H1a-DOI: When overall firm internationalization is low, there will be a positive relationship between degree of internationalization and the proportion of expatriates in the firm as a whole.

HIb-DOI: When overall firm internationalization is high, there will be a negative relationship between degree of internationalization and the proportion of expatriates in the firm as a whole. 


\section{The Determinants of Expatriate Success as Firms Internationalize}

Successful expatriate assignments can be attributed to a variety of factors. These may range from individual skills and abilities to organizational training programs to hostcountry culture to family issues. Individual-level determinants of success refer to those personal characteristics, such as skills and abilities, behavioral patterns, and demographic features, which are said to influence expatriate effectiveness. Factors specific to the organization include training efforts (Black, Mendenhall, \& Gregersen, 1992; Deshpande \& Viswesvaran, 1991; Earley, 1987), financial inducements (Gregersen, 1992; Guzzo, Noonan, \& Elron, 1994), and mentoring programs (Feldman \& Thomas, 1992; Feldman \& Tompson, 1993; Gregersen \& Black; 1992). Environmental determinants refer to those factors external to the organization, and, more specifically, to characteristics of the host country. These may include the host culture (Black \& Stephens, 1989; Mendenhall, Dunbar, \& Oddou, 1987), housing conditions (Black, 1994; Black \& Gregersen, 1991a), and the stability of the political environment (Boyacigiller, 1991). Family issues addressed in the expatriate literature usually focus on the ability of the expatriate's spouse to adjust to the host environment (Black \& Gregersen, 1991a; Harvey, 1985).

The fact that organizations develop over time suggests that what might be essential for success at one point in the development process may be less significant at another. According to Adler and Ghadar (1989), most staffing during the initial stage of the firm is done on an ad hoc basis, and expatriates are usually selected for their technical skills. Often, they receive little intercultural training, and organizational support services are not emphasized (Milliman, Von Glinow, \& Nathan, 1991). 
Smith and Zeithaml (1993) found that the macro-, organizational-, and micro-level environments all exerted influence during each phase of international expansion, but that their relative importance varied throughout. For example, early in the expansion process, micro-level, behavioral influences encourage international managers to experiment in an opportunistic manner. However, as the organization becomes increasingly committed to foreign markets (i.e. by investing large amounts of resources), it is forced to develop global strategy. Thus, firms in the initial stages of internationalization rely heavily on individuals and their skills to ensure the success of an expatriate assignment, as learning has not yet occurred. During this time, the characteristics of the host environment are also important to expatriate success as the firm does not yet have the routines and structure to buffer its executives from the environment. In this sense, the individual can be thought of as a buffer between the environment and the organization. Since the expatriate may depend a great deal on his/her spouse to interact with various aspects of the host country while he/she is at work, the spouse may act as a buffer as well. However, as the firm gains international experience and organizational learning occurs and is institutionalized, the necessary training and knowledge may be transmitted to the executive about how to embark on the overseas assignment. In this regard, the organization has entered a zone of higher learning, building on its prevailing resource base, as opposed to relying on any one particular source. The synthetic and institutional learning that it subsequently undergoes is at the higher level. At this stage, the organization is able to buffer the executive from the external environment, diminishing the importance of individual and environmental factors. 
Each of the hypotheses is tested for three measures of expatriate success - crosscultural adjustment, organizational commitment, and job satisfaction, as stated below. Detailed subsets of $\mathrm{H}_{2}, \mathrm{H} 3$, and $\mathrm{H} 4$, are shown in Tables 1, 2, and 3, respectively.

\section{$\underline{\mathrm{H} 2}$ - Cross-Cultural Adjustment}

$H 2(a-f)$ : There will be a significant relationship between individual characteristics and expatriate adjustment for expatriates of firms with little international experience.

$\mathrm{H} 2(g-r)$ : There will be a significant relationship between organizational characteristics and expatriate adjustment for expatriates of highly internationalized firms.

H2(s-z): There will be a significant relationship between environmental characteristics and expatriate adjustment for expatriates of firms with little international experience.

H2(aa-bb): There will be a significant relationship between family factors and expatriate adjustment for expatriates of firms with little international experience.

\section{H3 - Organizational Commitment}

H3(a-f): There will be a significant relationship between individual characteristics and expatriate organizational commitment for expatriates of firms with little international experience.

H3(g-r): There will be a significant relationship between organizational characteristics and expatriate organizational commitment for expatriates of highly internationalized firms.

H3(s-z): There will be a significant relationship between environmental characteristics and expatriate organizational commitment for expatriates of firms with little international experience.

H3(aa-bb): There will be a significant relationship between family factors and expatriate organizational commitment for expatriates of firms with little international experience. 


\section{H4 - Job Satisfaction}

H4(a-f): There will be a significant relationship between individual characteristics and expatriate satisfaction for expatriates of firms with little international experience.

H4(g-r): There will be a significant relationship between organizational characteristics and expatriate satisfaction for expatriates of highly internationalized firms.

H4(s-z): There will be a significant relationship between environmental characteristics and expatriate satisfaction for expatriates of firms with little international experience.

H4(aa-bb): There will be a significant relationship between family factors and expatriate satisfaction for expatriates of firms with little international experience.

\section{Expatriate Success}

To understand what is meant by expatriate success and how the concept has evolved through research, a review of the literature was conducted. It was determined a priori that nine journals served as the primary publication outlets for international human resource management topics over the past decade. ${ }^{1}$ A literature search for empirical studies on expatriation was then carried out for the 1985-1995 period, with the inclusion of certain key articles published prior to 1985. A total of 29 articles, 24 of which examined the determinants of expatriate success, were identified and subsequently coded on a variety of dimensions.

\footnotetext{
${ }^{1}$ These included Academy of Management Journal, Academy of Management Review, Administrative Science Quarterly, California Management Review, Columbia Journal of World Business, Human Resource Management, Journal of International Business Studies, Journal of Management Studies, and Management International Review.
} 


\section{TABLE 1}

\section{Cross-Cultural Adjustment Hypotheses for Country Experience and Degree of Internationalization}

\section{Country Experience}

\section{Individual Characteristics}

H2a: There will be a significant relationship between expatriate age and expatriate adjustment for expatriates assigned to young overseas subsidiaries.

$\mathrm{H} 2 \mathrm{~b}$ : There will be a significant relationship between expatriate tenure and expatriate adjustment for expatriates assigned to young overseas subsidiaries.

$\mathrm{H} 2 \mathrm{c}$ : There will be a significant relationship between expatriate international experience and expatriate adjustment for expatriates assigned to young overseas subsidiaries.

\section{Organizational Characteristics}

$\mathrm{H} 2 \mathrm{~g}$ : There will be a significant relationship between role ambiguity and expatriate adjustment for expatriates assigned to mature overseas subsidiaries.

$\mathrm{H} 2 \mathrm{~h}$ : There will be a significant relationship between role discretion and expatriate adjustment for expatriates assigned to mature overseas subsidiaries.

H2i: There will be a significant relationship between mentorship and expatriate adjustment for expatriates assigned to mature overseas subsidiaries.

H2j: There will be a significant relationship between long-term career planning and expatriate adjustment for expatriates assigned to mature overseas subsidiaries.

$\mathrm{H} 2 \mathrm{k}$ : There will be a significant relationship between expatriate training and expatriate adjustment for expatriates assigned to mature overseas subsidiaries.

H21: There will be a significant relationship between spouse training and expatriate adjustment for expatriates assigned to mature overseas subsidiaries.

\section{Degree of Internationalization}

\section{Individual Characteristics}

H2d: There will be a significant relationship between expatriate age and expatriate adjustment for expatriates of firms with a low degree of internationalization.

H2e: There will be a significant relationship between expatriate tenure and expatriate adjustment for expatriates of firms with a low degree of internationalization.

H2f: There will be a significant relationship between expatriate international experience and expatriate adjustment for expatriates of firms with a low degree of internationalization.

\section{Organizational Characteristics}

$\mathrm{H} 2 \mathrm{~m}$ : There will be a significant relationship between role ambiguity and expatriate adjustment for expatriates of firms with a high degree of internationalization.

H2n: There will be a significant relationship between role discretion and expatriate adjustment for expatriates of firms with a high degree of internationalization.

H20: There will be a significant relationship between mentorship and expatriate adjustment for expatriates of firms with a high degree of internationalization.

$\mathrm{H} 2 \mathrm{p}$ : There will be a significant relationship between long-term career planning and expatriate adjustment for expatriates of firms with a high degree of internationalization.

H2q: There will be a significant relationship between expatriate training and expatriate adjustment for expatriates of firms with a high degree of internationalization.

$\mathrm{H} 2 \mathrm{r}$ : There will be a significant relationship between spouse training and expatriate adjustment for expatriates of firms with a high degree of internationalization. 


\section{TABLE 1 (cont'd)}

\section{Country Experience}

\section{Environmental Characteristics}

H2s: There will be a significant relationship between geographic proximity and expatriate adjustment for expatriates assigned to young overseas subsidiaries.

$\mathrm{H} 2 \mathrm{t}$ : There will be a significant relationship between cultural familiarity and expatriate adjustment for expatriates assigned to young overseas subsidiaries.

$\mathrm{H} 2 \mathrm{u}$ : There will be a significant relationship between host-country development and expatriate adjustment for expatriates assigned to young overseas subsidiaries.

$\mathrm{H} 2 \mathrm{v}$ : There will be a significant relationship between host-country risk and expatriate adjustment for expatriates assigned to young overseas subsidiaries.

\section{Family-Related Factors}

H2aa: There will be a significant relationship between spousal adjustment and expatriate adjustment for expatriates assigned to young overseas subsidiaries.

\section{Degree of Internationalization}

\section{Environmental Characteristics}

H2w: There will be a significant relationship between geographic proximity and expatriate adjustment for expatriates of firms with a low degree of internationalization.

$\mathrm{H} 2 \mathrm{x}$ : There will be a significant relationship between cultural familiarity and expatriate adjustment for expatriates of firms with a low degree of internationalization.

$\mathrm{H} 2 \mathrm{y}$ : There will be a significant relationship between host-country development and expatriate adjustment for expatriates of firms with a low degree of internationalization.

$\mathrm{H} 2 \mathrm{z}$ : There will be a significant relationship between host-country risk and expatriate adjustment for expatriates of firms with a low degree of internationalization.

\section{Family-Related Factors}

$\mathrm{H} 2 \mathrm{bb}$ : There will be a significant relationship between spousal adjustment and expatriate adjustment for expatriates of firms with a low degree of internationalization. 


\section{TABLE 2}

\section{Organizational Commitment Hypotheses for Country Experience and Degree of Internationalization}

\section{Country Experience}

\section{Individual Characteristics}

H3a: There will be a significant relationship between expatriate age and expatriate organizational commitment for expatriates assigned to young overseas subsidiaries.

H3b: There will be a significant relationship between expatriate tenure and expatriate organizational commitment for expatriates assigned to young overseas subsidiaries.

H3c: There will be a significant relationship between expatriate international experience and expatriate organizational commitment for expatriates assigned to young overseas subsidiaries.

\section{Organizational Characteristics}

H3g: There will be a significant relationship between role ambiguity and expatriate organizational commitment for expatriates assigned to mature overseas subsidiaries.

$\mathrm{H} 3 \mathrm{~h}$ : There will be a significant relationship between role discretion and expatriate organizational commitment for expatriates assigned to mature overseas subsidiaries.

H3i: There will be a significant relationship between mentorship and expatriate organizational commitment for expatriates assigned to mature overseas subsidiaries.

H3j: There will be a significant relationship between long-term career planning and expatriate organizational commitment for expatriates assigned to mature overseas subsidiaries.

H3k: There will be a significant relationship between expatriate training and expatriate organizational commitment for expatriates assigned to mature overseas subsidiaries.

H31: There will be a significant relationship between spouse training and expatriate organizational commitment for expatriates assigned to mature overseas subsidiaries.

\section{Degree of Internationalization}

\section{Individual Characteristics}

$\mathrm{H} 3 \mathrm{~d}$ : There will be a significant relationship between expatriate age and expatriate organizational commitment for expatriates of firms with a low degree of internationalization.

H3e: There will be a significant relationship between expatriate tenure and expatriate organizational commitment for expatriates of firms with a low degree of internationalization.

H3f: There will be a significant relationship between expatriate international experience and expatriate organizational commitment for expatriates of firms with a low degree of internationalization.

\section{Organizational Characteristics}

H3m: There will be a significant relationship between role ambiguity and expatriate organizational commitment for expatriates of firms with a high degree of internationalization.

$\mathrm{H} 3 \mathrm{n}$ : There will be a significant relationship between role discretion and expatriate organizational commitment for expatriates of firms with a high degree of internationalization.

H30: There will be a significant relationship between mentorship and expatriate organizational commitment for expatriates of firms with a high degree of internationalization.

H3p: There will be a significant relationship between long-term career planning and expatriate organizational commitment for expatriates of firms with a high degree of internationalization.

H3q: There will be a significant relationship between expatriate training and expatriate organizational commitment for expatriates of firms with a high degree of internationalization.

H3r: There will be a significant relationship between spouse training and expatriate organizational commitment for expatriates of firms with a high degree of internationalization. 


\section{TABLE 2 (cont'd)}

\section{Country Experience}

\section{Environmental Characteristics}

H3s: There will be a significant relationship between geographic proximity and expatriate organizational commitment for expatriates assigned to young overseas subsidiaries.

H3t: There will be a significant relationship between cultural familiarity and expatriate organizational commiment for expatriates assigned to young overseas subsidiaries.

H3u: There will be a significant relationship between host-country development and expatriate organizational commitment for expatriates assigned to young overseas subsidiaries.

H3v: There will be a significant relationship between host-country risk and expatriate organizational commitment for expatriates assigned to young overseas subsidiaries.

\section{Family-Related Factors}

H3aa: There will be a significant relationship between spousal adjustment and expatriate organizational commitment for expatriates assigned to young overseas subsidiaries.

\section{Degree of Internationalization}

\section{Environmental Characteristics}

$\mathrm{H} 3 \mathrm{w}$ : There will be a significant relationship between geographic proximity and expatriate organizational commitment for expatriates of firms with a low degree of internationalization.

H3x: There will be a significant relationship between cultural familiarity and expatriate organizational commitment for expatriates of firms with a low degree of internationalization.

H3y: There will be a significant relationship between host-country development and expatriate organizational commitment for expatriates of firms with a low degree of internationalization.

H3z: There will be a significant relationship between host-country risk and expatriate organizational commitment for expatriates of firms with a low degree of internationalization.

\section{Family-Related Factors}

H3bb: There will be a significant relationship between spousal adjustment and expatriate organizational commitment for expatriates of firms with a low degree of internationalization. 


\section{TABLE 3 \\ Job Satisfaction Hypotheses for \\ Country Experience and Degree of Internationalization}

\section{Country Experience}

\section{Individual Characteristics}

H4a: There will be a significant relationship between expatriate age and expatriate satisfaction for expatriates assigned to young overseas subsidiaries.

H4b: There will be a significant relationship between expatriate tenure and expatriate satisfaction for expatriates assigned to young overseas subsidiaries.

$\mathrm{H} 4 \mathrm{c}$ : There will be a significant relationship between expatriate international experience and expatriate satisfaction for expatriates assigned to young overseas subsidiaries.

\section{Organizational Characteristics}

$\mathrm{H} 4 \mathrm{~g}$ : There will be a significant relationship between role ambiguity and expatriate satisfaction for expatriates assigned to mature overseas subsidiaries.

$\mathrm{H} 4 \mathrm{~h}$ : There will be a significant relationship between role discretion and expatriate satisfaction for expatriates assigned to mature overseas subsidiaries.

$\mathrm{H}+\mathrm{i}$ : There will be a significant relationship between mentorship and expatriate satisfaction for expatriates assigned to mature overseas subsidiaries.

H4j: There will be a significant relationship between long-term career planning and expatriate satisfaction for expatriates assigned to mature overseas subsidiaries.

$\mathrm{H} 4 \mathrm{k}$ : There will be a significant relationship between expatriate training and expatriate satisfaction for expatriates assigned to mature overseas subsidiaries.

H41: There will be a significant relationship between spouse training and expatriate satisfaction for expatriates assigned to mature overseas subsidiaries.

\section{Degree of Internationalization}

\section{Individual Characteristics}

H4d: There will be a significant relationship between expatriate age and expatriate satisfaction for expatriates of firms with a low degree of internationalization.

H4e: There will be a significant relationship between expatriate tenure and expatriate satisfaction for expatriates of firms with a low degree of internationalization.

H4f: There will be a significant relationship between expatriate international experience and expatriate satisfaction for expatriates of firms with a low degree of internationalization.

\section{Organizational Characteristics}

H4m: There will be a significant relationship between role ambiguity and expatriate satisfaction for expatriates of firms with a bigh degree of internationalization.

$\mathrm{H} 4 \mathrm{n}$ : There will be a significant relationship between role discretion and expatriate satisfaction for expatriates of firms with a high degree of internationalization.

H40: There will be a significant relationship between mentorship and expatriate satisfaction for expatriates of firms with a high degree of internationalization.

H4p: There will be a significant relationship between long-term career planning and expatriate satisfaction for expatriates of firms with a high degree of internationalization.

H4q: There will be a significant relationship between expatriate training and expatriate satisfaction for expatriates of firms with a high degree of internationalization.

$\mathrm{H} 4 \mathrm{r}$ : There will be a significant relationship between spouse training and expatriate satisfaction for expatriates of firms with a bigh degree of internationalization. 


\section{TABLE 3 (cont'd)}

\section{Country Experience}

\section{Environmental Characteristics}

H4s: There will be a significant relationship between geographic proximity and expatriate satisfaction for expatriates assigned to young overseas subsidiaries.

H4t: There will be a significant relationship between cultural familiarity and expatriate satisfaction for expatriates assigned to young overseas subsidiaries.

$\mathrm{H} 4 \mathrm{u}$ : There will be a significant relationship between host-country development and expatriate satisfaction for expatriates assigned to young overseas subsidiaries.

$\mathrm{H} 4 \mathrm{v}$ : There will be a significant relationship between host-country risk and expatriate satisfaction for expatriates assigned to young overseas subsidiaries.

\section{Family-Related Factors}

H4aa: There will be a significant relationship between spousal adjustment and expatriate satisfaction for expatriates assigned to young overseas subsidiaries.
Degree of Internationalization

\section{Environmental Characteristics}

H4w: There will be a significant relationship between geographic proximity and expatriate satisfaction for expatriates of firms with a low degree of internationalization.

$\mathrm{H} 4 \mathrm{x}$ : There will be a significant relationship between cultural familiarity and expatriate satisfaction for expatriates of firms with a low degree of internationalization.

H4y: There will be a significant relationship between host-country development and expatriate satisfaction for expatriates of firms with a low degree of internationalization.

$\mathrm{H} 4 \mathrm{z}$ : There will be a significant relationship between host-country risk and expatriate satisfaction for expatriates of firms with a low degree of internationalization.

\section{Family-Related Factors}

$\mathrm{H} 4 \mathrm{bb}$ : There will be a significant relationship between spousal adjustment and expatriate satisfaction for expatriates of firms with a low degree of internationalization. 
After careful consideration, it was concluded that expatriate success had traditionally been defined in terms of four broad categories - cross-cultural adjustment, organizational commitment, job satisfaction, and performance -- all of which have been attributed to individual, organizational, environmental, and/or family-related phenomena. However, performance is not considered in this study, as no consistently reliable scale for assessing expatriate performance has been identified. A review of the literature relevant to the remaining outcomes is provided below.

\section{Cross-Cultural Adjustment}

Cross-cultural adjustment has been defined as "the degree of psychological comfort with various aspects of a host country" (Black, 1988; Nicholson, 1984; Oberg, 1960) and has been the focus of many recent expatriation studies. Concerns include adjustment to working and living in the foreign environment, as well as to interacting with locals (Black, 1994; Black \& Gregersen, 1991a; Black \& Stephens, 1989). Furthermore, spousal adjustment has received increased attention as a measure of expatriate adjustment (Black \& Gregersen, 1991a, 1991b; Black \& Stephens, 1989).

The individual characteristics, as well as the organizational practices and the environmental and family-related factors, which have been found to influence expatriate cross-cultural adjustment are discussed in this section and are summarized in Appendix A. 


\section{Individual-Level Determinants of Adjustment}

Several personal dimensions have been found to impact a manager's transition to an overseas assignment. Black (1990), for example, concluded that cultural flexibility and social orientation were positively related to expatriate cross-cultural adjustment to work, interaction with host nationals, and to the environment in general.

When activities available at home cannot be found in the host country, there may be feelings of loneliness, isolation, and frustration, which contribute to culture shock and inhibit adjustment (Church, 1982). A person with cultural flexibility (the ability to replace activities enjoyed in one's home country with available, and usually different, activities in the host country) can avoid these negative feelings and more readily adjust abroad.

Social orientation (the individual's ability to establish relationships with host nationals) is also important to adjustment, especially for the information and feedback that can be obtained from host nationals when developing relationships with them (Mendenhall \& Oddou, 1985). The more information received regarding local behaviors, the more easily the expatriate can adopt culturally appropriate behavior and thus facilitate the adjustment process. Clarke \& Hammer (1995) found that interpersonal skills, which are similar to social orientation, tended to facilitate cross-cultural adjustment. Social skills appear to be critical to the manager's ability to complete tasks and to establish and maintain effective intercultural relationships, all of which assist in the cultural adjustment of the expatriate and his/her family.

Expatriate pre-departure knowledge can also contribute to both work and general adjustment overseas (Black, 1988), when such knowledge includes information about the 
transition. This can reduce many of the uncertainties associated with the new role. Interestingly, previous international experience was repeatedly found to be non-significant as a predictor of both expatriate and spousal general adjustment during expatriation (Black, 1988; Black \& Gregersen, 1991b; Black \& Stephens, 1989). This suggests that perhaps many aspects of overseas experience are not generalizable from one assignment location to another or that expatriate managers are not able to transfer their learnings concerning adjustment in one country to another. However, overseas experience did relate positively to expatriate work adjustment (Black, 1988), suggesting that knowledge gained in the work environment may be transferable.

\section{Organizational-Level Determinants of Adjustment}

At the organizational level, factors such as role discretion, role clarity, a clear description of the company's repatriation practices (Black, 1994), and long-term career planning (Feldman \& Thomas, 1992) have all been found to facilitate the expatriate adjustment process, either at work or in the general environment.

Role discretion enables individuals to more easily utilize successful past behaviors in the new role, since they have the freedom to modify the role to fit their abilities. In this way, the role becomes more familiar, predictable, and controllable, and the transition becomes easier (Kahn, Wolfe, Quinn, \& Snoek, 1964; Karasek, 1979). Role clarity and role discretion are also important upon repatriation (Black \& Gregersen, 1991a), in that returning employees are often caught in a holding pattern without a clear assignment, job, 
or set of responsibilities, and that this significantly inhibits work adjustment back in the parent company.

In addition to the factors mentioned above, the provision of training was found to reduce expatriates' perceived need to adjust (Black et al., 1992; Deshpande \& Viswesvaran, 1991; Earley, 1987). Training is the process of altering employee behavior and attitudes in a way that increases the probability of goal attainment (Hodgetts \& Kuratko, 1991). For expatriates who are unfamiliar with the customs, cultures, and work habits of the local people, such training may be critical to the outcome of overseas assignments. Specifically, both documentary training (which includes area studies exposing people to a new culture through written materials) and interpersonal approaches (such as sensitivity training and field experiences) have been shown to reduce the manager's perceived intensity of cultural adjustment (Earley, 1987). Training is beneficial in that it reduces the cultural shock experienced by people in new and different cultures. Culture shock has long been thought to reduce ability to function in a cultural setting because of the perceived discrepancy between an individual's expectations of how events should proceed and how they actually occur. Perhaps counterintuitive, however, is the observation that interpersonal techniques did not reduce intensity of adjustment any more than did the documentary training (Earley, 1987). This may be explained by the fact that an individual whose interpersonal style is quite stable may not be easily influenced by experiential exercises. 


\section{Environmental-Level Determinants of Adjustment}

In addition to individual- and organization-level determinants of expatriate adjustment, variables at the environmental level have been examined to a limited degree. The cultural factors of adjustment studied thus far include culture novelty in the case of expatriation (Black \& Stephens, 1989) and culture novelty, social status, and housing conditions in the case of repatriation (Black, 1994; Black \& Gregersen, 1991b). Repatriation, or the return back to the parent location, is an inherent part of the expatriation process. Consequently, repatriation adjustment may be attributed to many of the same factors as the initial overseas adjustment.

Culture novelty has had a negative impact on the general adjustment of American expatriates and their spouses during the overseas assignment (Black \& Stephens, 1989). This is not surprising, as the repatriation process involves a transfer back to an already familiar environment. Furthermore, the novelty between home and host cultures did not have a significant effect on the work dimension of expatriate or repatriate adjustment, most likely because elements of the work environment for a given firm are often similar across geographic locations.

\section{Family-Related Determinants of Adjustment}

Family-related factors, encompassed by the term "nonwork variables" in much of the expatriate literature (Black, Mendenhall, \& Oddou, 1991), have been studied as to their effects on expatriate cross-cultural adjustment. Specifically, research shows that if the expatriate's spouse and/or family members are having trouble adjusting abroad, the 
expatriate will have problems as well, including poor job performance (Black \& Gregersen, 1991a; Gaylord, 1979; Harvey, 1985), which could result in a premature return from the overseas assignment. Poor spousal adjustment may result from inadequate preparation for the move abroad or from the inability to obtain a visa to work in the foreign country.

\section{Organizational Commitment}

Organizational commitment has been defined as "A strong belief in, and acceptance of, the organization's goals and values, a willingness to exert considerable effort on behalf of the organization, and a strong desire to maintain membership in the organization" (Mowday, Porter, \& Steers, 1982). Aspects of commitment examined in the literature include loyalty to and identification with the organization (Banai \& Reisel, 1993), as well as intentions to remain both with the assignment and with the firm (Black \& Stephens, 1989; Feldman \& Thomas, 1992; Stephens \& Black, 1991). Commitment to the organization is especially important when on foreign assignment in the face of obstacles associated with day-to-day living. An individual who identifies with and is loyal to the organization will be less likely to give in to external pressures.

Research on the organizational commitment of expatriates has received increased attention over the past decade, with particular emphasis on personal characteristics and organizational practices thought to influence expatriate commitment. In fact, the current literature review did not reveal any empirical research on environmental-level or familyrelated determinants of expatriate commitment. 
Commitment itself has been conceptualized at its most general level (e.g. overall commitment) as well as in more specific terms (e.g. commitment to a parent company and to a local work unit). The determinants of expatriate organizational commitment are discussed below and are summarized in Appendix B.

\section{Individual-Level Determinants of Commitment}

Gregersen and Black (1992) concluded that tenure in the parent company is associated with increased commitment to the parent location during expatriation. In a similar study, Gregersen (1992) found a positive relationship between parent-company tenure and commitment to both the parent and the local unit during repatriation. Sending individuals with high tenure, then, is important for sustaining commitment to that company during and after an international assignment.

These findings are consistent with previous research (Luthans, McCaul, \& Dodd, 1985; Mowday et al., 1982) and are explained by the fact that the longer people have been with a firm, the greater are their investments in it. To capitalize on these investments, they become committed to the organization. Such investments may be economic early in a manager's tenure, but may later include psychological attachments from time and energy invested as well as the establishment of social networks. As length of service grows, so do these psychological investments, and thus employees demonstrate higher organizational commitment (Hrebiniak \& Alutto, 1972).

Other individual factors found to affect organizational commitment among expatriates include the age and rank of the expatriate manager (Banai \& Reisel, 1993). 
For individuals who remain with a single organization, as age increases, so do the years of experience in the organization, as well as the rank in the organizational hierarchy. Consequently, compensation packages tend to be higher, and it becomes less likely that the manager will find a comparable package elsewhere (March \& Simon, 1958), thereby increasing commitment to the organization.

\section{Organizational-Level Determinants of Commitment}

At the organizational level, determinants of expatriate commitment include various types of support and development programs provided by the firm. For example, Feldman and Thomas (1992) found that long-term career planning (on the part of the MNC) was associated with higher levels of commitment. If expatriate managers see a connection between their current assignments and their longer term career paths, they are more likely to invest time, energy, and commitment to the overseas assignment.

Furthermore, higher commitment to the parent company has been associated with the provision of pre-departure training (Gregersen \& Black, 1992) and realistic job previews (Feldman \& Tompson, 1993). Both training and previews aid in understanding host countries' cultures and may therefore help expatriates to develop accurate and realistic expectations. Firms may also demonstrate their supportiveness and dependability by making repatriation practices clear to employees, as clarification at the outset has translated into better actual repatriation management (Gomez-Mejia \& Balkin, 1987).

Expatriate commitment may also be a function of the fit between overall business strategy and human resource management strategy (Bird \& Beechler, 1995), where 
matched strategies are associated with lower turnover rates. Firms that are able to match business strategy and HRM strategies will be more likely to select people appropriate to the strategy they are pursuing. Consequently, better selection and retention suggests lower levels of turnover.

Finally, characteristics of the expatriate's job overseas have been found to impact organizational commitment. Role discretion (or the degree to which the individual is responsible for what work gets done, how it gets done, and by whom (Stewart, 1982)) has been linked to higher levels of expatriate commitment (Gregersen, 1992; Gregersen \& Black, 1992). The greater the discretion, the stronger the sense of felt responsibility, and the stronger the commitment to the organization in which that responsibility has been developed. Role discretion may be especially important to expatriates, given the autonomous nature of many overseas assignments (Black, 1988). Conversely, role conflict (Gregersen \& Black, 1992), or the existence of conflicting expectations, may reduce felt responsibility to the parent company during expatriation, but has not been significant in predicting organizational commitment during repatriation (Gregersen, 1992).

\section{Job Satisfaction}

Job satisfaction has been defined as "A positive emotional state resulting from the appraisal of one's job or job experiences" (Locke, 1976). A popular conceptualization of job satisfaction is the intrinsic-extrinsic distinction (Weiss, Dawis, England, \& Lofquist, 1967). Intrinsic satisfaction is derived from actually performing the work and experiencing feelings of accomplishment, self-actualization, and identity with the task. 
Extrinsic satisfaction is derived from the rewards bestowed upon an individual by peers, superiors, or the organization, and can take the form of recognition, compensation, advancement, and so forth. If expatriates are neither intrinsically nor extrinsically satisfied while on assignment, the motivation to perform well and/or to remain abroad for the specified length of time is diminished.

The utilization of job satisfaction in the expatriate literature has been limited, particularly in examining environmental determinants of expatriate satisfaction. What follows is a review of the research in this area, and the various relationships observed are depicted in Appendix C.

\section{Individual-Level Determinants of Satisfaction}

The use of various individual coping strategies has been tested as they relate to overall satisfaction (Feldman \& Thomas, 1992), and it has been found that psychological reappraisal enhances job satisfaction. Reappraisal is a problem-focused strategy used to take advantage of opportunities in the new environment by looking for the positive side of problems. Problem-focused strategies change the environment in the mind of the expatriate, making it more benevolent to him/her.

The manager's ability to deal with intercultural stress, communications, and relationships also enhances expatriate satisfaction (Stening \& Hammer, 1992). This is not surprising, as several studies have confirmed that the predominant reason for ineffective management abroad is not due to the technical competence of the managers but rather to the dynamics of the intercultural experience (Brislin, 1981; Tung, 1982). The ability to 
deal effectively with frustration, stress, different political systems, interactions with strangers, and a host of other intercultural dimensions, reduces anxiety and thus increases expatriate satisfaction.

Furthermore, Miller (1975) found international experience to relate positively to job satisfaction (when measured in terms of deficiencies in security, social, esteem, and self-actualization needs). The nature of the job, its responsibilities, promotion potential, and opportunities for need satisfaction may be perceived quite differently based on the manager's ability to master the host environment (Hodgetts, 1993), which is enhanced by previous international experience. In addition, culture shock may be minimal for repeat expatriates, as they may have already learned to deal with cross-cultural obstacles on a general level.

\section{Organizational-Level Determinants of Satisfaction}

At the organizational level, several job/task characteristics (skill variety, task identity, autonomy, and job feedback) were found to enhance both intrinsic and extrinsic satisfaction (Naumann, 1993). It seems logical that task autonomy, which is similar to role discretion, should lead to greater satisfaction, since the expatriate manager has the freedom to modify the role to fit his/her abilities. By the same token, the role can be modified in a way that fulfills the needs as perceived by the expatriate.

While the above-mentioned company practices exhibited positive associations with job satisfaction as a whole, Feldman and Tompson (1993) determined that various corporate career development programs contributed significantly to several aspects of 
employee satisfaction (e.g. satisfaction with pay and with coworkers). One such practice was ensuring that the expatriate assignment fit in with the employee's overall career plan. Furthermore, providing mentors, as well as opportunities for employees to develop new skills, was significant to expatriate satisfaction. According to Steers and Mowday (1981), worker expectations may be related to attitudes. Skill-development opportunities, perhaps provided through training, may help to clarify the complex set of expectations associated with an international assignment, leading to a higher congruency between expectations and subsequent job experiences. This should lead to more positive attitudes, and, ultimately, to greater job satisfaction.

\section{Environmental-Level Determinants of Satisfaction}

The only environmental factor tested against satisfaction has been assignment location (Miller, 1975). Findings indicate that American expatriates on assignment in Europe were more satisfied (i.e. were less need-deficient) than American expatriates in Latin America, lending some support to the idea that country or region may be important to expatriate satisfaction. This may be due, in part, to the inability of some countries to provide the foundation for fulfilling higher-order needs. For example, an expatriate on assignment in a politically unstable environment may be deficient in his/her needs for safety and security. 


\section{Summary of Expatriate Success Research}

A summary of empirical studies on expatriation addressing variables at each of the four levels of analysis (individual, organizational, environmental, and family) is summarized in Table 4. Immediately discernible from the table is the heavy emphasis on individual characteristics as determinants of expatriate success. It also appears that environmental factors have received little attention in the expatriate literature and have been limited in scope. Another observation is the scant amount of research over the past decade (Black, 1994; Black \& Gregersen, 1991a, 1991b; Gregersen \& Black, 1992) approaching the issue of expatriate effectiveness as a product of variables at all four levels of analysis (individual, organizational, environmental, and family).

It is also typical in the International Human Resource Management (IHRM) literature to analyze the determinants of success in a static context (Black, 1988; Feldman \& Thomas, 1992). This would be to imply that the positive relationship, for example, between role discretion and expatriate adjustment (Black, 1988) will always hold true, as would the positive relationship between firm tenure and organizational commitment. However, it may be the case that the relationships between certain phenomena (including personal, organizational, and environmental characteristics) and certain outcomes (e.g. expatriate adjustment, organizational commitment) may vary over time.

Recognizing the dynamic nature of the determinants of desirable expatriate outcomes, the hypotheses put forth in this study contend that the learning experienced through internationalization dictates these relationships. The determinants considered 


\section{TABLE 4}

\section{Summary of Empirical Studies on Expatriate Success}

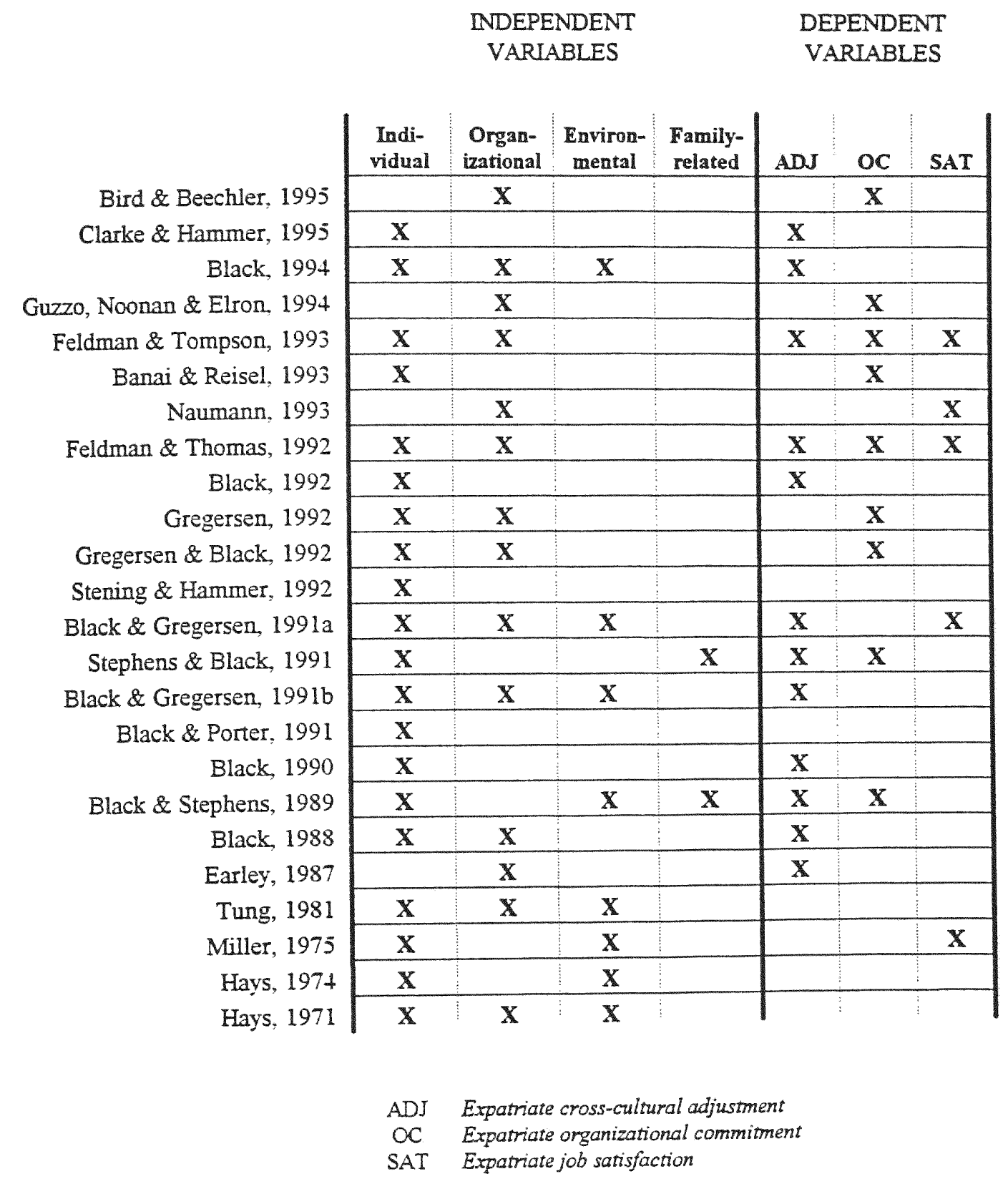


here, and the ways in which all relevant variables are measured, are detailed in the next chapter. 


\section{Chapter III \\ Methods}

\section{INTRODUCTION}

This chapter provides a detailed description of the research methods that were used in this study. First the research setting is discussed, followed by an explanation of the data collection techniques employed. Each variable is then described, together with its previous measures and those employed here. The chapter also includes a description of the sample of firms, subsidiaries, and individual expatriates that represented usable responses for analyses and provides a detailed account of those variables represented by scales of items, arrived at through the use of factor analytic techniques. The chapter closes with the results of some preliminary analyses of the data set, prior to hypothesis testing.

\section{SAMPLE AND SETTING}

The sample of companies for this study was drawn from U.S. Fortune $500 \mathrm{MNCs}$ in two sets of related industries. The first set included firms in the computers/office equipment and electronics industries, and the second set included companies in the petroleum refining and chemicals industries. The names of these organizations are reported in Table 5. The sample was restricted to U.S. MNCs in order to maintain parent-country homogeneity in terms of the political environment, the economy, and other country characteristics, since the phenomenon of expatriation is inherently influenced by cultural factors. Furthermore, data on the Fortune 500 is available and easily accessible, 
Fortune 500 Companies

\begin{tabular}{|c|c|c|c|}
\hline $\begin{array}{l}\text { COMPUTERS/ } \\
\text { OFFICE EOUTPMENT }\end{array}$ & ELECTRONICS & $\begin{array}{l}\text { PETROLEUM } \\
\text { REFINING }\end{array}$ & CHEMICALS \\
\hline IBM & General Electric & Exxon & E.1. Du Pont De Nemours \\
\hline Hewlett-Packard & Motorola & Mobil & Dow Chemical \\
\hline Digital Equipment & Intel & Texaco & Occidental Petroleum \\
\hline Compaq Computer & Rockwell Intemational & Chevron & Monsanto \\
\hline Apple Computer & Texas Instruments & Amoco & W.R. Grace \\
\hline Unisys & Raytheon & USX & PPG Industries \\
\hline Sun Microsystems & Westinghouse Electric & Atlantic Richrield & Union Carbide \\
\hline Pitney Bowes & Emerson Electric & Phillips Petroleum & Eastman Chemical \\
\hline Seagate Technology & Whirlpool & Coastal & FMC \\
\hline Dell Computer & Cooper Industries & Ashland & Lyondell Petrochemical \\
\hline Gateway 2000 & Litton Industries & Sun & Rohm Haas \\
\hline AST Research & AMP & Unocal & Air Products \& Chemicals \\
\hline Comer Peripherals & Loral & Amerada Hess & Sherwin-Wiliams \\
\hline Quantum & Maytag & Toseo & Morton Intemational \\
\hline Tandem Computers & Harris & Kerr-McGee & Hercules \\
\hline SCl Systems & Teledyne & Mapco & Praxair \\
\hline Amdahl & National Semiconductor & Diamond Shamrock & Olin \\
\hline Storage Technology & Advance Micro Devices & Pernzoil & Engelhard \\
\hline Western Digital & General instrument & Ultramar & Witco \\
\hline Silicon Graphics & E-Systems & Valero Energy & Dow Coming \\
\hline EMC & National Service Industries & Murphy Oil & B.F. Goodrich \\
\hline Cisco Systems & Duracell International & Crown Central & Great Lakes Chemical \\
\hline Maxtor & General Signal & Castle Energy & Mallinckrodt Group \\
\hline Data Genera! & Applied Materials & Tesoro Petroleum & CBI Industries \\
\hline Intergraph & Micron Technology & Quaker State & Cabot \\
\hline Cray Research & Magnetek & & Lubrizol \\
\hline \multirow[t]{20}{*}{ Wang Laboratories } & Zenith Electronics & & IMC Global \\
\hline & Solectron & - & Nalco Chemical \\
\hline & Sunbeam-Oster & & Geon \\
\hline & Thomas \& Betts & & Ecolab \\
\hline & Hubbell & & Ferro \\
\hline & DSC Communications & & CF Industries \\
\hline & Vishay Intertechnology & & Ethyl \\
\hline & Molex & & GAF \\
\hline & LSI Logic & & Cytec Industries \\
\hline & Hamman Int" Industries & & Arcadian \\
\hline & $3 \mathrm{Com}$ & & H.B. Fuller \\
\hline & Scientific-Atlanta & & Albemarle \\
\hline & Ametek & & Dexter \\
\hline & & & Georgia Gulf \\
\hline & & & Uniroyal Chemical \\
\hline & & & Wellman \\
\hline & $\because$ & & Sigma-Aldrich \\
\hline & & & Valhi \\
\hline & & & $\mathrm{RPM}$ \\
\hline & & & Valspar \\
\hline
\end{tabular}

* Companies are listed, in descending order, by revenues reported for 1995. 
and the international orientation of these firms makes it likely that overseas subsidiaries will have a large expatriate presence.

In order to capture whether the use of expatriates, or whether the factors important to expatriate success, will vary by level of internationalization, there must be sufficient variance on the internationalization continuum. Prior to collecting this information at the company level, one way to ensure such variance is to design the study around firms from industries with maximally different international histories. Both the petroleum refining and the chemicals industries have a long history of international operations, whereas the computer industry, and to a lesser extent electronics, are relatively new to the international arena. Effects due to industry can then be overcome during subsequent analyses by introducing industry as a control variable.

Considerable value may be added to our current understanding of both internationalization effects on outcomes, as well as those due to industry, by sampling this way. Moreover, a moderate degree of generalizability across industries is possible without sacrificing the relevance of the findings to those companies under study.

\section{DATA COLLECTION}

\section{Primary Sources}

Phone calls were made to each of the Fortune 500 firms in the above-mentioned industries, in an effort to solicit the interest and participation of the human resource manager or the individual responsible for expatriating employees abroad. (Any such contacts will herein be referred to as HR Managers). A one-page executive summary of 
the proposed research project was forwarded to each interested HR Manager, accompanied by a four-page survey to ultimately be administered to the firm's expatriates who were currently on assignment overseas.

Although a large initial mailing of surveys went out on June 1, 1996, the above process continued until mid-August. Thirty firms agreed to participate fully, by agreeing to mail the four-page survey to their expatriates, in addition to completing a one-page survey directed at the HR Manager him-/herself. Sixteen firms agreed to limited participation only, which involved the administration of only the HR Manager Survey. When added to the 30 that were participating at all levels, 46 firms were expected to complete the HR Manager Survey.

The two surveys addressed different research questions. Therefore, while all fully participating firms agreed to complete the HR Manager Survey as well, some neglected to do so, but their expatriates' responses remained usable. Whether fully participating, or just on a limited basis, packages were mailed to the HR Managers, who became the ongoing contacts for the remainder of the project.

\section{Packages}

The two sets of packages prepared and sent to consenting HR Managers included the following materials:

\section{Package A}

- a letter to the HR Manager with instructions on how to proceed, including time frames for completion (see Appendix D and E)

- a one-page HR Manager Survey (see Appendix F)

- an addressed, stamped return envelope for the completed HR Manager Survey 


\section{Package B}

- a letter to each individual expatriate explaining what the study was about and instructions for completion (see Appendix G)

- a package of four-page expatriate surveys ${ }^{2}$ consistent with the quantity previously agreed upon (see Appendix $\mathrm{H}$ )

- a demographic/biodata card to accompany each expatriate survey (see Appendix I)

- an addressed return envelope for the completed expatriate survey and biodata card

For firms which agreed to participate at the limited level, only Package A (with the letter shown in Appendix D) was forwarded to HR Managers. Fully participating firms received both Package A (with the letter shown in Appendix E) and Package B.

While survey distribution to expatriates abroad was handled through the central HR location, it was stated in both the letter to the HR Manager and to the individual expatriates that completed expatriate surveys were to be sent directly to research headquarters via mail or facsimile. Both HR Managers and expatriates were given six weeks to complete their surveys.

${ }^{2}$ The expatriate survey was administered in English, as all respondents were expatriates of U.S. based MNCs. Seven well-normed and reliable scales were embedded in the survey instrument, along with some ancillary questions regarding firm tenure, overseas experience, and the provision of company training. 


\section{Secondary Sources}

For each participating firm, annual reports for the years ending 1993, 1994, and 1995 were ordered through the company's investor relations department. These reports allowed for three-year averages on financial ratios used in computing firm degree of internationalization. Other components in this computation were obtained from reference materials such as Dun's 1996 Directory of American Corporate Families and International Affiliates and Dun's 1996 Reference Book of Corporate Managements.

A portion of the macro-level data was also collected by tapping published sources.

The Human Development Report (United Nations, 1996), which provides country-level economic indicators, was furnished by the United Nations office. Political Risk Services, a New York-based research firm, provided the reports necessary for ascertaining the levels of risk associated with operating in various locations worldwide.

\section{MEASURES \\ Primary Sources \\ Expatriate Success}

\section{Cross-Cultural Adjustment}

\section{Previous Measures}

In what might be considered a pioneering study of expatriate adjustment, Black (1988) recommended a multi-faceted conceptualization of the adjustment construct, where adjustment to work, to interacting with host nationals, and to the general environment were all components of the cross-cultural adjustment process. An existing six-item scale 
(Torbiorn, 1982) was adopted to measure general adjustment. This initial attempt to factor out the various adjustment dimensions produced only two facets, as adjustment to interacting with host nationals was highly correlated with adjustment to the environment in general.

Subsequent literature on expatriate adjustment has predominantly utilized the multi-faceted concept (Black, 1990; Black, 1989; Black, 1994; Black \& Gregersen, 1991a, 1991b; Black \& Stephens, 1989), validating the existence of all three adjustment dimensions. Moreover, the same dimensions have been used to measure adjustment to the home country upon repatriation (Black, 1992; Black, 1994; Black \& Gregersen, 1991b), and, in some cases, to measure spousal cross-cultural adjustment (Black \& Gregersen, 1991a, 1991b; Black \& Stephens, 1989). Each dimension has proved to be consistently reliable for assessing expatriate adjustment. Items addressing work responsibilities or work-related interaction with host nationals, however, were not included in the spouse measure of adjustment, because past evidence suggested that 80 percent of the spouses would not be working in the foreign country (Stephens \& Black, 1988).

While the multi-faceted structure of cross-cultural adjustment is well-normed in the expatriation literature, it should be noted that some research in the area has conceptualized adjustment quite differently (Clarke \& Hammer, 1995; Feldman \& Thomas, 1992; Feldman \& Tompson, 1993). For example, Feldman \& Tompson (1993) categorized several outcome variables (e.g. satisfaction with pay, coworkers, supervision, job security; psychological well-being; knowledge of international business; intent to remain; ability to work with a diverse work force) as indicators of adjustment. However, according to the 
definition stated earlier, only "ability to work with a diverse work force" is an indicator of cross-cultural adjustment, and specifically, a measure of work adjustment. Again, Feldman and Thomas' (1992) adjustment indicator, "relationships with local nationals", is a measure of interaction adjustment. A sample, Likert-scaled item used to measure this variable is "I've become genuinely fond of the host nationals I work with and will miss them when I leave." Finally, Clarke and Hammer (1995) assessed personal/family adjustment through trainer ratings of how well the expatriate and his/her family adopted (relative to others) to living in the foreign culture.

\section{Current Study}

In assessing adjustment, 14 items were used. These items were used by Black and Stephens (1989) and were drawn from Black's (1988) study of U.S. expatriate adjustment in Japan. They were designed to measure expatriate adjustment to interacting with local nationals, to work, and to the environment in general. General and interaction adjustment were assessed with four items each, whereas the work adjustment scale consisted of three items. These scales ${ }^{3}$ were chosen as they have been found to be highly reliable in previous research (Black \& Stephens, 1989), with reliabilities of $.89, .82$, and .92 for interaction, general, and work adjustment, respectively.

\footnotetext{
${ }^{3}$ Items $1-1+$ on page 4 of the expatriate questionnaire (see Appendix E) comprised the expatriate crosscultural adjustment scales.
} 


\section{Organizational Commitment}

\section{Previous Measures}

Organizational commitment among expatriates has been measured in a variety of ways. For example, Banai and Reisel (1993) invoked Cook and Wall's (1980) British adaptation of the well-established Organizational Commitment Questionnaire (Mowday, Steers, \& Porter, 1979), producing two organizational commitment factors (Loyalty/Identification and Involvement) with high reliabilities. Portions of the OCQ were also used by Guzzo at al. (1994) in an investigation of the effects of company expatriate practices and retention-relevant outcomes.

Another application of the organizational commitment construct (Gregersen \& Black, 1992) assessed commitments to the parent company and to the local operation, adopting scales from Mowday et al. (1982). Subsequently, Gregersen (1992) re-adopted these scales, selecting only those items that would easily apply to each commitment target (parent company and local operation) and reflect the expatriate's identification with that target.

Although the studies mentioned above focus on organizational commitment as a distinct and measurable outcome, other research has assessed various expatriate intentions (e.g. to remain on assignment, to remain with the company) as well as expatriate turnover, all of which reflect an individual's overall commitment to the organization.

Guzzo et al. (1994) assessed three distinct intentions -- to request an early return to a domestic assignment with the company, to change employers in the near future, and 
to remain in the current location even if it means changing employers. In a similar vein, other researchers assessed intentions to remain with the assignment or with the organization through independently-developed Likert-type measures (Black \& Stephens, 1989; Feldman \& Thomas, 1992; Stephens \& Black, 1991).

\section{Current Study}

The Organizational Commitment Questionnaire (OCQ) (Porter, Steers, Mowday, \& Boulian., 1974), consisting of nine items, was used to assess the organizational commitment construct -- measuring identification, involvement, and loyalty, with responses recorded on a seven-point Likert scale. ${ }^{4}$ This scale is a replication of Cook and Wall's (1980) adaptation of the well-established Organizational Commitment Questionnaire (Mowday et al., 1979), originally yielding an overall coefficient alpha of 87 .

Job Satisfaction

\section{Previous Measures}

Feldman and Tompson (1993) conceptualized job satisfaction as part of the overall adjustment to the new job assignment, looking at domestic job relocators as well as expatriates and repatriates. In addition to general job satisfaction, they assessed the employee's satisfaction with pay, coworkers, supervision, job security, and growth opportunities.

\footnotetext{
${ }^{4}$ Items $15-23$ on page 2 of the expatriate questionnaire (see Appendix E) comprised the organizational cornmitment scales.
} 
While Feldman and Tompson (1993) have examined various aspects of individual satisfaction, most other expatriation researchers have focused exclusively on general job satisfaction (Feldman \& Thomas, 1992) or on the distinction between intrinsic and extrinsic job satisfaction (Naumann, 1993). Naumann (1993) used the Minnesota Satisfaction Questionnaire (MSQ) Short Form to measure job satisfaction, which consists of 20 items and provides both intrinsic and extrinsic job satisfaction scores (Weiss et al., 1967).

Expatriate satisfaction has also been conceptualized somewhat uniquely as the opposite of need deficiency (Miller, 1975). In this case, satisfaction data were collected through the administration of a Porter need satisfaction questionnaire, which contained 11 items classifiable into a Maslow-type need hierarchy. As an example, by assessing feelings of worthwhile accomplishment in the employee's present position, in terms of how much is there and how much should be there, it is possible to assess the individual's need deficiency and hence his/her level of satisfaction.

Finally, Stening and Hammer (1992) assessed expatriate satisfaction through selfratings as to how satisfied the managers were with each of 24 intercultural effectiveness items (e.g. frustration, anxiety, misunderstandings, empathy with others) that comprised the three scales measuring intercultural abilities (skills, communications, and relationships). 


\section{Current Study}

The Minnesota Satisfaction Questionnaire (MSQ) Short Form was used to measure satisfaction. ${ }^{5}$ The MSQ Short Form consists of 20 items and is a measure of both intrinsic and extrinsic job satisfaction.

\section{Proportion of Expatriates}

The proportion of expatriates in a given overseas subsidiary was calculated by dividing the number of U.S. nationals in each subsidiary by the total number of employees in that subsidiary. The proportion of expatriates in each MNC as a whole was calculated by dividing the number of U.S. expatriates employed by the firm in all of its overseas subsidiaries combined by the total number of employees in all of the overseas subsidiaries. Data on the number of expatriates used in each subsidiary as well as in the company as a whole was provided by HR Managers on the one-page HR Manager Surveys.

\section{Determinants of Expatriate Success}

Individual-Level Determinants

Age

Expatriate age was operationalized in years and was asked of the expatriates in the surveys sent abroad.

${ }^{5}$ Items 1-20 on page 1 of the expatriate questionnaire (see Appendix E) comprised the satisfaction scales. 


\section{Firm Tenure}

Tenure in the organization was measured as the total number of years the expatriate had worked for the parent organization and was also assessed through the expatriate him-/herself.

\section{Previous Overseas Experience}

Individual overseas experience was measured as the total number of years that the expatriate had spent in his/her lifetime working overseas (not including the current assignment). Again, these responses came from the expatriates directly.

\section{Organizational-Level Determinants}

\section{Role Ambiguity \& Role Discretion}

Six items on a five-point Likert scale from Rizzo, House, and Lirtzman (1970) were used to measure role ambiguity. ${ }^{6}$ As role clarity is the opposite of role ambiguity, this scale may also be thought of as a measure of role clarity. For role discretion, eight items on a five-point scale were adopted from Gregersen and Black (1992), ${ }^{\top}$ which represent a modified version of Stewart's (1982) work role discretion measure. The scale yielded an original coefficient alpha of 86 (Gregersen \& Black, 1992).

\section{Career Development Practices}

Three dimensions of company support are considered here - long-term career planning, mentoring, and training. Long-term career planning is defined as the extent to

\footnotetext{
${ }^{6}$ Items 1.6 on page 2 of the expatriate questionnaire (see Appendix E) comprised the role ambiguity scale. 'Items 7-14 on page 2 of the expatriate questionnaire (see Appendix E) comprised the role discretion scale.
} 
which expatriates see a clear connection between their current expatriate assignments and their overall career plans. It was measured on a 14-item, five-point Likert scale, developed by Feldman and Thomas (1992), ${ }^{8}$ which originally produced a coefficient alpha of .93 .

Mentoring is defined as the extent to which expatriates feel they have an advocate back at their domestic site who is looking out for their best interests. It was measured on a six-item, five-point Likert scale (Feldman \& Thomas, 1992). ${ }^{9}$

In order to assess the extent of training received, the study applied Tung's (1981) framework for cross-cultural training methods based on rigor, which has laid the foundation for other such frameworks (Landis \& Brislin, 1983; Mendenhall \& Oddou, 1986). Respondents were asked to check any of five types of training that were provided to them and to their spouses for their overseas assignments. ${ }^{10}$ These included (1) Area Studies Programs, (2) Culture Assimilator, (3) Sensitivity Training, (4) Field Experiences, and (5) Language Training.

\section{Environmental-Level Determinants}

\section{Cultural Familiarity}

Cultural familiarity, or the extent to which the expatriate is familiar with the hostcountry culture, was measured as a function of the following two items:

(1) Whether the expatriate had lived in the host country prior to the current assignment.

\footnotetext{
${ }^{8}$ Items 3043 on page 3 of the expatriate questionnaire (see Appendix E) comprised the long-term career planning scale.

${ }_{9}^{9}$ Items 24-29 on page 2 of the expatriate questionnaire (see Appendix E) comprised the mentoring scale.

${ }^{10}$ These items appear, unnumbered. at the bottom of page 3 of the expatriate questionnaire.
} 
(2) Whether the expatriate speaks any of the official languages of the host country.

These dimensions were scored as 1 for "yes" and 0 for "no" and were then summed for an overall cultural familiarity score.

\section{Family-Related Determinants}

Spousal Cross-Cultural Adjustment

In assessing spousal adjustment, nine Likert-type items were used (Black \& Stephens, 1989). These items were designed to measure spousal adjustment to the general environment of the host country and to interacting with local nationals. ${ }^{11}$

\section{Country Experience}

While country experience may be thought of as a subset of the overall Degree of Internationalization (DOI) construct (described in the next section), it is not directly captured by any of the DOI components. Furthermore, measures such as country-level sales and assets are not accessible through sources such as annual reports (indicated by the consolidated figures reported in the financial statements), nor are they highly reliable due to transfer pricing. Therefore, subsidiary age was used to capture the phenomenon of country experience. Subsidiary age was assessed twice in the current study -- once through the individual expatriates and later through the HR Managers.

${ }^{11}$ Items $15-23$ on page 4 of the expatriate questionnaire (see Appendix E) comprised the spousal crosscultural adjustment scales. 


\section{Secondary Sources}

\section{Degree of Internationalization}

Sullivan's (1994) composite index was used to measure the DOI of the firm, as it is the most recent conceptualization with sufficiently high reliability $($ alpha $=.79)$. The DOI index incorporates five objective, ratio measures of overseas involvement:

1. Foreign Sales as a Percentage of Total Sales (FSTS)

2. Foreign Assets as a Percentage of Total Assets (FATA)

3. Overseas Subsidiaries as a Percentage of Total Subsidiaries (OSTS)

4. Psychic Dispersion of International Operations (PDIO)

5. Top Mangers' International Experience (TMIE)

The DOI score for each MNC is the sum of each individual measure, where the range of values for DOI is 0.0 (absolutely no international involvement) to 5.0 (absolutely total international involvement). As an example, BBM's value of 2.91 for DOI in 1990 was derived accordingly:

$$
.59_{\mathrm{FSTS}}+.50_{\mathrm{FATA}}+.77_{\mathrm{OSTS}}+.90_{\mathrm{PDIO}}+.15_{\mathrm{TM} E}=2.91
$$

All components of the index were obtainable from published sources. FSTS and FATA were represented by three-year averages (1993, 1994, and 1995), in order to control for changes in exchange rates and accounting standards, and were obtained from company annual reports. Dun's Directory of American Corporate Families and International Affiliates (Dun \& Bradstreet, 1996a) supplied the frequencies and distributions of subsidiaries necessary to calculate OSTS and PDIO. PDIO was simply the 
proportion of those psychic zones identified by Ronen and Shenkar $(1985)^{12}$ in which the firm had international subsidiaries.

In order to assess TMIE for each participating firm, data on the career histories of top managers was obtained from Dun's Reference Book of Corporate Managements (Dun \& Bradstreet, 1996b). This ratio represented the number of years of overseas work experience of all top managers combined as a proportion of the team's total work experience.

\section{Determinants of Expatriate Success}

Environmental-Level Determinants

\section{Geographic Proximity}

It has been suggested (Johanson \& Vahlne, 1975) that physical distance can be used as a proxy for the psychic, or cultural distance, between cultures. Therefore, the geographic distance between the parent location (always the U.S. in this case) and the host nation was measured for all overseas assignment locations. This distance was computed as a function of the longitudinal and latitudinal difference between the capital cities. To illustrate, to calculate the distance between Washington D.C. and Canberra, Australia, one would be looking for the length of "c" (or the hypotenuse of a right triangle), as shown below:

\footnotetext{
12 These zones, or country clusters, with the addition of a category for "other" countries, include Anglo, Germanic, Nordic, Near Eastern. Arab, Far Eastern, Latin American, Latin European, Independent and Other.
} 


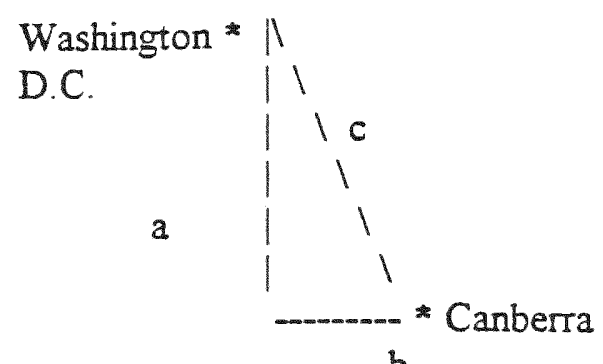

$\mathrm{b}$

This length was determined using the formula

$$
a^{2}+b^{2}=c^{2}
$$

where " $\mathrm{a}$ " is the longitudinal difference between the two capitals and " $\mathrm{b}$ " is their latitudinal difference. Smaller values for "c" represent geographically proximate capital cities.

\section{Level of Development}

The level of development of the host locations was operationalized using the Human Development Index (HDI). This index was developed by the United Nations in 1990 and is published annually in the Human Development Report. The index is based on four measures -- life expectancy at birth; adult literacy rates; combined first-, second-, and third-level gross enrollment ratios; and real GDP per capita. The HDI is a three-digit value with scores ranging from 0 to 1 in ascending order of development. This report also provides scores on the various components used to produce the index.

\section{$\underline{\text { Risk }}$}

Risk indices were obtained from Political Risk Services (1996), a New York-based research firm that publishes an annual index based on risk factors, including political turmoil, as well as financial transfer, direct investment, and export market risk. Scores on 
the index range from 0 for countries with the most favorable environments to 100 for those with the riskiest climates. These scores were reverse-coded for the current analyses.

\begin{abstract}
ANALYSIS
Preliminary procedures to hypothesis testing included the calculation of response rates and descriptive statistics on expatriate respondents. In addition, scaled measures were factor analyzed to ensure sound psychometric properties, and correlations among all variables were calculated to prevent any confounding effects due to multicollinearity of measures. The last step prior to testing the current model was in performing $T$-tests for mean differences in the scores on the various expatriate outcomes.
\end{abstract}

\title{
Response Rates
}

Information on the HR Manager Surveys was used to test two different research hypotheses ( $\mathrm{Hla}$ and $\mathrm{Hlb}$ ). Therefore, while some of the information was incomplete or unavailable, most HR Manager Surveys were rendered usable for testing at least one of these hypotheses.

The first addresses the level of overall firm internationalization and the proportion of expatriates used by the firm as a whole. Each HR Manager Survey (or each firm) counted as one case. The total number of cases considered usable for Hla was 32 .

$\mathrm{H} 1 \mathrm{~b}$ addresses the extent of firm experience in a given country subsidiary and the proportion of expatriates used in each subsidiary. Therefore, each subsidiary is a case in and of itself. Where the HR Manager did not report on all subsidiaries (most times due to 
the fact that there were too many to research), Hlb could still be tested on any case for which country experience (or subsidiary age) and proportion of expatriates in the subsidiary were provided. The age of each subsidiary was obtained from the central location. Therefore, all HR Managers from firms participating at both levels were contacted for subsidiary ages. The total number of cases considered usable for the second hypothesis in this set was 235 .

When primary data collection was complete, response rates were computed for expatriates whose firms agreed to participate fully and for firms and subsidiaries where limited participation was expected.

230 expatriate surveys were received, out of a total of 580 that were sent out (representing 15 firms across the two sets of industries), for a response rate of 40 percent. ${ }^{13}$ Thirty-two HR Manager Surveys were received, out of a total of 46 that were sent out, for a response rate of 70 percent. Of these 32,13 represented fully participating firms from which corresponding expatriate surveys were received. The remaining 19 were from firms that participated at the limited level only.

\section{Respondent Profiles}

Table 6 provides a summary of the expatriate sample characteristics. As stated previously, the 230 expatriate respondents represented 15 different firms. More

\footnotetext{
${ }^{13}$ The number of surveys that went out refers to those that were indeed forwarded by HR Managers. Although expatriate responses were received from 15 firms, 30 had originally agreed to participate. However, follow-up phone calls revealed that 11 firms had in fact NOT EVEN SENT the surveys abroad. and some had even sent the packages back. The total number of surveys that were sent to HR Managers that did not leave their desks was 266.
} 
TABLE 6

Respondent Profiles

\begin{tabular}{|c|c|c|c|}
\hline $\begin{array}{l}\text { Industries Represented } \\
\text { Computers } \\
\text { Electronics } \\
\text { Petroleum } \\
\text { Chemicals }\end{array}$ & $\begin{array}{l}\underline{\pi} \\
42 \\
44 \\
95 \\
49\end{array}$ & $\begin{array}{l}\% \\
18.3 \\
41.3 \\
19.1 \\
21.3\end{array}$ & $\begin{array}{c}\text { No. of Firms } \\
5 \\
2 \\
5 \\
3\end{array}$ \\
\hline Age of Firms Represented & $\frac{\text { Range }}{2-124 \text { yrs. }}$ & $\begin{array}{l}\text { Mean } \\
82.3 \mathrm{yrs} .\end{array}$ & \\
\hline Internationalization of Firms Represented & $\frac{\text { Range }}{.40-.60}$ & $\frac{\text { Mean }}{3.12}$ & \\
\hline $\begin{array}{l}\text { Expatriate Position } \\
\text { President, Partner, VP } \\
\text { Director/Manager } \\
\text { Coordinator/Administrator } \\
\text { Consultant, Advisor } \\
\text { Other }\end{array}$ & & $\begin{array}{r}\% \\
8.8 \\
74.8 \\
2.2 \\
4.0 \\
10.2\end{array}$ & \\
\hline $\begin{array}{l}\text { Expatriate Functional Area } \\
\text { Finance, Accounting } \\
\text { Sales, Marketing } \\
\text { Human Resources } \\
\text { Production Operations } \\
\text { Information Systems } \\
\text { Other or Not Specified }\end{array}$ & & $\begin{array}{r}\% \\
11.9 \\
11.9 \\
4.4 \\
37.2 \\
9.2 \\
25.2\end{array}$ & \\
\hline $\begin{array}{l}\text { Gender } \\
\text { Male } \\
\text { Female }\end{array}$ & & $\begin{array}{r}\% \\
91.7 \\
8.3\end{array}$ & \\
\hline $\begin{array}{l}\text { Marital Status } \\
\text { Married } \\
\text { Not Married }\end{array}$ & & $\begin{array}{r}\% \\
85.6 \\
14.4\end{array}$ & \\
\hline $\begin{array}{l}\text { Number of Children } \\
\text { Have Children } \\
\text { Do not Have Children }\end{array}$ & & $\begin{array}{r}\% \\
20.1 \\
79.9\end{array}$ & \\
\hline $\begin{array}{l}\text { Level of Education } \\
\text { High School Diploma } \\
\text { 2-Year College Degree } \\
\text { Bachelor's Degree } \\
\text { Master's Degree } \\
\text { Doctoral Degree }\end{array}$ & & $\begin{array}{r}\% \\
2.2 \\
3.1 \\
51.7 \\
32.6 \\
8.3\end{array}$ & \\
\hline $\begin{array}{l}\text { Country of Birth } \\
\text { U.S. } \\
\text { Outside U.S. }\end{array}$ & & $\begin{array}{l}\frac{\%}{84} \\
16\end{array}$ & \\
\hline $\begin{array}{l}\text { Foreign Languages Spoken } \\
\text { Yes } \\
\text { No }\end{array}$ & & $\begin{array}{l}\% \\
53.9 \\
46.1\end{array}$ & \\
\hline $\begin{array}{l}\text { Lived Abroad Prior to Current Assignment } \\
\text { Yes } \\
\text { No }\end{array}$ & & $\begin{array}{l}\% \\
60.3 \\
39.7\end{array}$ & \\
\hline
\end{tabular}


specifically, they represented five firms in the computer industry $(n=42)$, two firms in electronics ( $n=44)$, five in petroleum refining ( $n=95)$, and three in the chemicals industry $(n=49)$. When related industries were combined, there were 86 and 144 respondents in the two sets of industries, respectively.

Almost all respondents were male $(91.7 \%)$, and the proportion of expatriates who were married was 85.6 percent. In addition, 79.9 percent reported that they had children, for an average of 1.9 children per respondent. An overwhelming majority of the respondents were born in the U.S. $(84.0 \%)^{14}$, as were both of the expatriates' parents (mothers, $80.7 \%$; fathers, $82.0 \%$ ). With regard to expatriate levels of education, 94.7 percent held at least a bachelor's degree, with 33.0 and 8.5 percent holding master's and doctorates, respectively.

Respondents were also queried as to other countries in which they had previously lived, as well as to other languages spoken. Forty percent of the expatriates had never lived outside of the U.S. prior to the assignment. All in all, the respondents had lived in an average of 1.2 other countries $(9.6 \%$ had lived in three other countries, and there were a handful still that had lived in four, five, six, and even seven other countries, with England, Norway, and Australia appearing the most frequently). Almost half (46.3\%) of the respondents did not speak a language other than English. In fact, the mean number of foreign languages spoken among the respondents was .87 . Of the 54 percent who did

\footnotetext{
${ }^{14}$ All respondents were U.S. citizens, expatriated from U.S. Fortune 500 companies to overseas locations. However, 16 percent were actually born outside of the U.S.
} 
speak another language, 5.2 and 1.7 percent spoke three and four languages, respectively. The most commonly spoken languages were Spanish, French, and German.

The majority of the expatriates held positions at the management level $(74.8 \%)$, which was indicated by such titles as "Manager", "Senior", "Supervisor", and "Director", while 8.8 percent were even higher up in the organizational hierarchy, primarily as vicepresidents. In addition, a handful were coordinators, administrators, or some type of consultant or specialist without the management title. The functional area of expertise with the highest concentration was in production/operations $(37.2 \%)$, while the area of lowest concentration was in human resources (4.4\%). All other business functions (finance, accounting, sales and marketing, and information systems) were fairly evenly represented by the expatriate respondents.

Only 2.7 percent of the expatriates had a title reflecting the international nature of their assignments. Words indicative of such international orientation were "international", "global", "foreign", and "worldwide". However, 20.8 percent did have titles indicating the regional nature of their assignments. This was indicated by "regional", "area" or "country", or by the actual country or region as part of the title (i.e. "Manager of Business Development, European Operations").

In terms of total length of the assignment, the mean was 43.5 months, with responses ranging from 2 to 102 months. Close to 25 percent were on 60 -month assignments, and 17.3 percent were on assignments for 36 months. It should be noted that 12.6 percent reported that the length of their stays abroad were indefinite. However, since overseas assignments rarely exceed 60 months, indefinite responses were recoded to equal 
60. In the cases where the expatriate had already been in the assignment for more than 60 months, the length of the assignment was set equal to the number of months served to date. The mean number of months that had already been served at the time of the study was 24.7 , with time in ranging from 1 to 114 months.

\section{Reliability and Validity of Measures}

For those variables represented by scales of items, valid and reliable measures were arrived at through the use of factor analytic techniques. These procedures are described below, and factor solutions for the expatriate success measures and the determinants of expatriate success are displayed in Tables 7 and 8, respectively.

\section{Expatriate Success}

\section{Cross-Cultural Adjustment}

The 14 expatriate adjustment items were entered into a constrained three-factor solution. The solution was strong, explaining 68.5 percent of the variance in the correlation matrix, with eigenvalues ranging from 4.00 down to 1.47 . The interaction items loaded first, followed by work and then general adjustment. The items on adjustment to living and housing conditions and to health care facilities, however, did not discriminate sufficiently across the factors and were subsequently dropped from the structure. Reliabilities for the interaction, work, and general scales, respectively, were 88 (with loadings from .81 to .88 ), .77 (with loadings from .85 to .89 ), and .72 (with loadings 

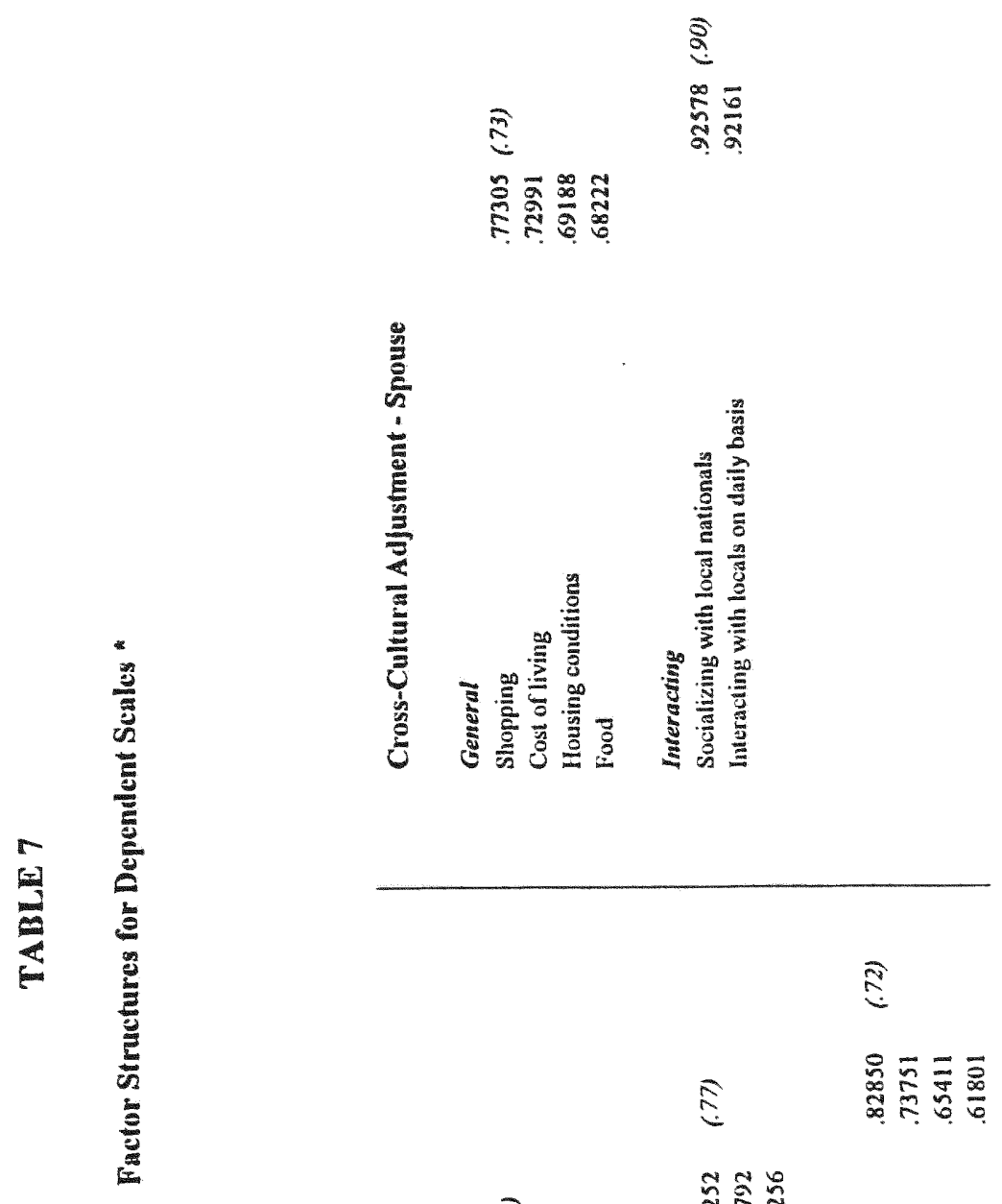

क्

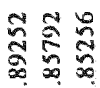

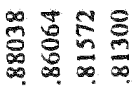
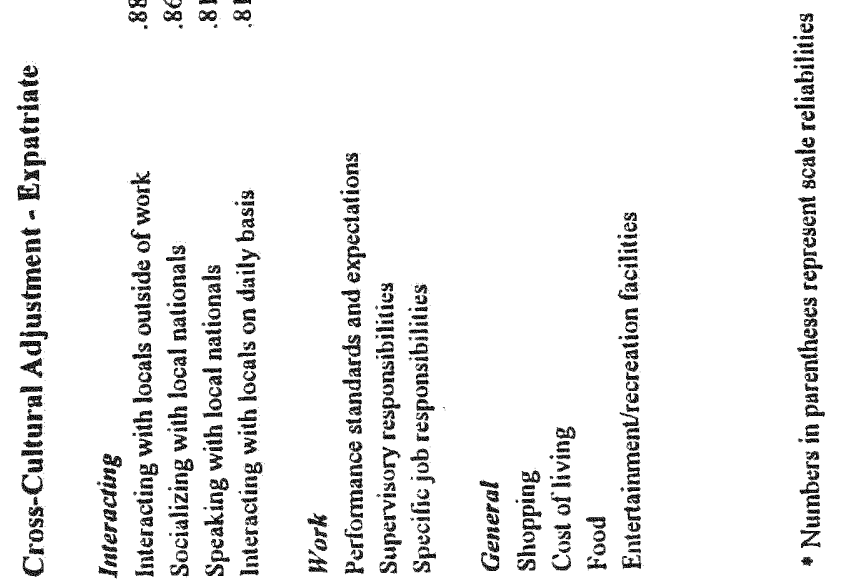
옹

E

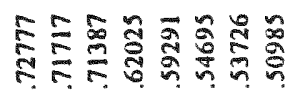

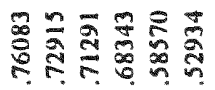

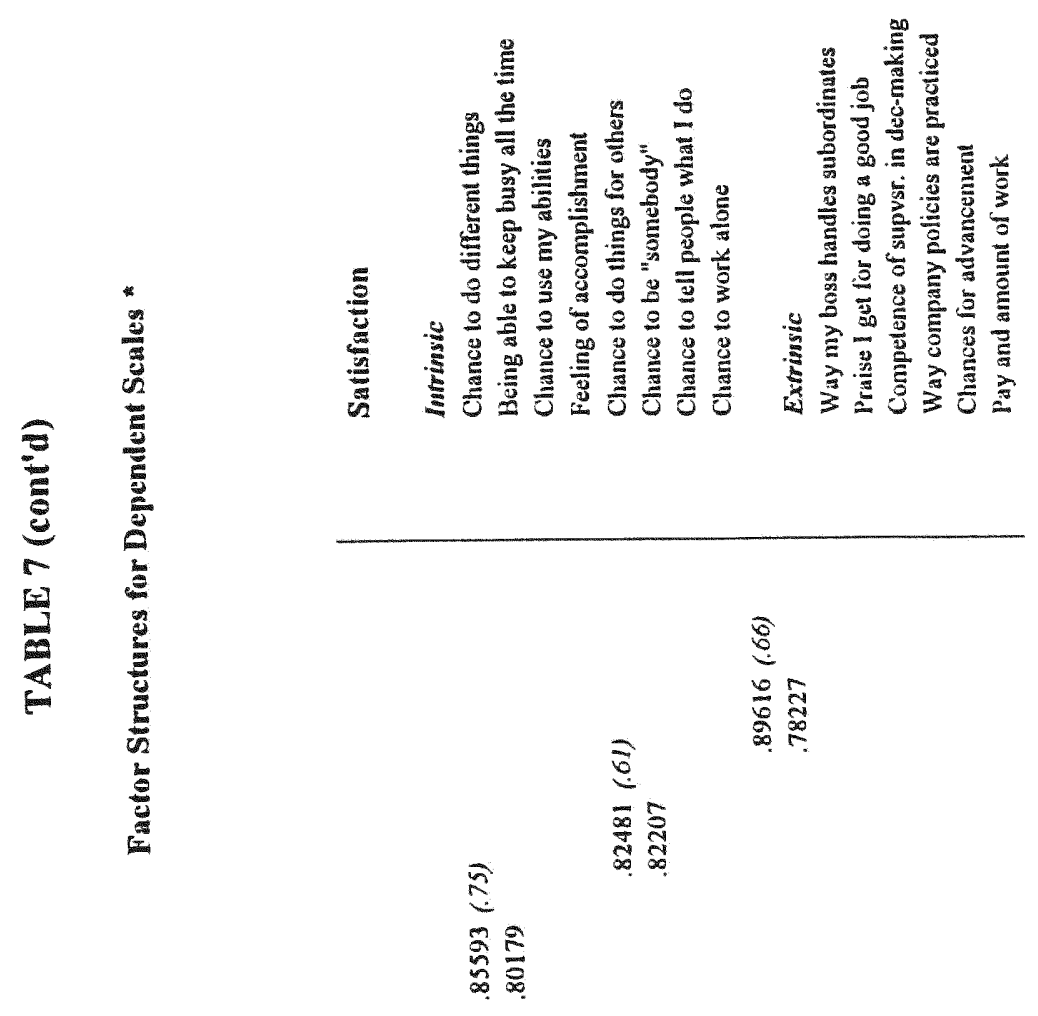

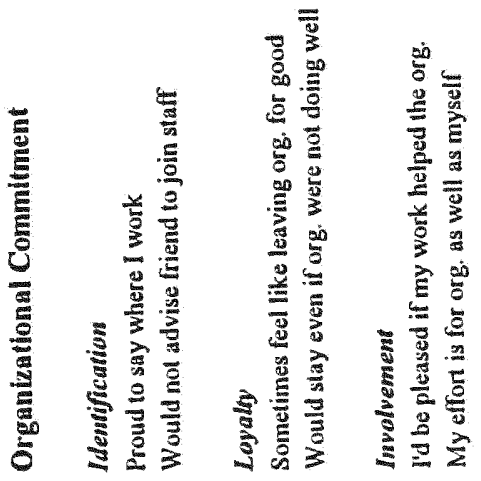

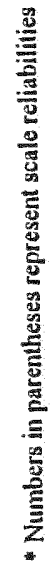


बे

\$

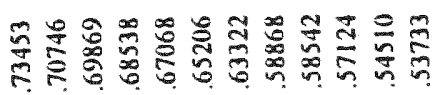

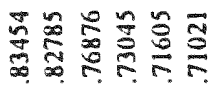

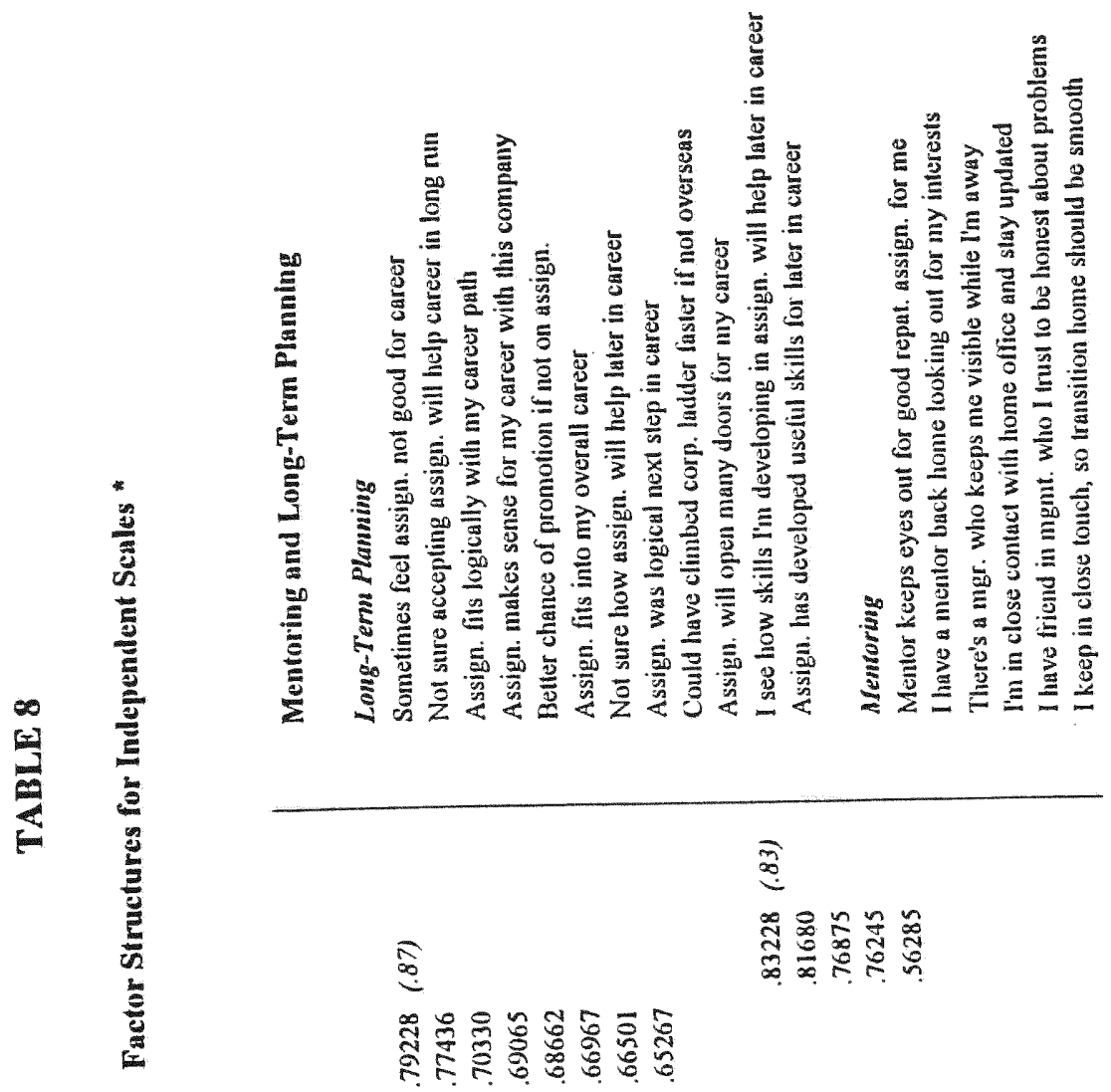

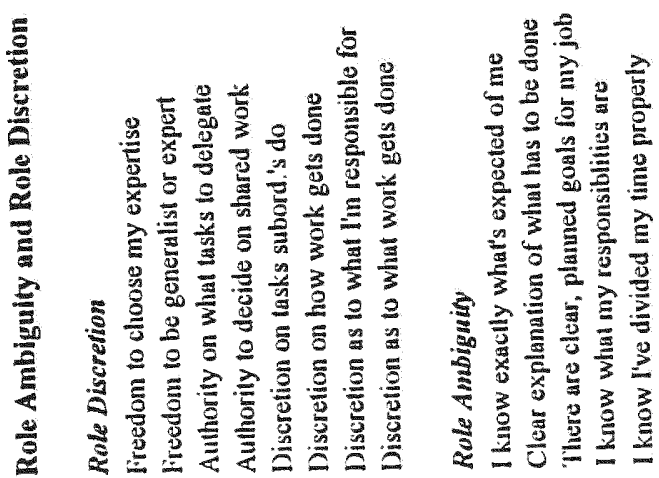

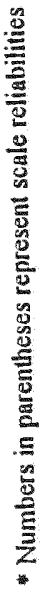


from .62 to .83 ). Scores on the 11 items which were retained were then averaged to arrive at an overall cross-cultural adjustment score (alpha $=.81$ ).

\section{Organizational Commitment}

The nine items designed to measure organizational commitment were entered into a constrained three-factor solution, using principal components method of extraction and varimax rotation, after reverse coding negatively worded items. Retaining only those items which demonstrated both convergent and discriminant validity, the three organizational commitment constructs were captured with two items each. For identification, loadings ranged from .80 to .86 , with an alpha of .75 . For loyalty, both loadings were .82 , with an alpha of .61 . And, for involvement, loadings ranged from .78 to 90 , with an alpha of 66 . The factor structure explained 76.5 percent of the variance in the correlation matrix, with eigenvalues of $2.62,1.32$ and .65 , respectively. While factors with eigenvalues of less than one are typically dropped from factor solutions, the items in the third factor (involvement) were necessary for capturing a dimension that may be very different for the current expatriate sample than for those previously studied. Overall organizational commitment was captured by averaging scores on the six items which demonstrated convergent and discriminant validity for the dimensions described above $($ alpha $=.73)$. 
Job Satisfaction

The 20 items comprising the MSQ Short Form were designed to assess the overall satisfaction construct. Therefore, while 18 of these items measure either intrinsic or extrinsic satisfaction, it was not necessary to consider the factor structures of these dimensions for assessing the global satisfaction construct. Instead, scores on the 20 items were averaged, and the satisfaction scale yielded a coefficient alpha of 87 . To confirm that intrinsic and extrinsic measures were embedded in the overall satisfaction scale, the corresponding 18 items were entered into a constrained two-factor solution using the same factor analytic procedures as above. Items were reverse-coded so that higher values would reflect higher levels of satisfaction. All items loaded as expected, with the exception of an item concerning satisfaction with the way the job provides for steady employment. While this item was expected to load with the intrinsic satisfaction items, it appeared on the extrinsic factor, albeit with a low factor score of .45. Furthermore, three other items did not identify highly with their respective factors and were therefore omitted from the solution. Subsequent attempts to produce the tightest, most reliable constructs, without sacrificing prevailing theory, led to an eight-item intrinsic scale (alpha $=.79$ ) with loadings from .51 to .73 , and a six-item extrinsic scale (alpha $=.77$ ) with loadings from .53 to .76 . The solution explained 44.9 percent of the variance in the correlation matrix, with eigenvalues of 4.42 and 1.86 . 


\section{Determinants of Expatriate Success}

\section{Role Ambiguity \& Role Discretion}

The 14 items used to measure role discretion and role ambiguity were factor analyzed, using the principal components method of extraction and varimax rotation, into a constrained two-factor solution. All eight items designed to measure role discretion clearly identified with a single factor, with loadings ranging from .65 to .79 and with a Cronbach's alpha of .87 . Any reduction in the number of items would have reduced the scale's reliability. While all six role ambiguity items loaded on a single factor as well, one item did not demonstrate discriminant validity and was therefore eliminated. Loadings for role ambiguity ranged from .56 to .83 , and the scaled proved highly reliable (alpha $=.83$ ). This two-factor solution explained 56.7 percent of the variance in the correlation matrix, with eigenvalues ranging from 5.46 down to 1.92 . Scores on each of these scales were simply the item means.

\section{Career Development Practices}

Items for all three types of organizational development programs were entered into a constrained four-factor solution. The logic behind the use of four factors was that the training items may have represented two different theoretical constructs (interactive and non-interactive training techniques). However, since no empirical analyses had ever been performed on these training items, the initial attempt to separate these constructs was purely exploratory. Using principal components method of extraction and varimax rotation, there indeed emerged one factor with items measuring long-term planning, one 
with those measuring mentoring, and two capturing training. Two long-term planning items were eliminated, due to lack of discriminant validity, as well as the repetitive nature of some items. The new long-term planning scale yielded an alpha of .89 , with loadings from .54 to .73 . The six-item mentoring scale, on the other hand, remained intact (alpha=90), with loadings from .71 to .83 . The four-factor solution explained 52.8 percent of the variance in the correlation matrix, and eigenvalues ranged from 7.76 down to 1.83 .

Training items did not factor as expected. Therefore, scores on training were simply computed as the number of programs provided to the expatriate, so that scores ranged from 0 to 5 .

\section{Spousal Cross-Cultural Adjustment}

For spousal adjustment, nine items were entered into a factor solution which was constrained to two factors, as work adjustment was not applicable here. Six of the nine items loaded with convergent and discriminant validity, producing a solution that explained 67.7 percent of the variance in the correlation matrix and with eigenvalues of 3.04 and 1.02 . Reliabilities for general and interaction scales were .73 (with loadings from .68 to .77 ) and .90 (with loadings from .92 to .93 ), respectively. While interaction adjustment for the expatriate and the spouse were captured with the same items (where applicable for the spouse), general adjustment was structured slightly differently. Whereas expatriate general adjustment consisted of adjustment to entertainment and recreational facilities, this aspect was replaced by adjustment to housing conditions for the spouse. 
Overall spousal adjustment was measured as a function of adjustment to the general environment and to interacting with locals, averaging scores on the six items that were retained $($ alpha $=.80)$.

\section{Variables and Correlations}

All bivariate correlations, together with means, standard deviations, and scale reliabilities where applicable, are shown in Table 9. The table indicates high bivariate correlations among only two pairs of independent variables. These include the provision of expatriate training (TREXP) and spouse training (TRSP), with a correlation coefficient of .89 , and the level of host-country development (HDI) and risk (RISK), with a correlation coefficient of .76 . However, all variance inflation factors produced in the subsequent regression analyses were less than 10.0, indicating that there were no significant multicollinearity effects on the outcome variables (Haire, Anderson, Tatham, \& Black, 1992).

In order to address $\mathrm{H} 2, \mathrm{H} 3$, and $\mathrm{H} 4$ (See Tables 1,2 , and 3), multiple linear regression analysis was used to build models explaining the various outcomes. It was decided a priori that separate analyses would be run to test the moderating effects of overall firm internationalization and those of country experience. Therefore, with the exception of the moderator, models included the same set of variables. The following variables were included in each regression equation: 


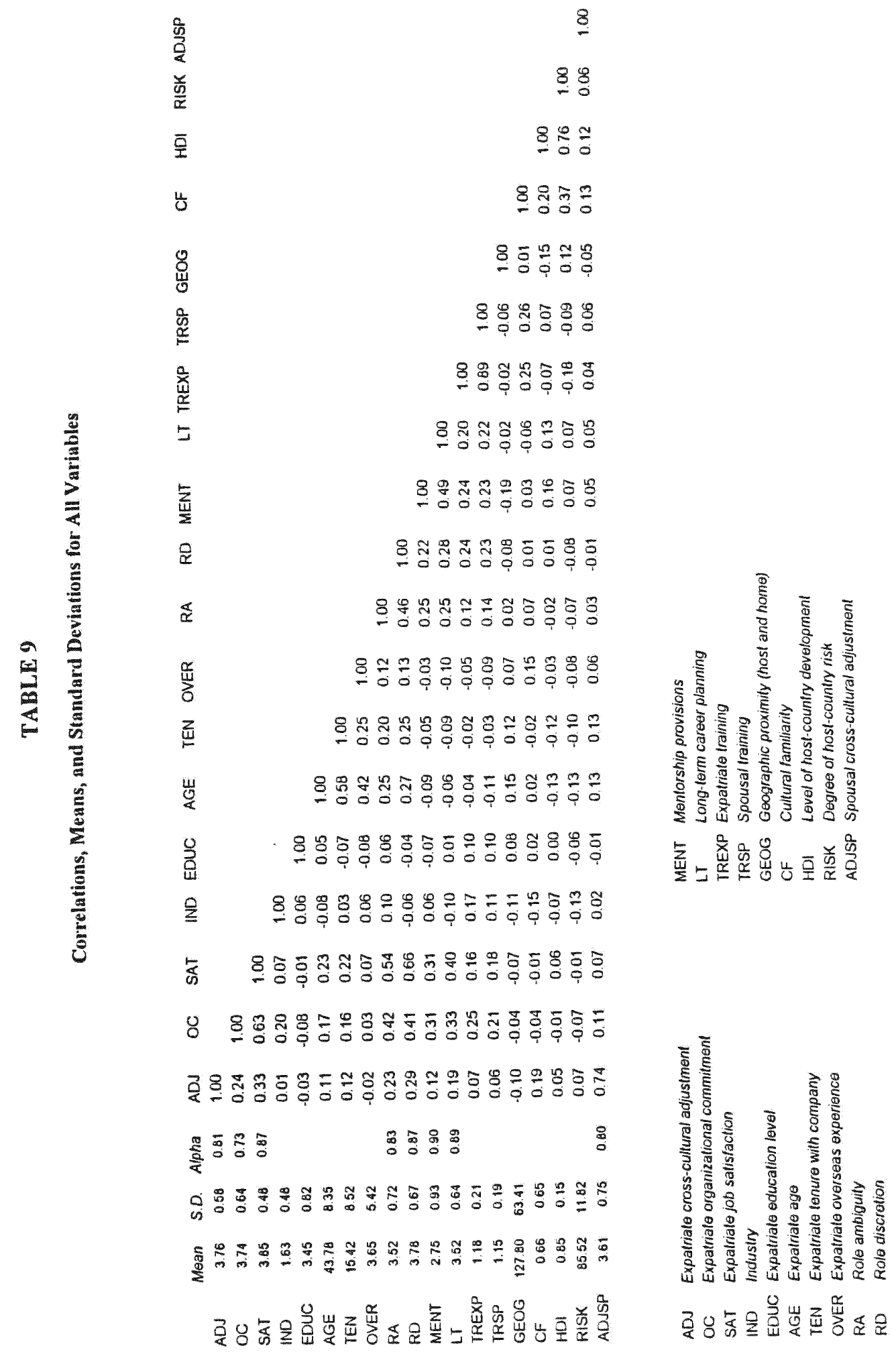


Cross-Cultural Adjustment (ADJ)

Organizational Commitment (OC)

Job Satisfaction (SAT)

Individual Characteristics:

Expatriate Age (AGE)

Expatriate Tenure with the Firm (TEN)

Expatriate Overseas Experience (OVER)

Organizational Characteristics:

Role Ambiguity (RA)

Role Discretion (RD)

Mentoring (MENT)

Long-Term Career Planning (LT)

Expatriate Training (TREXP)

Spouse Training (TRSP)

Environmental Characteristics:

Geographic Proximity (GEOG)

Cultural Familiarity (CF)

Host-Country Development (HDI)

Host-Country Risk (RISK)

Family-Related Variables:

Spousal Adjustment (ADJSP)

\section{Differences Among Means}

Country experience, as a dummy variable, was divided on the basis of one-sixth of a standard deviation from the mean subsidiary age in either direction. As a result, subsidiary ages of 17 years or less were considered young, ages of 23 or more were considered mature, and those expatriates in subsidiaries between 17 and 23 years old (23 cases) were removed from the analyses to allow for sufficient variance across the two categories of country experience. In dummy coding DOI, low and high categories were divided on the basis of one-fourth of a standard deviation from the mean DOI value in 
either direction. As a result, DOI values of 1.57 or less were considered low, values of 2.01 or greater were considered high, and those falling between 1.57 and 2.01 (18 cases) were removed from the analyses to allow for sufficient variance between the two DOI categories.

Means and standard deviations for all variables, grouped by degree of internationalization and country experience, are provided in Table 10. For the three dependent variables (adjustment, commitment, and satisfaction), T-Tests for differences among means were conducted based on degree of internationalization, country experience, and industry (also dummy coded into two categories). The results of these tests are provided in Table 11. It is clear from the table that there were no significant differences in the mean values for adjustment and for organizational commitment, but that mean levels of satisfaction differed significantly for those expatriates in firms with low and high degrees of overall internationalization.

The hypotheses were tested by dichotomizing country experience and DOI in a similar manner. However, the study tests hypotheses at three levels of analyses (the individual, the subsidiary, and the firm). Consequently, the distributions of subsidiary ages and of DOI scores will vary depending on the sample being considered and hence the means, standard deviations, and the subsequent dividing points will differ. While the Ttests described here are based on the expatriate sample (230 observations), results for the first set of hypotheses described at the beginning of the next chapter are subsidiary- and firm-specific. 


\section{TABLE 10}

Means and Standard Deviations by Country Experience and Degree of Internationalization

Country Experience

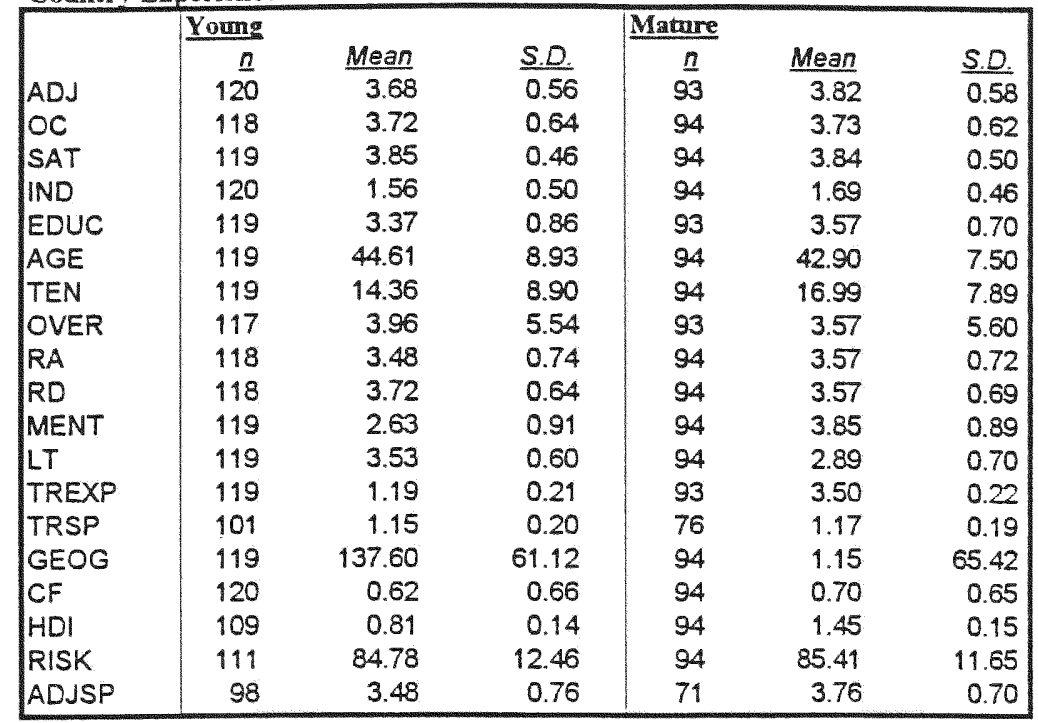

Degree of Internationalization

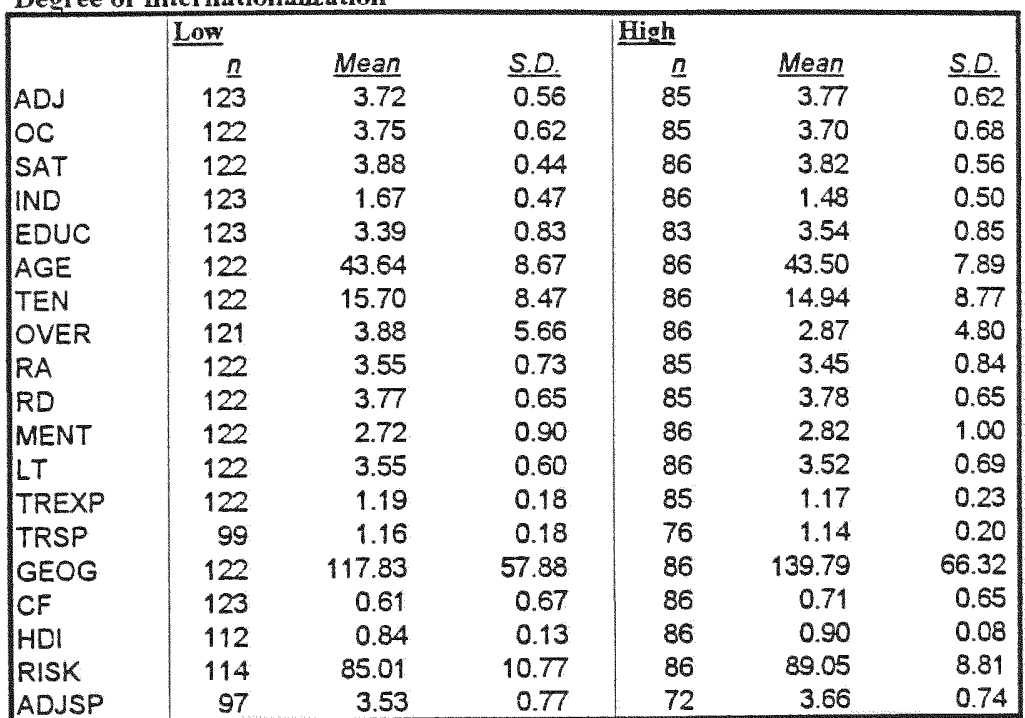

$\begin{array}{ll}\text { ADJ } & \text { Expatriate cross-cutural adjustment } \\ \text { OC } & \text { Expatriate organizational commit } \\ \text { SAT } & \text { Expatriate job satisfaction } \\ \text { IND } & \text { industry } \\ \text { EDUC } & \text { Expatriate education level } \\ \text { AGE } & \text { Expatriate age } \\ \text { TEN } & \text { Expatriate tenure with company } \\ \text { OVER } & \text { Expatriate overseas experience } \\ \text { RA } & \text { Role ambiguity } \\ \text { RD } & \text { Role discretion }\end{array}$

MENT Mentorship provisions LT Long-term career planning TREXP Expatriate training TRSP Spousal training GEOG Geographic proximity (host and home) CF Cuhural familiarity

$\mathrm{HDI} \quad$ Level of host-country development RISK Degree of host-country risk

ADJSP Spousal cross-cuitural adjustment 


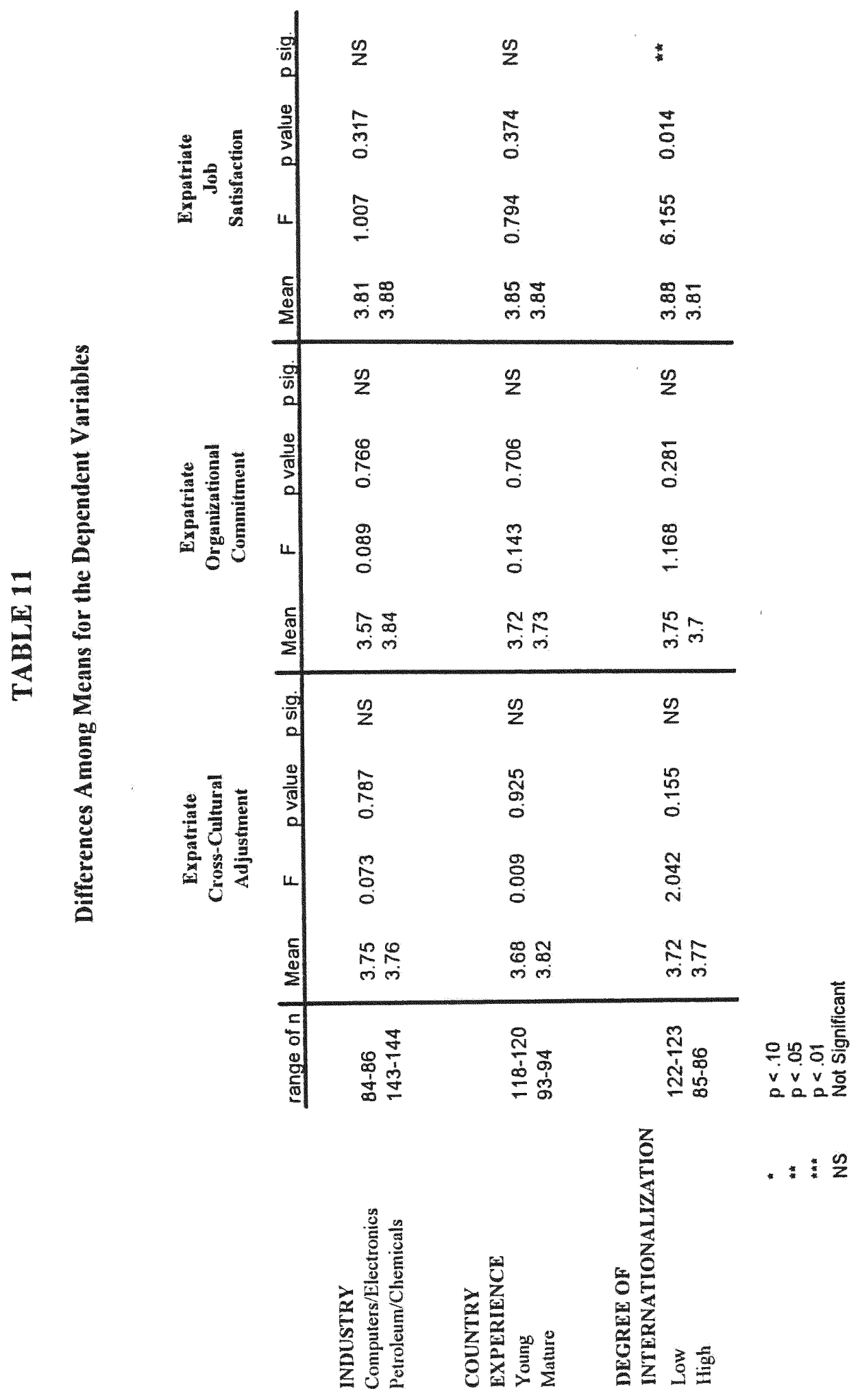




\section{Chapter IV \\ Results}

\section{THE USE OF EXPATRIATES AS FIRMS INTERNATIONALIZE}

$H I$ was based on the expectation that as firms internationalize, they will gradually increase their expatriate populations in order to expand their international knowledge base, but that the use of expatriation will diminish as international experience is gained. Specifically, Hla stated that, when international experience is low, there will be a positive relationship between internationalization and expatriation. HIb stated that, when international experience is high, there will be a negative relationship between internationalization and expatriation. To test $\mathrm{Hl}$, two sets of multiple linear regressions were run, with both country experience and degree of internationalization (DOI) operationalized as continuous variables in order to maintain the richness of information available. Results of these analyses are displayed in Table 12 and are discussed in turn.

\section{Expatriation and Country Experience}

HIa-CE stated that, when there is little country experience, there will be a positive relationship between country experience and the proportion of expatriates in that country's subsidiary. Conversely, $H 1 b-C E$ stated that, when there is extensive country experience, there will be a negative relationship between country experience and the proportion of expatriates in that country's subsidiary.

Country experience was operationalized as subsidiary age, dichotomized as either young or mature, in order to assess the relationship in both age categories. Since the 235 


\section{TABLE 12}

Results of H1: The Use of Expatriates as Firms Internationalize

\section{Country Experience}

Expressed by the function: PROPEXP $_{\text {sub }}=f\left(b_{0}\right.$.. sageb $b_{1}$. ind $\left._{2} . . e\right)$

Young Subsidiaries

$\mathrm{n}=78$, Adjusted Rsq $=.122$, F Statistic $=6.370, \mathrm{p}=.0028$

PROPEXP $_{\text {sub }}=-3.376-.027_{\text {sub }}+1.154_{\text {ind }}+1.491$

Mature Subsidiaries

$\mathrm{n}=42$, Adjusted Rsq $=.151$, F Statistic $=4.653, \mathrm{p}=.0154$

PROPEXP sub $=-2.007-.026_{\text {sub }}+.516_{\text {ind }}+1.468$

\section{Degree of Internationalization}

Expressed by the function: PROPEXP $_{\text {firm }}=f\left(b_{0} .\right.$. doib $_{1} .$. indb $\left._{2} . . e\right)$

\section{Low DOI}

$\mathrm{n}=13$, Adjusted Rsq $=.258, \mathrm{~F}$ Statistic $=3.090, \mathrm{p}=.0902$

PROPEXP $_{\text {firm }}=-.908+1.231_{\text {doi }}=1.009_{\text {ind }}+.862$

\section{High DOI}

$\mathrm{n}=17$, Adjusted Rsq $=.203$, F Statistic $=3.031, \mathrm{p}=.0806$

PROPEXP $_{\text {firm }}=-7.404-.486_{\text {doi }}+1.494_{\text {ind }}+1.160$

PROPEXP sub

PROPEXP

sage

doi

ind
Proportion of expatriates in the subsidiary

Proportion of expatriates in the firm

Subsidiary age

Degree of firm internationalization

Industry 
observations here represented subsidiaries (as opposed to the expatriates upon which means, standard deviations, and T-tests were based in the previous chapter), the distribution of subsidiary ages was different. As a result, country experience, as a dummy variable, was divided on the basis of one-fourth of a standard deviation from the mean subsidiary age in either direction. In this case, the mean age of the subsidiaries was 21.35 years. Therefore, subsidiary ages of 16 years or less were considered young, ages of 27 or more were considered mature, and those ages falling between 16 and 27 years ( 51 cases) were removed from the analyses to allow for sufficient variance across the two categories of country experience. It should be noted that 16 of these observations represented 21 year-old subsidiaries. Furthermore, casewise plots of standardized residuals (based on simple regressions of subsidiary age on proportion of expatriates) revealed two cases exceeding 2.5 standard deviations and 28 cases exceeding 3.0 standard deviations from the mean. While guidelines (Haire et al., 1992) permit the exclusion of those exceeding the 3.0 threshold with a sample of this size, only the first two outliers were removed due to the fact that 51 observations had already been eliminated.

Independent variables in the analyses included country experience and a dummy variable to control for industry. It was necessary to transform the variable of interest (proportion of expatriates in the subsidiary) to its natural log, as proportions were not normally distributed. However, in transforming the data, proportions of 0 were treated as missing values and hence as missing cases. As a result, sample sizes in either the young or mature categories (or both) may be distorted. Therefore, all analyses for $H \mathrm{la}-\mathrm{CE}$ and $H I b-C E$ were run with both the observed and the transformed data. 
Using the observed values, sample sizes included 115 young and 119 mature subsidiaries. In both age categories, the relationship between subsidiary age and proportion of expatriates was negative, but neither was significant. Furthermore, the regression equation for the mature group produced a negative adjusted $R^{2}(-.01)$. Upon transforming the data, sample sizes included 78 young subsidiaries and 42 mature subsidiaries. The two regression models explained a greater percentage of the variance in the proportion of expatriates $\left(R^{2}=.122\right.$ for the young subsidiaries; $R^{2}=.151$ for the mature subsidiaries). Furthermore, while the relationship was again negative in both age categories, it was significant for the mature subsidiaries at the .05 level of confidence $(p<$ .0154 ), and thus $H 1 b-C E$ was supported. A scatter plot of the relevant data is shown in Figure 4 .

\section{Expatriation and Degree of Internationalization}

HIa-DOI stated that, when overall firm internationalization is low, there will be a positive relationship between degree of internationalization and the proportion of expatriates in the firm as a whole. In contrast, $H 1 b-D O I$ stated that, when overall firm internationalization is high, there will be a negative relationship between degree of internationalization and the proportion of expatriates in the firm as a whole.

Overall firm internationalization was operationalized using Sullivan's DOI index and was dichotomized as either low or high, in order to assess the relationship at stages of internationalization. There were 32 observations (or firms), with a mean DOI score of 1.592 (on a scale of 0 to 5). Low and high DOI categories were divided on the basis of 

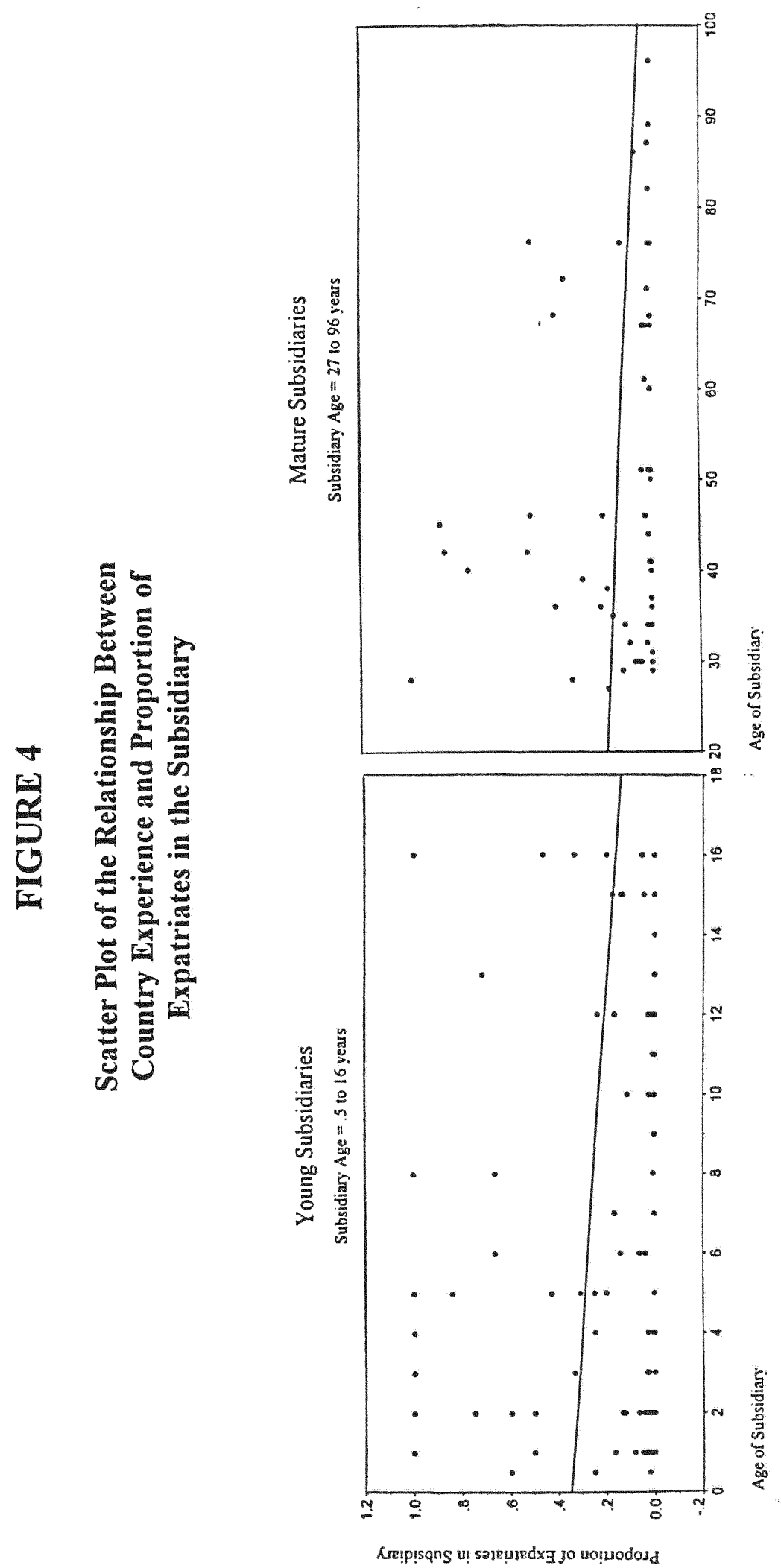
one-eighth of a standard deviation from the mean DOI value in either direction. As a result, values of 1.43 or less were considered low, values of 1.75 or greater were considered high, and those falling between 1.43 and 1.75 (two cases) were eliminated from the analysis. Casewise plots of standardized residuals indicated that three cases exceeded 1.0 standard deviation from the mean. These observations, however, were not treated as outliers, because, due to the limited number of observations, these may indeed represent a segment of the population.

Again, regression equations included a dummy variable to control for industry, and data for the dependent variable (proportion of expatriates in the firm as a whole) was transformed to a natural log to meet the assumption of normality. Proportions were never equal to zero for the firm as a whole, since having an expatriate population was a criteria for inclusion in the study. Therefore, HIa-DOI and HIb-DOI were tested with regressions using only the transformed data.

Sample sizes included 13 firms with low DOI values and 17 firms with high DOI values. For low DOI firms, the relationship between DOI and proportion of expatriates was positive and significant at the .10 level of confidence $(p<.0905)$, thus supporting HIa-DOI. This regression model explained 25.8 percent of the variance in proportion of expatriates in the firm. For high DOI firms, the relationship was negative, as expected, but was not significant. However, with an $\mathrm{R}^{2}$ of .203 , industry was a significant predictor of expatriation, and the positive beta value indicates that petroleum/chemicals firms expatriate more than do firms in computers/electronics. A scatter plot of the relevant data is shown in Figure 5. 


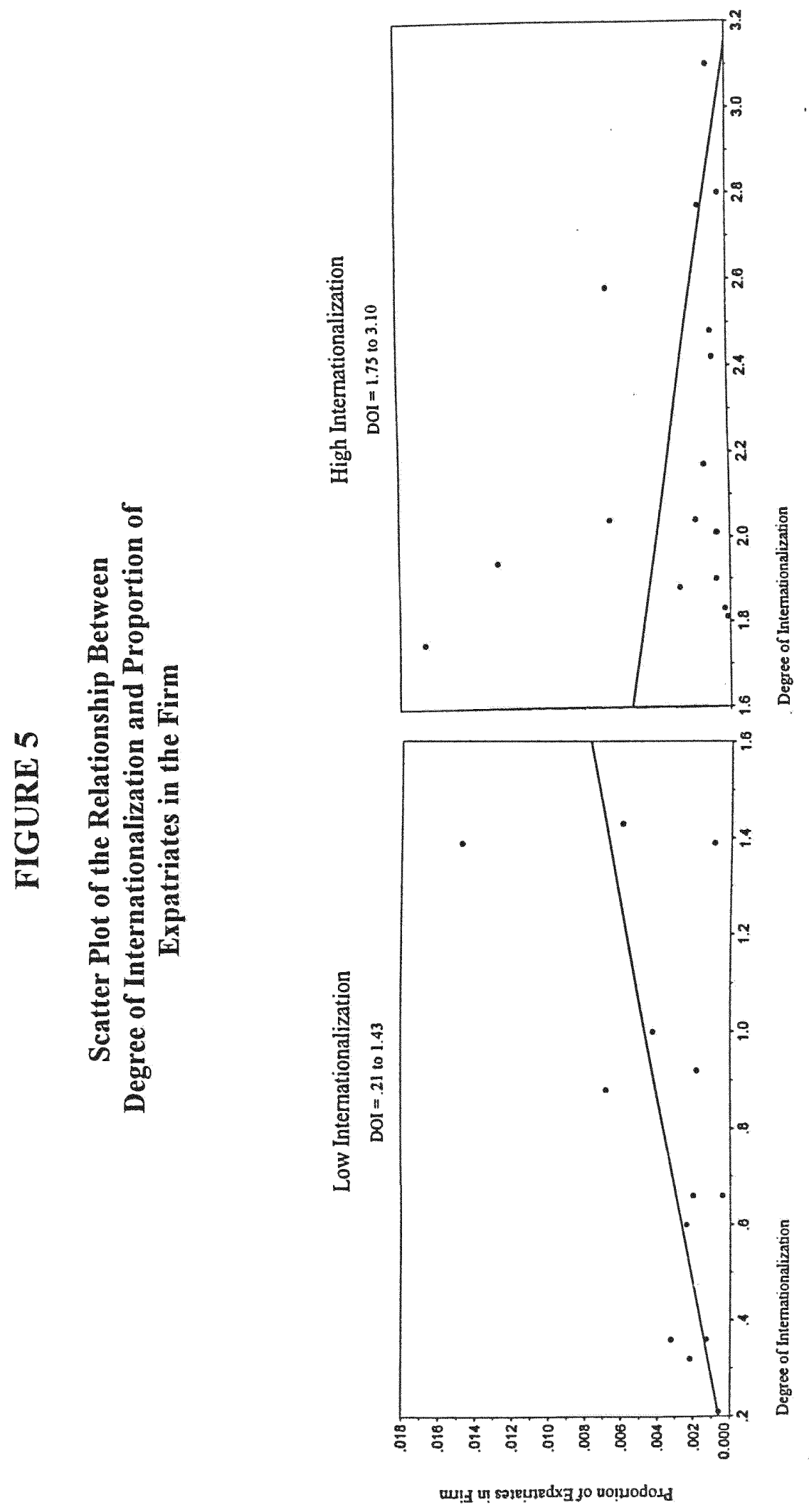




\section{THE DETERMINANTS OF EXPATRIATE SUCCESS AS FIRMS INTERNATIONALIZE}

There were three sets of regression equations using country experience (young and mature) and three sets using firm internationalization (low and high) to moderate the determinants of expatriate adjustment, commitment, and satisfaction. These dichotomies are the same as those for the T-tests described in Chapter III.

Although the effects of industry were of interest here, the amount of data available for each industry group did not lend itself to a split of the data set. Therefore, industry was entered into the regression equations as a dummy variable in order to control for any variance that it might explain. Finally, for each model, the remaining two dependent variables were entered as independent variables to account for any variance that these might explain. All variables entered into the linear regression models were normally distributed across the range of possible values, determined by plotting the distribution of each of the variables separately. Results of the regression analyses for each dependent variable are provided in turn.

\section{The Determinants of Expatriate Cross-Cultural Adjustment}

H2 stated that individual, environmental, and family-related characteristics will each have a significant effect on expatriate cross-cultural adjustment for expatriates whose subsidiaries and firms are low on internationalization, and that each of the organizational 
characteristics will have a significant effect on adjustment for expatriates of highly internationalized subsidiaries and firms. Some hypotheses were supported at either the subsidiary or the overall firm level of analysis.

A summary of the support received for $H 2$ is provided in Table 13. The table provides the beta coefficients for all variables entered into the models, and those which are bold-faced indicate significant effects on expatriate adjustment. The table also provides the amount of variance in the dependent variable explained by each model as well as results of the overall significance tests. Shaded areas indicate support for the hypothesis with respect to that variable. Linear regressions were then run with only those variables which emerged as significant. Results of these analyses are provided in Table 14.

Each regression model met the remaining assumptions of the general linear model. The first was the linearity of the relationship between the dependent and independent variables. By plotting the standardized predicted values for adjustment against the studentized residuals, it was shown that the change in adjustment was constant across the range of values for the independent variables. The same plot was helpful in determining the constant variance of the error term (or homoscedasticity), where no systematic patterns in the error terms were observed. Furthermore, independence of the error terms was assumed, since the basic conditions of the model were not changed. Finally, normal probability plots indicated normality of the error term distribution. With a straight diagonal line representing a normal distribution, plotted residuals fell close to this line, if not directly on it. Having met the assumptions of the general linear model, and with low enough variance inflation factors to assume no multicollinearity effects, the regression 


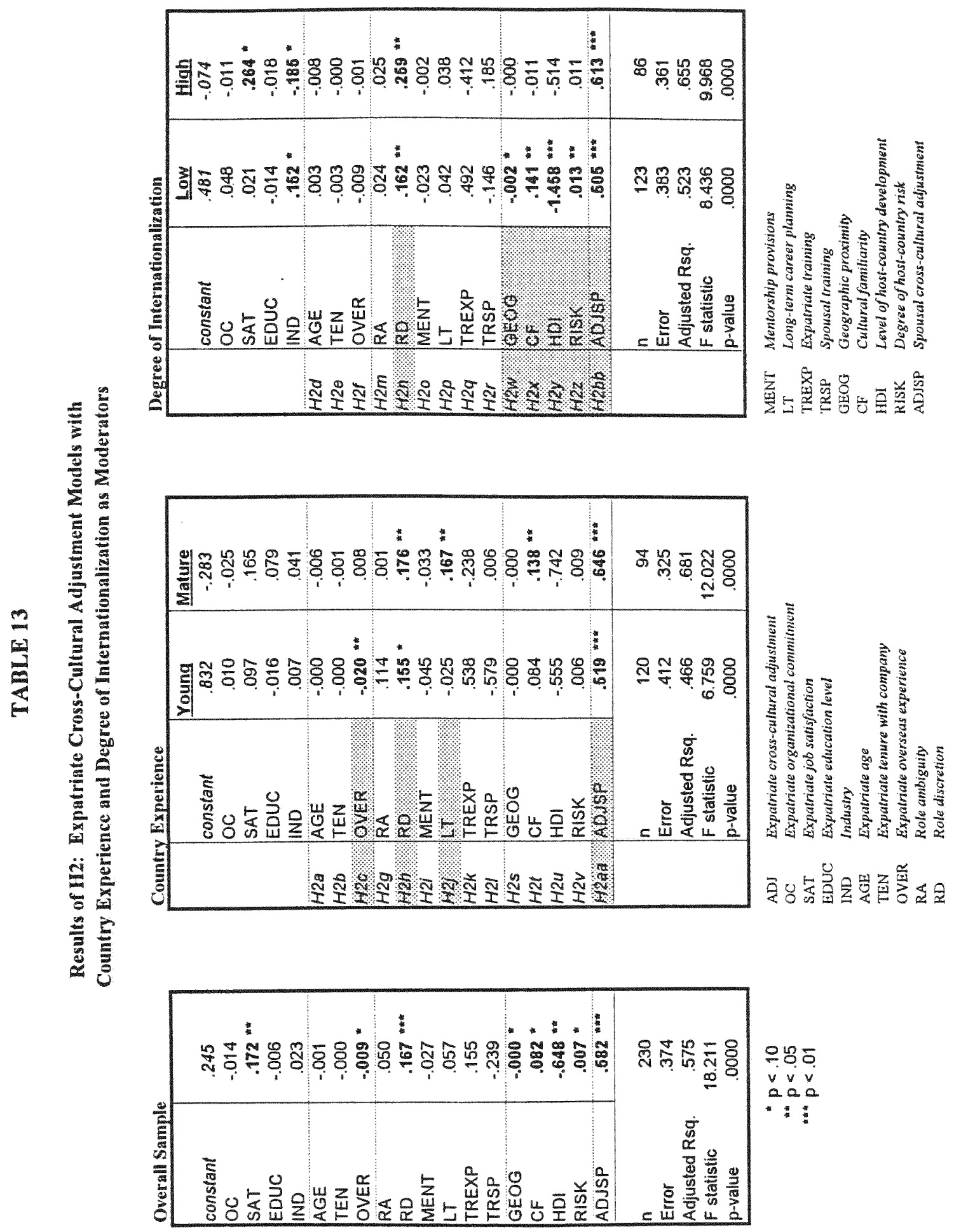



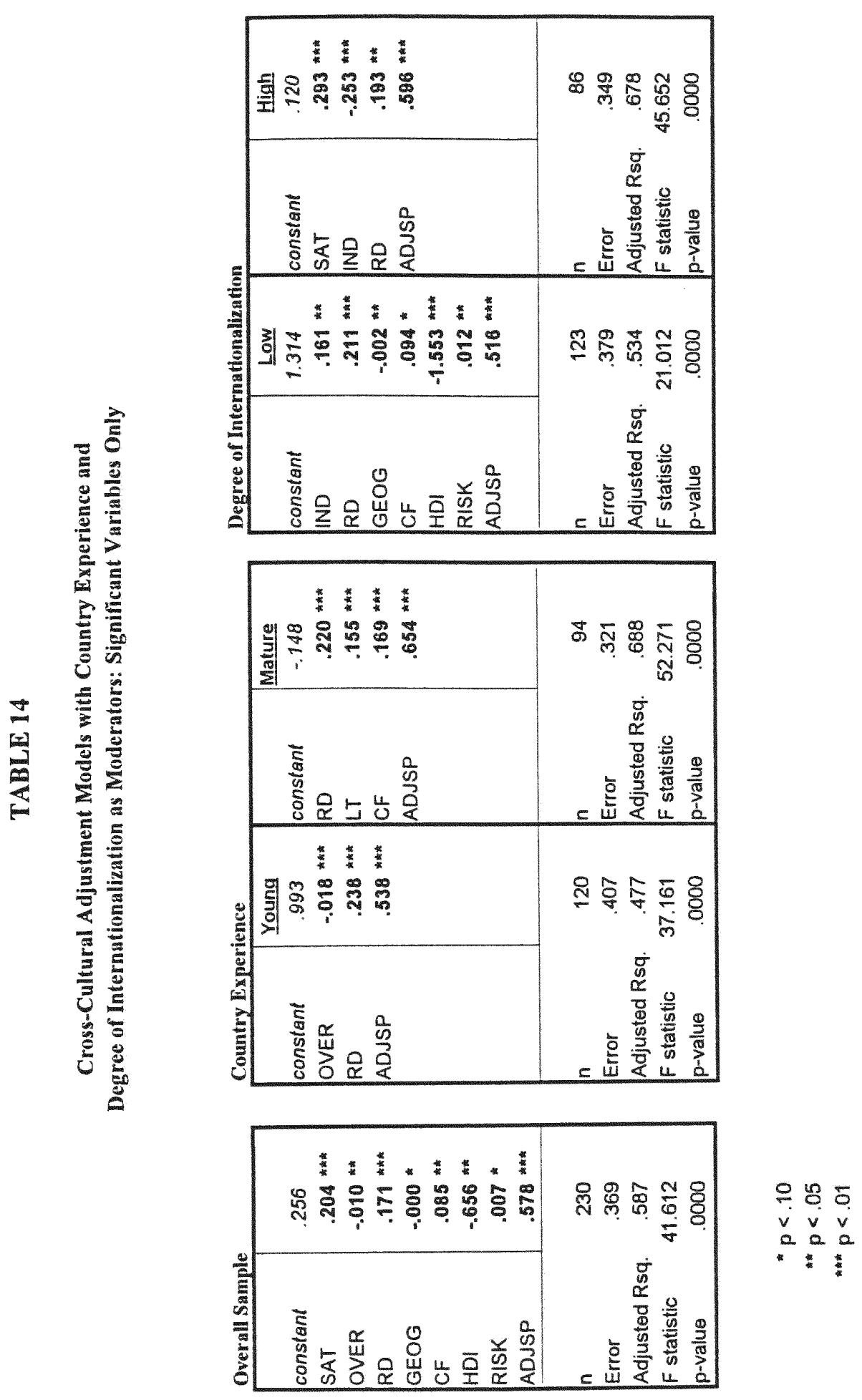
models shown in Table 14 represent strong sets of predictors of expatriate cross-cultural adjustment across the levels of internationalization.

Before considering the internationalization phenomenon, significant predictors of adjustment included expatriate satisfaction, previous overseas experience, role discretion, geographic proximity to the host country, cultural familiarity with the host country, level of host-country development, degree of risk in the host country, and spousal cross-cultural adjustment. With an adjusted $R^{2}$ of $.575(p<.0000)$, these variables represent a strong set of predictors of expatriate adjustment. In fact, when only these significant variables were entered into a regression model, the adjusted $R^{2}$ increased to .587 .

When internationalization is considered, findings indicate that predictors of adjustment will vary depending on the extent of international experience of the expatriate's firm and of the subsidiary to which he/she is assigned. The roles played by host-country experience and firm degree of internationalization (DOI) in predicting expatriate adjustment are examined below.

\section{Country Experience}

\section{Young Subsidiaries}

The regression model for expatriates assigned to young subsidiaries explained 46.6 percent of the variance in expatriate adjustment $(p<.000)$. Significant predictors of expatriate adjustment included individual overseas experience, role discretion, the extent to which long-term career planning was provided by the organization, and spousal adjustment. Therefore, hypotheses for individual characteristics $(H 2 a-c)$ were supported 
for $H 2 f$, the hypothesis for family-related characteristics (H2aa) was supported, and the hypotheses for environmental characteristics $(H 2 s-v)$ were not supported. Those variables which were significant to adjustment for expatriates in young subsidiaries were entered into a new regression model for an adjusted $\mathrm{R}^{2}$ of .477 .

The relationship between expatriate experience abroad and adjustment was negative, indicating that less experience may prove more beneficial in the long run. This is due to the fact that overseas experience is typically gained in another location, and some market-specific knowledge that was gained on a previous assignment may have to be unlearned. This finding is specific to expatriates assigned to young subsidiaries, indicating that, for the more mature subsidiaries, the means for applying accumulated market-specific knowledge to a new location have been established.

Spousal adjustment, while important to the adjustment of expatriates in young subsidiaries, was in fact highly significant in predicting expatriate adjustment at all stages of the firm's international life.

\section{Mature Subsidiaries}

For $H 2 g-l$, both $H 2 h$ (role discretion) and $H 2 j$ (long-term planning) were supported. As hypothesized, role discretion was significant to the adjustment of expatriates in mature subsidiaries. Given the institutionalized procedures in place for subsidiaries which have been up and running for years, it was expected that a certain degree of discretion would discourage the expatriate from becoming too comfortable with the status quo. Since the expatriate is no longer required to interact extensively with the 
external environment, he/she is free to exercise creativity within the confines of the organization. It was also found that, when the organization articulates the importance of the current assignment to the expatriate's career path, adjustment is more likely in mature subsidiaries. This is simply because, having experience in that locale, the organization is able to make historical inferences about the future of its repatriates based on the types of knowledge gained in that particular country. For expatriates assigned to young subsidiaries, the organization is not able to offer such wisdom.

Other significant predictors of adjustment for expatriates of mature subsidiaries included the expatriate's familiarity with the host culture and the adjustment of the expatriate's spouse. The adjusted $\mathrm{R}^{2}$ was 681 for the original model $(\mathrm{p}<.0000)$, and .688 for the reduced model entering only the significant variables.

\section{Degree of Internationalization}

\section{Low DOI}

This regression model was similar to that where the full sample was used. In fact, the only differences in the predictor set were that industry emerged as significant here, whereas satisfaction and overseas experience were significant for the entire sample. The adjusted $\mathrm{R}^{2}$ for the low DOI model was $.523(\mathrm{p}<.0000)$ and increased to .534 when only the significant variables were entered into the regression.

The hypotheses for environmental (H2w-z) and family-related (H2bb) characteristics were fully supported, since each variable was significant to adjustment when DOI was low. These included geographic proximity, cultural familiarity, level of 
host-country development, degree of host-country risk, and spousal adjustment. The negative beta value for GEOG (operationalized as geographic distance) indicates that, in these early stages, expatriates assigned to farther host locations did not adjust as well as those assigned closer by. The negative beta value for HDI indicates that, when overall DOI is low, it is in the less developed host locations that expatriates are better able to adjust. While this may seem counterintuitive, it could be that, due to its inexperience on the international front, the firm overcompensates for underdeveloped conditions by providing unusually high incentives and hardship allowances. The level of host-country risk was positively associated with adjustment, indicating that expatriates adjusted more easily in less risky environments. This may be explained by the fact that firms with little international experience overall have not encountered the variety of situations from which to learn effective risk management techniques. These may range from ingratiating host governments to hedging against foreign exchange discrepancies. The individual characteristics of age, tenure, and overseas experience, on the other hand, were not significant to adjustment in this early stage, and thus $H 2 d-f$ were not supported.

One organizational characteristic, that of role discretion, emerged as significant when DOI was low. It may be the case that, when the firm has little experience abroad, expatriates perceive the overseas assignment as empowering -- as an opportunity to be one's own boss, and as a token of top management's faith in his/her abilities. Therefore, when the overseas assignment meets these expectations, adjustment is made easier. However, hypotheses were not offered for role discretion, nor for any of the other 
organizational characteristics, for expatriates of low DOI firms, but rather that they would be significant predictors of adjustment for expatriates of highly internationalized firms.

\section{High DOI}

For $H 2 m-r$, only $H 2 n$ was supported, as role discretion was significant to adjustment when DOI was high. While expatriates may have expected a certain degree of role discretion when DOI was low, they may become accustomed to setting their own agendas and deciding how tasks are to be carried out. As a result taking this authority away may inhibit adjustment. The regression model yielded an adjusted $R^{2}$ of .655 $(p<.0000)$, increasing to .678 when only the significant variables were entered into the model. In addition to role discretion, expatriate satisfaction, spousal adjustment, and industry were significant predictors of adjustment for expatriates of highly internationalized firms.

\section{The Determinants of Expatriate Organizational Commitment}

H3 stated that individual, environmental, and family-related characteristics will each have a significant effect on organizational commitment for expatriates whose firms and subsidiaries have little international experience, and that each of the orgamizational characteristics will have a significant effect on the organizational commitment of expatriates of highly internationalized firms and subsidiaries. While the analyses did produce significant models of organizational commitment for the entire sample as well as 
for the various levels of internationalization, the hypotheses for organizational commitment were not supported.

Table 15 provides the beta coefficients for all variables entered into the models, and again, those which are bold-faced indicate significant effects on expatriate commitment to the organization. The information provided in Table 15 for organizational commitment is similar to that of Table 13 for adjustment. The absence of shaded areas, however, indicates the lack of support for H3. Similar to the adjustment models, subsequent linear regressions were run with only those variables which emerged as significant. Results of these analyses are shown in Table 16. The assumptions of the general linear model were met for each regression, using the same procedures described in the previous section.

Significant predictors of expatriate organizational commitment, without considering internationalization, included expatriate satisfaction, level of education, the extent of training provided to the expatriate for the current assignment, and the industry in which the expatriate's firm competes. The original regression model yielded an adjusted $\mathrm{R}^{2}$ of $.436(\mathrm{p}<.0000)$, increasing to .441 when only the significant variables were entered.

When considering firm internationalization and country experience, predictors of organizational commitment did vary depending on stage of internationalization. The moderating roles of country experience and DOI on the relationships between these predictors and organizational commitment are examined below. 


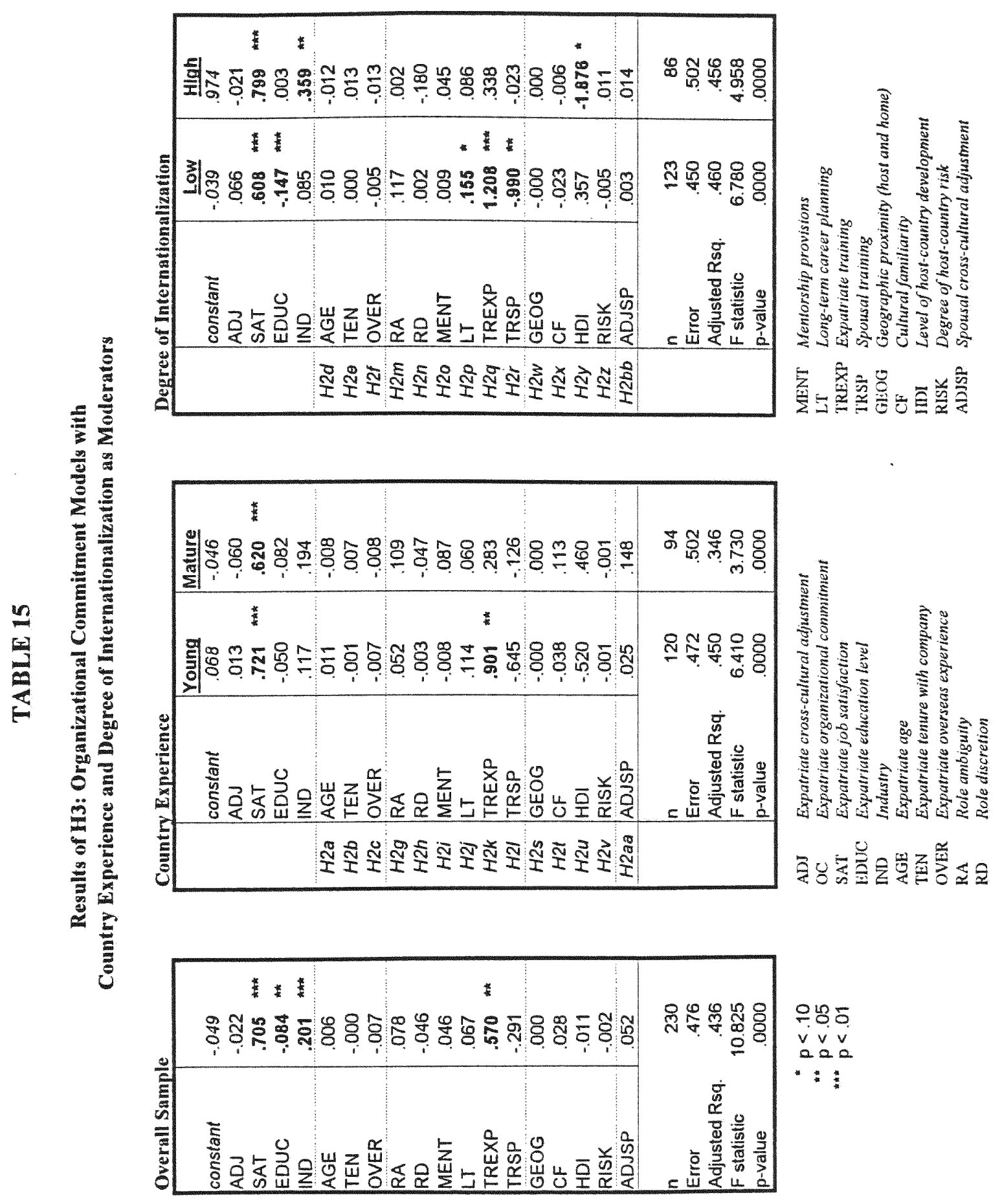




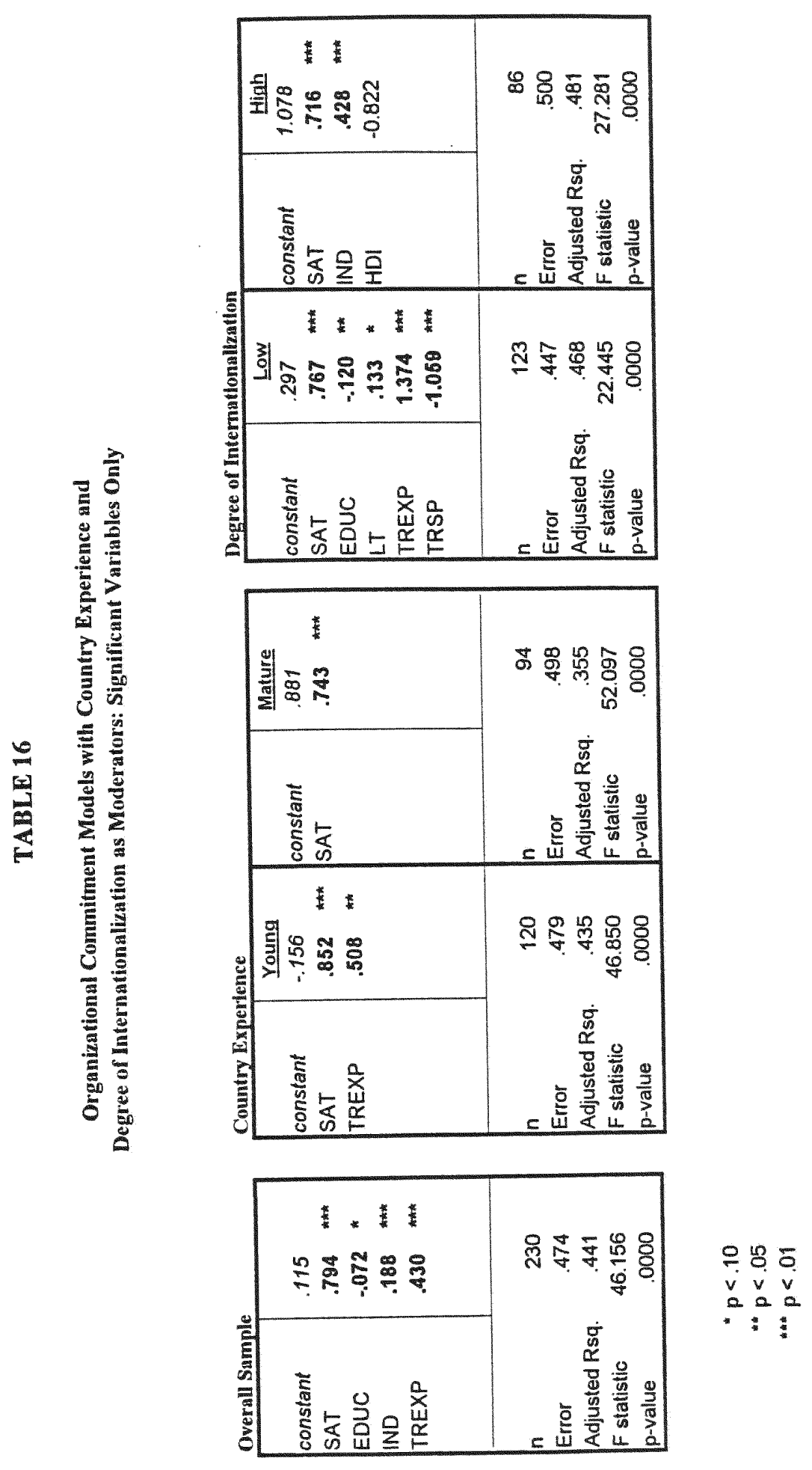




\section{Country Experience}

Young Subsidiaries

The most significant predictor of commitment for expatriates in young subsidiaries was the expatriate's level of satisfaction. The extent of training provided to the expatriate was significant to his/her commitment as well. The model explained 4.50 percent of the variance in expatriate commitment, and was still strong when only those two significant variables were entered into a regression $\left(R^{2}=.435\right)$.

\section{Mature Subsidiaries}

As with expatriates in young subsidiaries, satisfaction had a significant effect on commitment for expatriates in mature subsidiaries. In fact, no other variables were significant to commitment at this stage. The model yielded an adjusted $R^{2}$ of 346 $(p<.0000)$ and increased to .355 when satisfaction was the only independent variable in the equation.

\section{Degree of Internationalization}

\section{Low DOI}

Those factors significant to expatriate commitment to the organizational during this early stage of internationalization included expatriate satisfaction, level of education, and the provision, on the part of the organization, of long-term career planning and training for both the expatriate and the spouse. The adjusted $\mathrm{R}^{2}$ for the low DOI model was $.460(p<.0000)$ and increased to .468 when only the significant variables were entered into the regression. 


\section{High DOI}

A shift in the set of predictors of organizational commitment left only expatriate satisfaction as significant in both stages. Other significant predictors when DOI was high included the industry and the level of economic development in the host country.

\section{The Determinants of Expatriate Job Satisfaction}

H4 stated that individual, environmental, and family-related characteristics will each have a significant effect on job satisfaction for expatriates whose firms and subsidiaries have little international experience, and that each of the organizational characteristics will have a significant effect on the job satisfaction of expatriates of highly internationalized firms and subsidiaries.

A summary of support for $H^{4}$ is provided in Table 17. Again, shaded areas indicate support for that variable and hence that hypothesis. Results of each linear regression with only the significant variables are shown in Table 18. As with all regression models described thus far, those for expatriate job satisfaction met the assumptions of the general linear model by applying the same procedures as previously described.

When considering the entire sample, regardless of firm internationalization or country experience, significant predictors of satisfaction included expatriate adjustment and organizational commitment, role ambiguity, role discretion, the provision of long-term career planning and the extent to which the organization provided training to the expatriate for the current assignment. The adjusted $R^{2}$ was $.626(p<.0000)$ for the original 


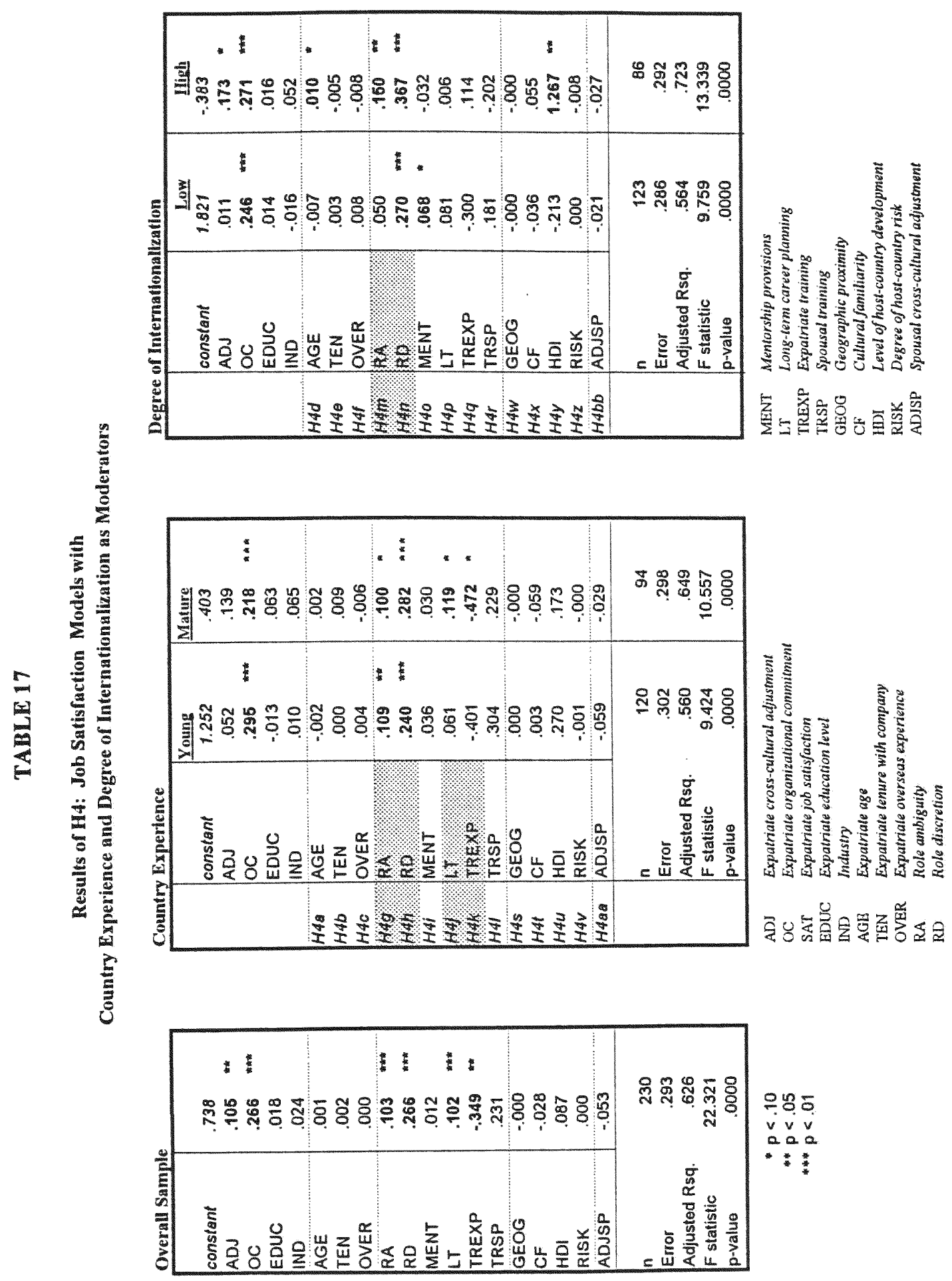



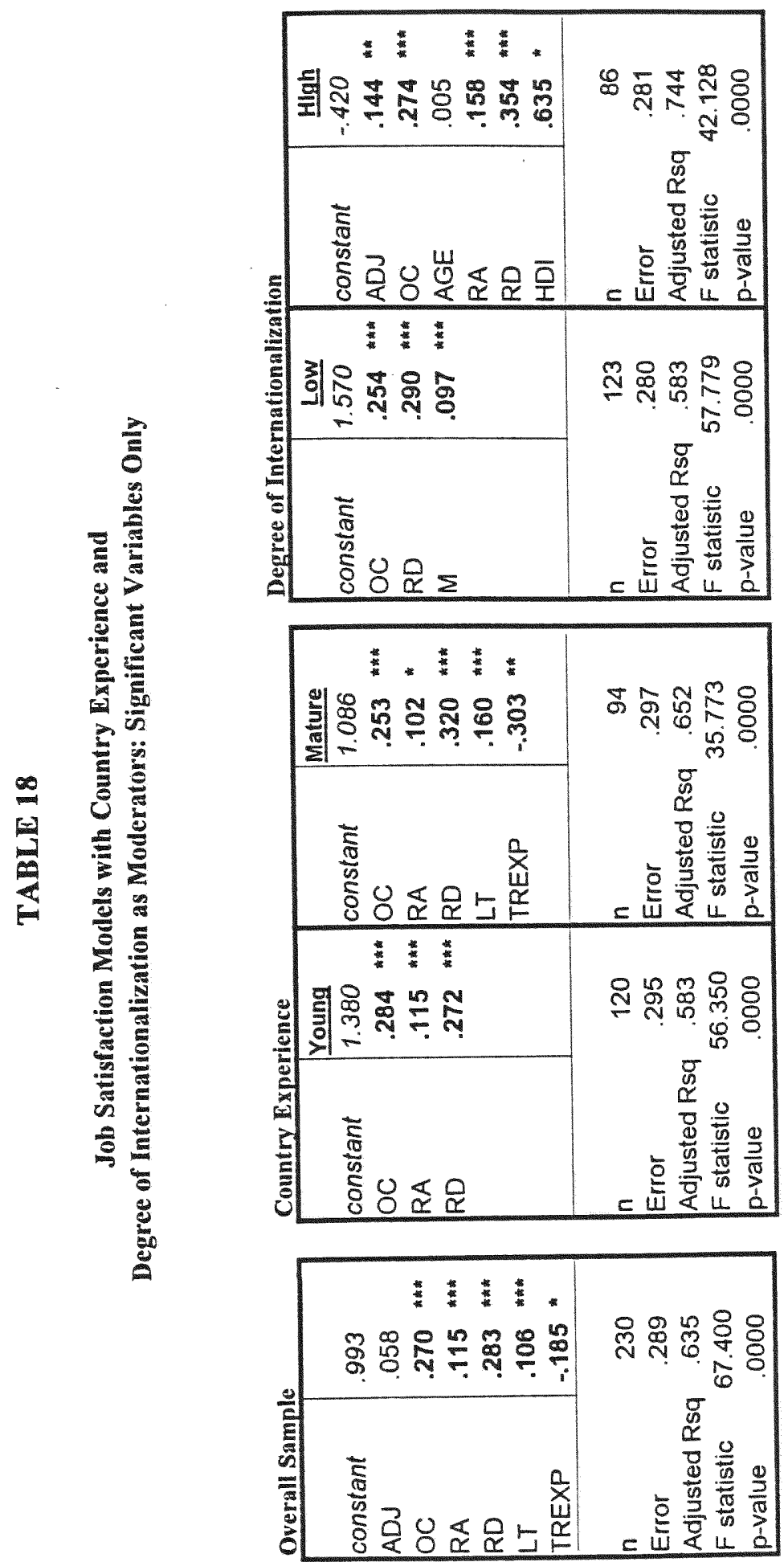

$\circ$ 농 $\begin{array}{lll}v & v \\ 0 & 0 & \end{array}$ 
model and .635 for the reduced model, which included only the significant independent variables.

While some of these factors are significant for expatriates of firms and subsidiaries with little international experience, others are significant when there is increased internationalization. In addition, some factors have a significant impact on satisfaction in both stages of the internationalization process. The roles of DOI and country experience in moderating the predictors of expatriate satisfaction are discussed below.

\section{Country Experience}

\section{Young Subsidiaries}

While the model for young subsidiaries was highly significant in predicting job satisfaction, the variables hypothesized to be significant were not. These included the individual characteristics $(H 4 a-c)$, environmental characteristics $(H 4 s-y)$ and family-related characteristics $(H+a a)$. However, organizational commitment, as well as two of the organizational characteristics (role ambiguity and role discretion) did have a significant effect on the satisfaction of expatriates assigned to young subsidiaries. In fact, this was a highly significant set of predictors, with an adjusted $\mathrm{R}^{2}$ of .560 in the original regression model, and of .583 in the model with only these significant variables included.

\section{Mature Subsidiaries}

Again, findings indicate a highly significant model for predicting job satisfaction. For expatriates of mature subsidiaries, results confirmed four of the six hypotheses which 
were offered. Significant effects of organizational characteristics, hypothesized in $\mathrm{H} 4 \mathrm{~g}-\mathrm{l}$, were found for $H 4 g$ (role ambiguity), $H 4 h$ (role discretion), $H 4 j$ (long-term planning) and $H 4 k$ (expatriate training).

Ambiguous roles, offering considerable expatriate discretion, contributed to job satisfaction in mature subsidiaries. In fact, these factors were important to expatriates in young subsidiaries as well. The fact that long-term planning leads to satisfaction, when expatriates were assigned to mature subsidiaries, is attributed to the accuracy with which organizations can predict the future of the expatriate's career upon return. With experience in a particular host environment, the firm is aware of the skills which the expatriate will acquire and the value of these skills to the organization as a whole.

With regard to expatriate training, a negative beta value indicates that expatriates in mature subsidiaries exhibited higher levels of satisfaction when less training was provided. This may be because firms are simply providing the wrong types of training, passing on knowledge that is not applicable in certain host locations. In young subsidiaries, perhaps any type of training will add value, but in these mature subsidiaries, expatriates must be trained to assimilate into the established subsidiary culture.

In addition to the organizational characteristics mentioned above, expatriate commitment had a significant effect on satisfaction in this mature stage. Adjusted $\mathrm{R}^{2}$ for the regression model was $.649(p<.0000)$, increasing to .652 when only the significant predictors were entered. 


\section{Degree of Internationalization}

\section{Low DOI}

The adjusted $\mathrm{R}^{2}$ for the low DOI model was $.564(\mathrm{p}<.0000)$, increasing to .583 when only the significant variables were entered into the model. These include expatriate commitment to the organization, as well as role discretion and the provision of mentorship to the expatriate. Since there were no significant variables characteristic of the individual $(H 4 d-f)$, the environment $(H 4 w-z)$ or the family $(H 4 b b)$, these hypotheses were not supported.

\section{High DOI}

For those hypotheses at the organizational level (H4m-r) both $\mathrm{H} 4 m$ (role ambiguity) and $H 4 n$ (role discretion) were supported. Expatriates were more satisfied with their jobs when their roles were ambiguous and when they were able to exercise considerable discretion within their work roles. While discretion was also important to satisfaction in low DOI firms, this was not the case for role ambiguity. It may be the case that, while expatriates would like to set their own agendas, roles must be clearly defined in the absence of accumulated knowledge regarding overseas operations.

Both expatriate adjustment and organizational commitment also had a significant effect on the job satisfaction of expatriates in high DOI firms, as did one individual characteristic (expatriate age) and one environmental characteristic (level of host-country development). The model produced an adjusted $R^{2}$ of $.723(p<.0000)$, increasing to .744 
with only the significant variables included. In addition, in the second regression run, expatriate age was no longer a significant determinant of job satisfaction.

\section{The Relative Importance of Individual, Organizational, Environmental, and Family-Related Characteristics}

Until now, discussion has focused on the difference in the effects of individual, organizational, environmental, and family-related characteristics across two stages of internationalization (low and high, young and mature). However, it may also be interesting to examine which groups of factors play a larger role within a given stage of the internationalization process. A comparison of standardized betas will determine the importance of each of the sets of independent variables, relative to each other. Standardized betas for the analyses for given levels of country experience and DOI are provided in Tables 19,20, and 21, for expatriate adjustment, commitment, and satisfaction, respectively. Each of these is discussed in turn below.

\section{Expatriate Cross-Cultural Adjustment}

\section{Country Experience}

Again, while overseas experience and role discretion had a significant effect on the adjustment of expatriates assigned to young subsidiaries, spousal adjustment, with a standardized beta coefficient of .655 , clearly had the largest effect. The same is true for expatriates assigned to mature subsidiaries. 


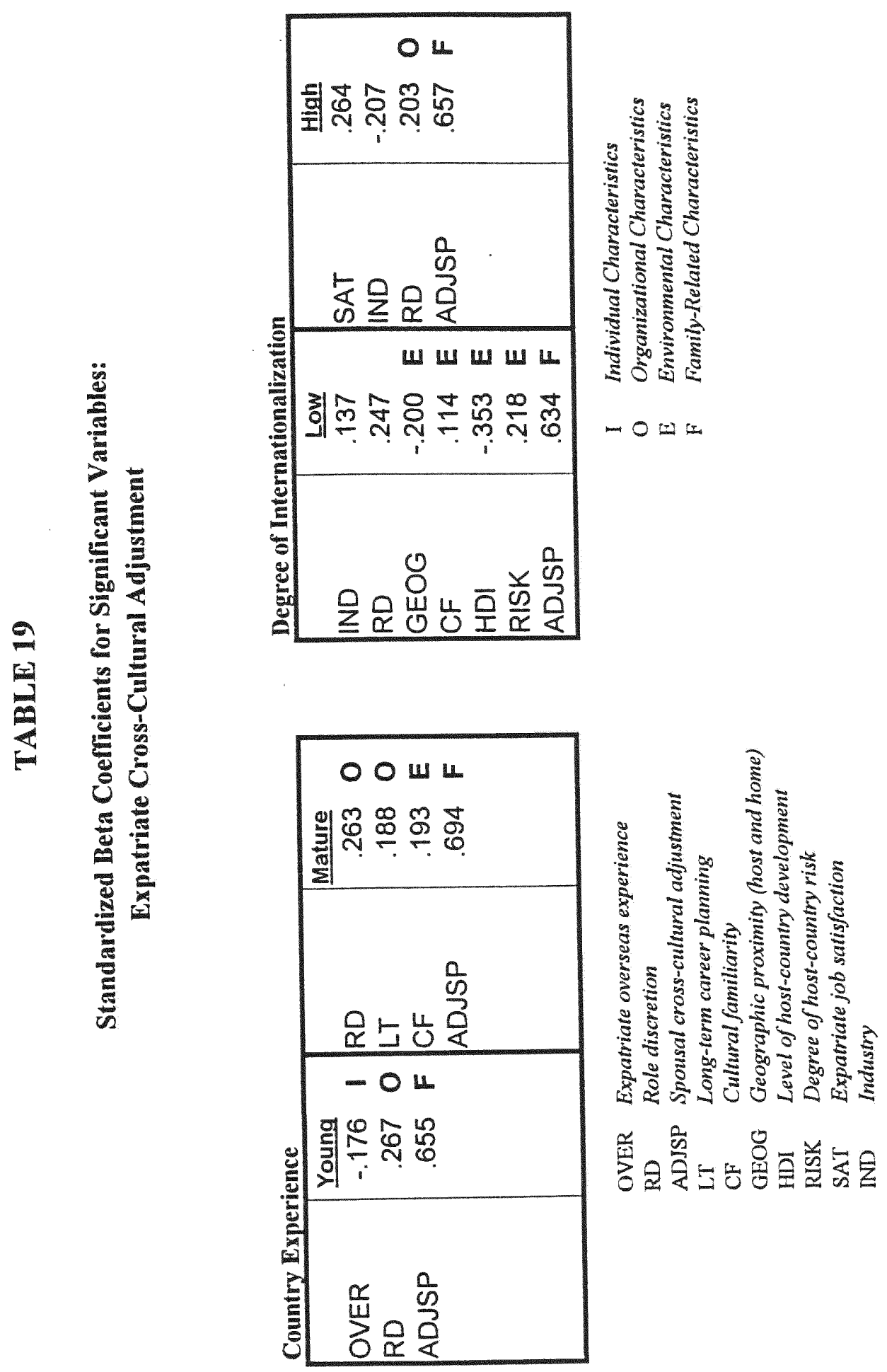




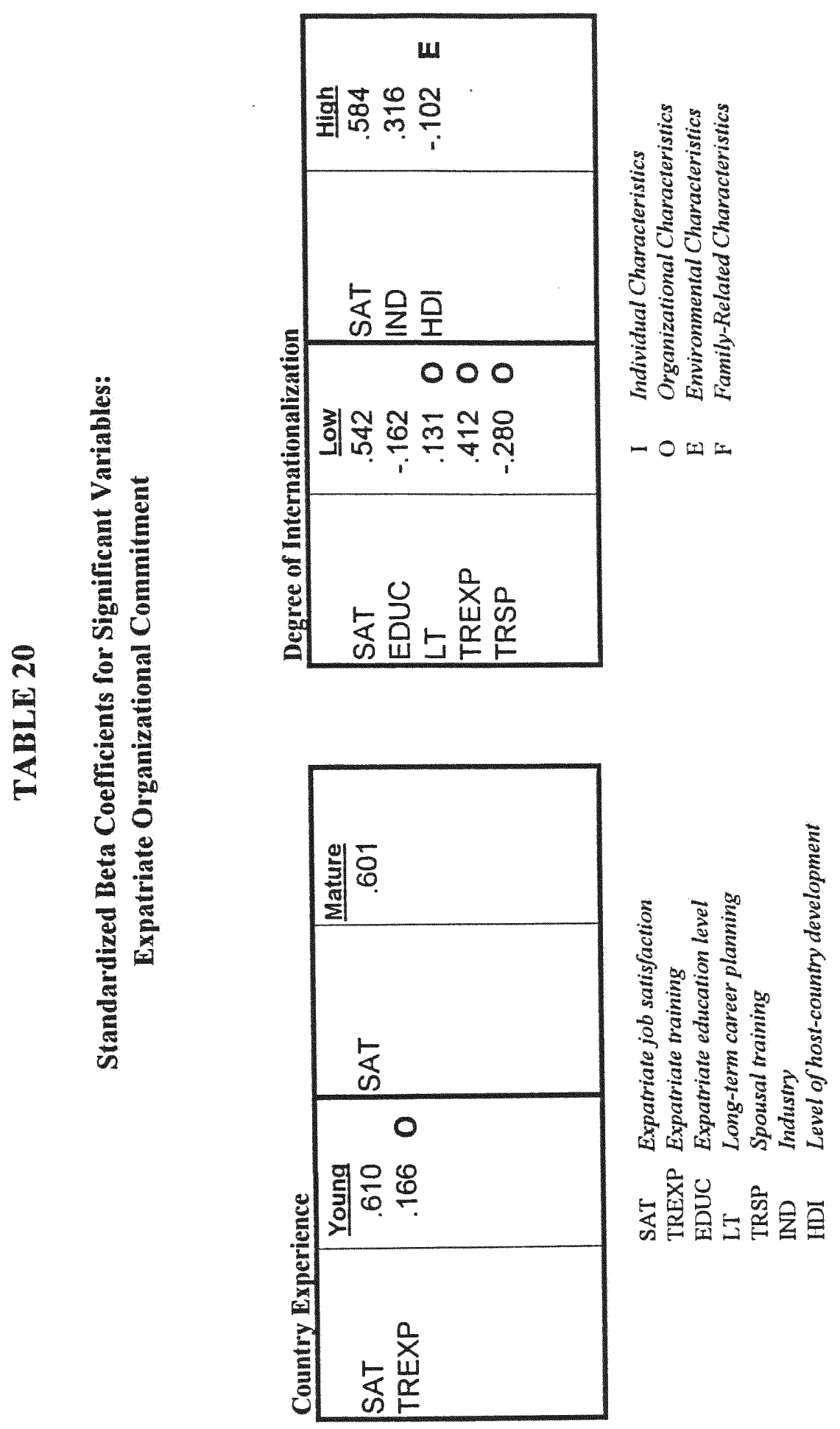




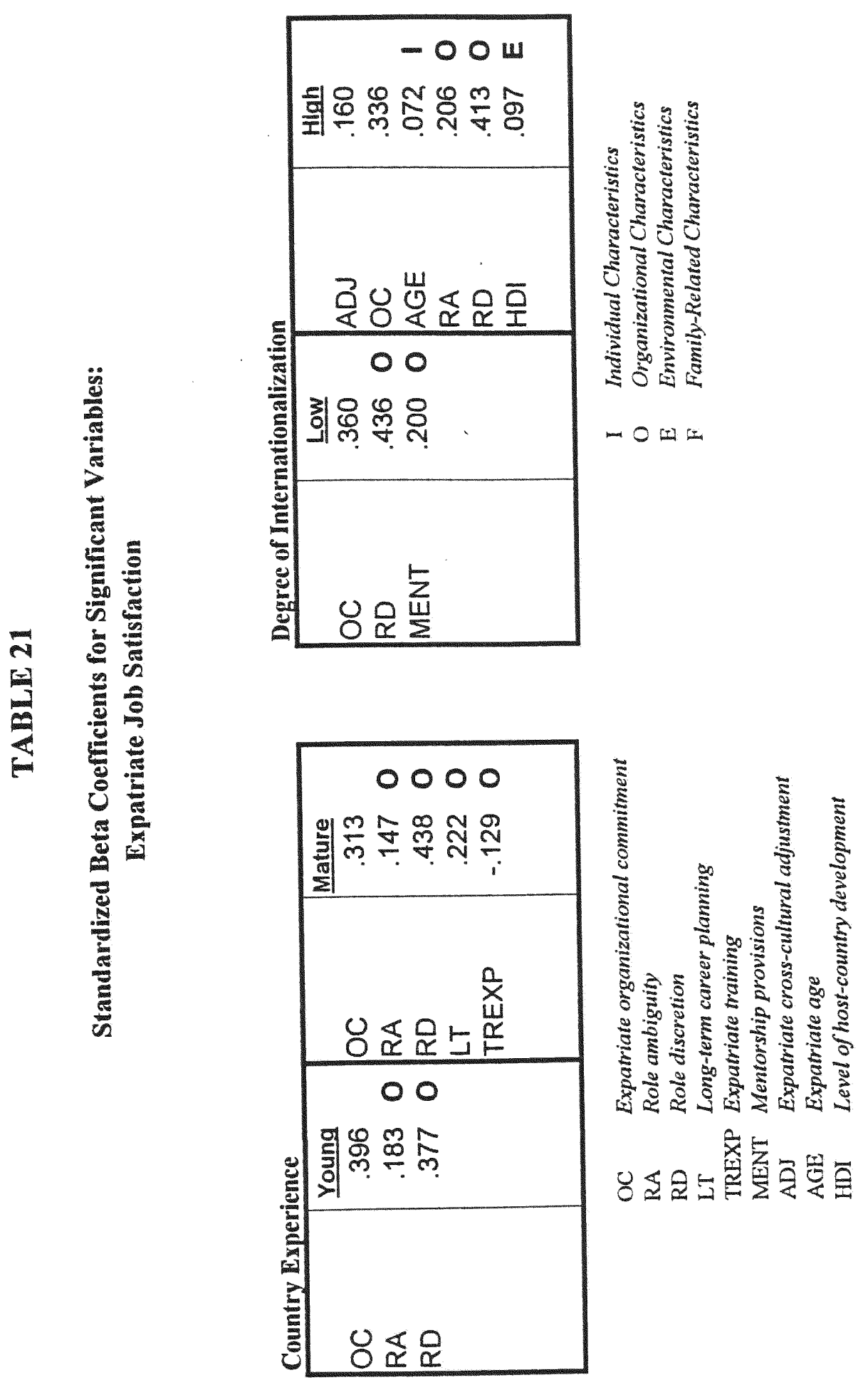


Both environmental and family-related characteristics were significant to expatriate adjustment when DOI was low, as were industry and role discretion. Upon comparison of standardized beta coefficients, it is clear that spousal adjustment (.634) is the single most important factor to adjustment at this time. For expatriates in highly internationalized firms, again we find spousal adjustment $(.657)$ to be more important than the other significant predictors of expatriate adjustment.

\section{Expatriate Organizational Commitment}

\section{Country Experience}

Satisfaction had the strongest effect on the commitment of expatriates in both young and mature subsidiaries (.610 and .601 , respectively), although training was also important in young subsidiaries.

DOI

With regard to the various categories of determinants considered in this study, only organizational factors were significant to commitment when firms were less internationalized. However, when considering all variables included in the equation, the standardized beta coefficient for expatriate job satisfaction indicated the largest effect on commitment (.542). The same is true for the commitment of expatriates of highly internationalized firms. While HDI, an environmental characteristic, was the most 
important predictor out of the set of determinants of interest, the effect of satisfaction was stronger (.584).

\section{Expatriate Job Satisfaction}

\section{Country Experience}

For expatriates of both young and mature subsidiaries, findings indicate that satisfaction is a function of organizational factors and of expatriate commitment to the organization. In young subsidiaries, however, commitment appears to be most important to satisfaction (.396), whereas in mature subsidiaries, role discretion is the most predictive (.438).

DOI

Only the organizational characteristics, in addition to commitment, were significant to the satisfaction of expatriates in low DOI firms. Based on the standardized beta coefficients, role discretion had the strongest effect on satisfaction (.436), followed by commitment ( .360$)$. For highly internationalized firms, there were significant determinants at several levels. However, those at the organizational level (role discretion, .413; and role ambiguity, 206), as well as commitment (.336), had the strongest impact on expatriate job satisfaction.

\section{Summary of Results}

The results reported above indicate partial support for the first set of hypotheses, concerned with the use of expatriates at two distinct stages of internationalization. At the 
subsidiary level, the proportion of expatriates did increase significantly along with subsidiary age when subsidiaries were young, and the practice of expatriating did taper off in the mature subsidiaries, although this relationship was not significant. For the firm as a whole, the relationship between degree of internationalization and expatriation was negative regardless of whether internationalization was low or high. This relationship, however, was only significant for highly internationalized firms.

Partial support was also received for the second set of hypotheses $(\mathrm{H} 2, \mathrm{H} 3$, and H4), which were concerned with the determinants of expatriate success for distinct levels of country experience and degrees of internationalization. Environmental and familyrelated factors were significant to expatriate cross-cultural adjustment when firms were low on internationalization. In addition, the majority of organizational-level factors considered were significant determinants of expatriate satisfaction once experience had been gained in a particular country. The implications of these findings for theory and for practice are discussed in the next chapter. 


\section{Chapter V \\ Discussion}

\section{INTRODUCTION}

The primary goal of this study was to examine the role of expatriate managers in the learning process that firms undergo as they increase their international involvement. In doing so, two issues were addressed: (i) the employment of an expatriation strategy as a company internationalizes and (ii) the importance of individual, organizational, environmental, and family-related factors to expatriate success as the company gains international experience. As indicated in Chapter II, the study of expatriate success has been limited to the assessment of relationships at one point in time, or under a given set of circumstances. Recognizing that circumstances change, and that organizations learn over time how to cope with otherwise unfamiliar situations, the hypotheses incorporate a dynamic, contingency perspective. In other words, the expectation that relationships may change should be built into a model of the determinants of expatriate adjustment, commitment, and satisfaction. The proposed model was tested on a sample of current expatriates of Fortune 500 corporations in the computers/electronics and petroleum/chemicals industries.

This chapter reviews the empirical findings for the two research questions and discusses the implications of these findings for both International Human Resource Management (IHRM) theory and practice. Potential limitations from both a theoretical and methodological perspective are then addressed, followed by some possible avenues for pursuing this stream of research. The chapter closes by juxtaposing the findings of both 
research questions, synthesizing their implications, and offering some concluding remarks on international human resource management in general and on expatriation in particular.

\section{HYPOTHESIS 1: \\ THE USE OF EXPATRIATION AS FIRMS INTERNATIONALIZE}

The primary purpose of the first research question was to investigate the relationship between organizational learning and expatriation. Specifically, $H I$ examined the relationship between international experience and the proportion of expatriates employed, as both market-specific knowledge and general organizational knowledge is gained. A significant relationship emerged between country experience and proportion of expatriates in a given subsidiary, but only when there was considerable experience in that host environment. This relationship is negative, indicating that, after a certain level of experience, or market-specific knowledge, is gained in a host country, firms tend to reduce their expatriate populations in subsidiaries located there. A significant, positive relationship emerged between degree of internationalization (DOI) and the proportion of expatriates in the firm, for those firms with little international experience. While this relationship was also negative for highly internationalized firms, it was not significant, indicating that the economies of scope associated with the accumulated general knowledge and subsequent applications to other subsidiaries reaches a point of diminishing returns. Thus, it is no longer advantageous, from a learning perspective, to continue to expatriate home-country nationals to foreign subsidiaries. 


\section{Implications}

\section{Theory}

A theoretical model of intraorganizational knowledge transfer by expatriates was presented in Chapter II (see Figure 2). This model depicted the learning process, facilitated by the transfer of knowledge, as dynamic and cyclical, occurring at both the market-specific level and at the overall firm level. Further, Path 1, as distinguished from Path 2, represented an increasingly holistic approach that firms may take in pursuing international endeavors, based on the accumulation and translation of many marketspecific experiences.

Based on the empirical analyses, it was shown that MNCs do develop sufficient knowledge about host environments, which diminish the need for expensive expatriate practices in those locations. In fact, firms tend to reduce their expatriate populations almost immediately after subsidiaries are established (in this case, after six months of operation). After 27 years of experience in a given location, this reduction is more drastic, indicating a progression along the learning curve. Knowledge that is gained may include characteristics of the business climate and structure of the market system, as well as an ability to negotiate successfully with host governments.

Findings also provide empirical evidence of an overall increase in expatriation during the early stages of overall firm internationalization and a reduction in the use of expatriates over time. This increase is significant in the early stages (when DOI is low), indicating that firms seek to gain as much general overseas knowledge as possible when initially pursuing international business. Once a considerable portion of firm assets, sales, 
and subsidiary locations are accounted for by its international operations, it begins to rely less and less on expatriates to manage overseas subsidiaries. This reduction comes at a slower rate than the increase of expatriates in the early stages, since the relationship between DOI and expatriation, while negative, is no longer significant.

By looking at the pattern of expatriation that emerges as experience in a country increases, research can move beyond an examination of this practice as a static phenomenon. A significant relationship between internationalization and expatriation allows for an advancement in the field of IHRM by providing a theoretical explanation for why expatriation prevails as a staffing practice among MNCs. The inclusion of organizational learning, a theory which is embedded in the literatures in both strategy and internationalization, represents a logical step in legitimizing the practice of expatriation from a theoretical perspective.

\section{Practice}

Based on the findings, young subsidiaries have proportionately larger expatriate populations than do those which have been up and running for many years. In addition to an overall reduction in expatriation managers over the life of the subsidiary, results indicate that the drop was quite significant after approximately 27 years of operations. This pattern is consistent with the organizational objectives behind expatriating - to transfer tangible as well as tacit resources to the overseas affiliate through the expatriates and to pull back on the use of expatriate assignments as these transfers are completed. 
Examples of such tacit resources include the overall company philosophy and corporate mission, technical expertise, and managerial know-how.

By looking at the pattern of expatriation that emerges as market-specific knowledge is acquired, organizations may benefit from reconsidering current IHRM paradigms and perhaps taking a more country-specific approach toward overseas staffing. In the dynamic global environment, where industry configurations and hence the nature of competition are constantly changing, conceptual learning, or the accumulation of "knowwhy" on the part of the organization is the key to its long-term survival. In other words, organizations must continually challenge the nature of existing practices, which may include prevailing HR management strategies.

The pattern of expatriation at the firm level shows that, while firms tend to reduce their expatriate presence in individual subsidiaries, their overall expatriate populations increase until they have achieved a certain degree of internationalization. This indicates that firms are entering many markets during these early stages, at which time knowledge about these specific environments is being accumulated at the corporate location and general organizational knowledge is being widely disseminated. Once a certain degree of internationalization is reached, expatriation is reduced, but at a much slower rate. This may be the result of technological advancements and/or product and service innovations, which may render some previous knowledge obsolete and perhaps dictate updates in subsidiary learning. It is also possible that expatriate rotations overlap more in mature subsidiaries since organizational initiatives are often in place abroad to facilitate the transfer back home. 
The examination of this research question, however, was not intended for prescriptive purposes. Rather, it is a prelude to understanding the phenomenon of learning and how it can be attributed to a transfer process through individuals. In assessing the effects of learning about specific markets and about operating overseas in general, the fundamental purpose of pursuing an expatriation strategy becomes clear. While it has been shown that the expatriation of home-country nationals is an expensive organizational endeavor, the benefits may outweigh the costs. What is gained in terms of knowledge may increase the firm's bottom line by incorporating this knowledge into strategic initiatives and allowing for the gradual replacement of expatriates with HCNs. However, since this learning is a continuous process, the need for expatriate personnel in overseas affiliates will not disappear completely, thus underscoring the importance of the next set of research questions, concerned with achieving desirable outcomes for these individuals and for the organization.

\section{Limitations}

As with the majority of research that focuses on particular industries, the internal validity of the findings is improved at the expense of generalizability across a wider array of companies. While this study represents an attempt to balance both internal and external validity, by selecting two sets of related industries, generalizability remains somewhat limited. Furthermore, while ample data was available at the country level, it should be noted that Fortune 500 firms in the two sets of industries studied here do not represent the youngest of subsidiaries. 
With respect to the way in which international experience was operationalized here, the DOI measure has recently come into question for the way in which each of the five components (FSTS, FATA, OSTS, PDIO, and TMIE) are weighted. It was important, however, that each of these elements be taken into consideration in this study. As this index is relatively new and perhaps its reliability not yet established on a consistent basis, duplications of Sullivan's (1994) efforts may serve future research well. This matter is somewhat overcome, however, by also assessing international experience at the country level. It became apparent, early on, though, that expatriates did not know the ages of their respective subsidiaries, and it was therefore necessary to obtain this information from $H R$ managers at the central location. It also became evident that country experience may date back beyond that of the established subsidiary, as sales and distribution activities sometimes preceded foreign direct investment.

\section{Suggestions for Future Research}

Subsequent research on patterns of expatriation may be well-served to study other industries, both for comparative purposes and to assess the generalizability of the current findings. For those studies pursuing the role of internationalization, it may be helpful to preselect firms and subsidiaries based on the variance they represent on international experience, both at the overall firm level and at the subsidiary level. At the subsidiary level, it is recommended that experience be assessed at the point of initial presence in a given country in order to get an accurate account of the firm's country-level familiarity. 
It may also be interesting to examine whether the use of expatriates may be more prevalent in some subsidiaries based on host-country characteristics. For example, homecountry nationals may be preferred in LDCs as opposed to the more industrialized locations, where infrastructures for cross-border communications and the use of other technologies are in place to support business operations. Further, host government restrictions on foreign personnel may preclude the use of expatriate assignments in an effort to pursue their own employment agendas. In addressing these issues, future research endeavors may include more qualitative components for capturing the dynamics behind the use of expatriates which may vary by country as well as by region.

\section{HYPOTHESES 2, 3, and 4: \\ THE DETERMINANTS OF EXPATRIATE SUCCESS AS FIRMS INTERNATIONALIZE}

In an effort to enhance the expatriate experience, in terms of greater adjustment, commitment, and satisfaction levels, the determinants of these outcomes was assessed. Of particular interest was which determinants were significant in firms with limited international experience and which were significant in highly international firms. Again, international experience was examined both at the subsidiary and firm levels, and implications stemming from these results are discussed below. 


\section{Implications}

\section{Theory}

The knowledge gained through expatriation at distinct stages of the internationalization process was modeled in Chapter II (see Figure 3). The upper portion of the diagram shows that, when firms with little international experience expatriate homecountry nationals abroad, specific-market knowledge is only relevant in the location where it is gained. Further, as these experiences are novel to the firm, it has not built up an infrastructure to shield the expatriate from any environmental obstacles. Therefore, the expatriate remains vulnerable to elements of the host culture, as well as its economic and political systems. Hypotheses to test this portion of the model offered that individual, environmental, and family-related characteristics would have a significant effect on the success of expatriates in firms low on internationalization.

In contrast, the bottom portion of Figure 3 shows that highly internationalized firms have the ability to buffer its home-country personnel from outside pressures, by virtue of the knowledge gained about how to operate in specific markets as well as in the international arena in general. This suggests that learning is transferable from market to market. When there is extensive experience abroad, firms need not expose expatriates to the host environment as a means of gaining market-specific knowledge, since scanning mechanisms have no doubt been institutionalized. Hypotheses to test this portion of the model offered that organizational systems would have a significant effect on the success of expatriates in highly internationalized firms. 
This theoretical model was tested for three measures of expatriate success: $(i)$ cross-cultural adjustment, (ii) organizational commitment, and (iii) job satisfaction. Further, a selected set of individual, organization, environmental, and family-related factors were included as determinants of success in each model. Environmental and family-related factors were significant to expatriate cross-cultural adjustment when firms were low on internationalization. In addition, the majority of organizational-level factors considered were significant determinants of expatriate satisfaction firms once experience had been gained in a particular country, indicating that "learning-by-doing" overseas does tend to promote organizational initiatives to shield individual expatriates from hostcountry pressures.

The model specified here combines two distinct streams of research. This study is the first of its kind, integrating paradigms from the organizational development and international human resource management disciplines into a cohesive platform for understanding how relationships can change given different sets of circumstances. While the body of literature in several disciplines has incorporated longitudinal dimensions, as well as other contingencies, into theoretical models, the potential role played by internationalization has been largely overlooked. In fact, recent research on internationalization has been primarily psychometric in nature, in search of adequate measures of this phenomenon. It is likely that various conceptualizations will be introduced over time. This study moves beyond basic measurement issues, incorporating a dynamic element into a model of expatriate success by linking internationalization to 
Organizational Learning Theory. The basic tenets of organizational learning are still relevant but are now applied on a worldwide scale.

\section{Practice}

Due to the complexity of variables considered, practical implications borne from the results become more clear when interpreted from three different angles - (i) support of the model based on the outcome considered, (ii) support of the model for individual, organizational, environmental, and family-related characteristics, and (iii) the role of firm country experience and internationalization in moderating these relationships. These issues are addressed in turn.

\section{Support of the Model Based on Outcome}

The preponderance of support was found for those hypotheses looking at expatriate cross-cultural adjustment in the early stages of overall firm internationalization. The majority of hypotheses were supported regarding the effect of organizational characteristics on expatriate job satisfaction when there is extensive country experience. And, no support was received for those assessing the determinants of expatriate organizational commitment. Therefore, the model offered in this study was supported for some outcomes more than for others.

Organizations may capitalize on these findings, enhancing both expatriate adjustment and satisfaction abroad through an emphasis on certain characteristics at distinct stages of internationalization. For example, to increase expatriate adjustment, 
organizations with little international experience overall would be well-served to select operation sites with favorable conditions. These may include politically stable, economically developed environments with which the expatriate is relatively familiar. In addition, firms may benefit from giving extra consideration to spousal issues, including assistance in obtaining work visas and training both before departure and on an ongoing basis. Expatriation satisfaction may be enhanced through increased attention to organizational initiatives, such as long-term career planning and expatriate training programs, once subsidiaries have been up and running for many years.

Support for Individual, Organizational, Environmental, and Family-Related Characteristics

At first, it may seem as though implications for management are limited to those characteristics at the organizational level, since those are the only ones that the firms can control. After all, it would be difficult to alter individual traits, and more difficult still to change the macro environment of the host country. In actuality, however, the firm has control over all of these.

Once it is known in which stage of internationalization individual traits are significant to expatriate outcomes, it is at this time that the greatest amount of resources should be invested in the staffing process, which is typically the responsibility of international human resource management. This includes recruitment, screening, and selection. In this study, individual overseas experience was a significant determinant of adjustment for expatriates assigned to young subsidiaries. In fact, it less experience abroad was more desirable. This may be due to the fact that previous experience was 
market-specific and not directly applicable to the current host environment. This would be particularly true if this experience was very recent, not allowing for sufficient transfer to and processing by the parent. While $\mathrm{HCN}$ s may possess the knowledge specific to the current host environment, this option should be considered along with the goals set forth for the transfer process. Most likely these $\mathrm{HCNs}$ will not complete the transfer process and the learning experience for the firm by returning to the corporate location. Therefore, their experiences will not be shared, or "added to the pot" of knowledge about international operations.

It is also possible to place greater emphasis on the environment in the early stages of the internationalization process. This may be accomplished through the process of site selection, which is really part of the firm's overall corporate strategy, In assessing such issues of scope, it might serve newly internationalized firms to seek out geographically proximate locations with at least a moderate level of economic development, due to the firm's inexperience in dealing with foreign cultures. Such inexperience may be characterized by a lack of established networks with suppliers and/or customers, a lack of familiarity with distribution channels within the host as well as those associated with the transportation of materials both in and out of the host, and overall limited knowledge about how to work around these issues through negotiations with host governments. Each of these concerns may be a direct result of the fact that sufficient organizational learning on an international scale has not yet occurred. As the firm gains experience and knowledge in these areas, it is possible to transfer this knowledge from subsidiary to subsidiary, with subsequent knowledge accumulated along the way. If the expatriate is 
"thrown" into an unfamiliar environment, he/she is faced with challenges that extend beyond the job. The external environment may be a source of stress and contribute to an inability to adjust to the surrounding conditions.

Finally, firms are advised to look closely at spousal adjustment as an important predictor of expatriate adjustment. In fact, the adjustment of the spouse to the general host environment and to interacting with the locals was significant to expatriate adjustment regardless of country experience or firm internationalization. Therefore, organizations may make arrangements for a representative in the host country to assist the spouse with shopping and with establishing social networks. Furthermore, attempts should be made to provide housing with conditions comparable to that in the home country, and to compensate for any cost-of-living discrepancies.

The Role of Overall Firm Internationalization v. Specific Country Experience

A comparison of the two levels at which international experience is considered begs the question of whether organizational learning is transferable across firm subsidiaries, or whether each learning process is unique to its respective host environment. Findings indicate that overall firm internationalization dictates the determinants of success more often than does specific country experience. This is particularly true for characteristics of the macro environment, such as geographic proximity, economic development, and levels of risk. Therefore, what the firm learns through its expatriates about foreign environments may aid in enhancing subsequent expatriate assignments in other host locations as well. 


\section{Limitations}

It can be said that there are constant trade-offs involved in developing and testing theoretical frameworks. In constructing a model of expected relationships, comprehensiveness is often sacrificed for the sake of parsimony, and vice versa. It is also possible, as this study exemplifies, to build a model that is all-inclusive from a levels-of-analysis standpoint, necessitating a restriction in the variable set at each level. Here, independent variables at the individual, organizational, environmental, and family levels were chosen on the basis that each had been a significant determinant in the various outcomes in previous tests of "static" models. The question then remained as to whether these determinants would play as strong a role as firm international experience increased.

Moreover, as suggested in the expatriation literature, particularly those studies on expatriate cross-cultural adjustment, characteristics of the task (or role) at work and those of the organization may be two distinct categories. This suggests that some findings at the organizational level were actually task-specific, and may also explain why results for role ambiguity and role discretion supported the hypotheses more often than did those for other organizational-level characteristics.

Testing of the proposed model was limited to U.S.-based firms, for the purpose of maintaining parent country homogeneity and thus making it easier to attribute the variance of the dependent variables to the factors of interest. Again, the issue of the trade-off between internal and external validity emerges. 


\section{Suggestions for Future Research}

While the expatriate outcomes considered here (adjustment, commitment, and satisfaction) were assessed through well-established measurement instruments, the question of which correspond most directly to organizational objectives remains unanswered. Although it is likely that each is important in its own right, the fact that adjustment and satisfaction, for example, are not attributed to the same set of factors, and at the same stages in the internationalization process, necessitates the alignment of firm and expatriate objectives for the assignment. Future research on expatriate outcomes should focus on determining which expatriate success measures will enable the organization to achieve its stated objectives.

In addition, expatriate performance was not considered here, due to the lack of a valid and reliable method for assessment. Past studies have used expatriate recollections of their most recent performance evaluations, begging a host of methodological concerns. Future endeavors on expatriate success should seek actual performance ratings through the central HR location. Appraisals from expatriate subordinates (who are likely represented by host-country nationals) may offer additional insight into how he/she was received by the local environment.

Other independent variables should also be considered, particularly at the individual and organizational levels. These may include expatriate language ability, functional area of expertise, and position in the organizational hierarchy, as well as firm strategy and structure. It is further recommended that future studies compare the 
application of this model to U.S. (or North American firms) to its application with respect to firms of other national parentage. It may be interesting to find, for instance, whether the organizational learning process plays a similar role for expatriates of Japanese or Western European firms.

\section{OVERALL IMPLICATIONS AND CONTRIBUTIONS}

Through the investigation of both research questions, it was determined that organizations do learn, either about specific markets or about international operations in general, by increasing their international experience. In an era where learning, or the transfer of core competencies, is the key to sustained competitive advantage, firms may benefit by internationalizing on a strategic rather than ad hoc basis. This may entail more rapid international expansion for the purpose of location economies and first-mover advantages. In addition, creating an international cadre of managers with diverse experiences overseas may be part of this internationalization effort.

The practice of expatriation represents a large investment for both the organization and for the assignee, but firms continue to send home-country nationals abroad for several reasons. While it is unlikely that expatriate adjustment, commitment, or satisfaction is articulated in the company's expatriation agenda, its objectives may be more closely tied to some of these outcomes than to others.

Expatriates may act as vehicles through which the organization can communicate its vision, overall philosophies, and corporate mission to the overseas location, in an attempt to align subsidiary goals with those of the organization. This may also aid in 
gaining company loyalty among local nationals, who may "buy in" to the company culture and thus be less inclined to seek other employment. Expatriates may also be tools for disseminating information and knowledge to the subsidiary locations, whether technical or managerial in nature, in a manner that is consistent worldwide. The process of sending home-country nationals abroad may also be part of a company-wide initiative to develop an international cadre of managers, who collectively and cumulatively contribute to organizational learning and hence the international experience of the organization as a whole. When speaking directly with corporate HR managers, an objective which emerged consistently was the acquisition and development of skills, which are transferred back to the corporate location when expatriates return. This essentially completes the transfer loop by adding to the organization's existing knowledge base.

In order for organizational objectives to be fulfilled, the expatriate must remain in their assignment long enough to be effective, as well as to incorporate any new information into his/her resident base of knowledge. It is therefore an implicit organizational objective that expatriates remain abroad throughout the designated length of the assignment, during which time they seek to fulfill their own individual objectives. As mentioned above, the alignment of individual and organizational objectives may differ from firm to firm, and some individual outcomes may be more relevant to those of the firm than will others.

For the expatriate, the international assignment may be viewed as a necessary rung on the corporate ladder. As such, the material rewards associated with promotional opportunities upon return, as well as the premiums and allowances received while abroad, 
provide attractive inducements. The expatriate may also accept the assignment in fulfillment of his/her own self-actualization, by acquiring and developing skills, which in turn will make him/her more marketable in both the internal and external labor markets. Regardless of stated, or even implicit objectives, it is safe to expect that positive outcomes of a behavioral/attitudinal nature, such as those evaluated here, will enhance the expatriate's ability to succeed.

\section{CONCLUSION}

Based on the findings, it can be concluded that organizational learning, manifested in the extent to which organizations have acquired international experience, does dictate the determinants of expatriate cross-cultural adjustment and to a lesser extent expatriate satisfaction. Therefore, what may be important to adjustment and satisfaction at one level of internationalization may be less so at another. Knowing what predicts these outcomes at the various stages can assist the organization (most likely the IHRM function) in the screening and selection of candidates for overseas assignments, as well as in initiating the appropriate programs.

This study represents a significant breakthrough in realizing the potential outcomes of overseas assignments. The results found here, when combined with existing models of the determinants of expatriate success, provide a contingency framework for improving future expatriate assignments both for the individual and for the organization. By exploring the concept of expatriate success over distinct stages of internationalization, this study incorporates a dynamic element into the heretofore static expatriation literature. 
Research such as this can provide the expatriate and potential expatriate with more realistic expectations about the experience of an overseas assignment and the factors most likely to facilitate or impede it. The cost of expatriation combined with the reportedly high failure rates makes the topic one of great interest to human resource managers. In an era when geographic expansion is essential to long-term survival, insights into the determinants of enhanced expatriate experiences have the potential to add significant value to multinational corporations as they approach the new millennium. 


\section{LIST OF REFERENCES}

Adler, N., \& Ghadar, F. (1989). Globalization and human resource management. In A. Rugman (Ed.), Research in global strategic management: A Canadian perspective (Vol. 1, pp. 179-205). Greenwich, CT: JAI Press.

Aldrich, H. E., \& Pfeffer, J. (1976). Environments of organizations. In A. Inkeles (Ed.), Annual Review of Sociology (Vol. 2, pp. 79-105). Palo Alto, CA: Annual Reviews.

Ansoff, H. I. (1965). Corporate strategy. New York: McGraw-Hill.

Argyris, C. \& Schön, D. (1978). Organizational learning: A theory of action perspective. Reading, MA: Addison Wesley.

Banai, M., \& Reisel, W. D. (1993). Expatriate managers' loyalty to the MNC: Myth or reality? An exploratory study. Journal of International Business Studies, 24(2), 233-247.

Barkema, H. G., Bell, J. H. J., \& Pennings, J. M. (1996). Foreign entry, cultural barriers, and learning. Strategic Management Journal, 17, 151-166.

Bilkey, W. J., \& Tesar, G. (1977). The export behavior of smaller-sized Wisconsin manufacturing firms. Journal of International Business Studies, $\underline{8}$ (Spring/Summer), 93-98.

Bird, A., \& Beechler, S. (1995). Links between business strategy and human resource management strategy in U.S.-based Japanese subsidiaries: An empirical investigation. Journal of International Business Studies, 26(1), 23-46.

Bird, A. \& Dunbar, R. (1991). Getting the job done over there: Improving expatriate productivity. National Productivity Review, Spring, 145-156.

Black, J. S. (1988). Work role transitions: A study of American expatriate managers in Japan. Journal of International Business Studies, 19(2), 277-294.

Black, J. S. (1990). The relationship of personal characteristics with the adjustment of Japanese expatriate managers. Management International Review, 30(2), 119-134.

Black, J. S. (1992). Coming home: The relationship of expatriate expectations with repatriation adjustment and job performance. Human Relations, 45 (2), 177-192.

Black, J. S. (1994). O Kaerinasai: Factors related to Japanese repatriation adjustment. Human Relations, 47(12), 1489-1508. 
Black, J. S., \& Gregersen, H. B. (1991a). The other half of the picture: Antecedents of spouse cross-cultural adjustment. Journal of International Business Studies, 22(3), 461-477.

Black, J. S., Gregersen, H. B. (1991b). When Yankee comes home: Factors related to expatriate and spouse repatriation adjustment. Journal of International Business Studies, 22(4), 671-694.

Black, J. S., Mendenhall, M., \& Gregersen, H. B. (1992). Global Assignments: Successfully expatriating and repatriating international managers. San Francisco, CA: JosseyBass.

Black, J. S., Mendenhall, M., \& Oddou, G.R. (1991). Towards a comprehensive model of international adjustment: An Integration of multiple theoretical perspectives. Academy of Management Review, 16(2): 291-317.

Black, J. S., \& Stephens, G. K. (1989). The influence of the spouse on American expatriate adjustment and intent to stay in Pacific Rim overseas assignments. Journal of Management, 15(4), 529-544.

Bontis, N. (1996). There's a price on your head: Managing intellectual capital strategically. Business Quarterly, Summer, $41-47$.

Boyacigiller, N. (1990). The role of expatriates in the management of interdependence, complexity and risk in multinational corporations. Joumal of International Business Studies, 21(3), 357-381.

Boyacigiller, N. (1991). The international assignment reconsidered. In M. E. Mendenhall \& G. R. Oddou (Ed.), International Human Resource Management, (pp. 148-155). Boston: PWS-Kent.

Brislin, R. (1981). Cross-cultural encounters: Face-to-face interaction. New York: Pergamon.

Brown, L. T., Rugman, A. M., \& Verbeke, A. (1989). Japanese joint ventures with Western multinationals: Synthesizing the economic and cultural explanations of failure. Asia Pacific Journal of Management, $\underline{6}(2), 225-242$.

Cangelosi, V. E., \& Dill, W. R. (1965). Organizational learning: Observations toward a theory. Administrative Science Quarterly, 10, 175-203.

Carlson, S. (1974). Investment in knowledge and the cost of information. Acta Academiae Regiae Scientaiarum Upsaliensis: Uppsala.

Chandler, A. D. (1977). The visible hand. Cambridge, MA: Belknap Press. 
Chang, S. J. (1995). International expansion strategy of Japanese firms: Capability building through sequential entry. Academy of Management Journal, 38(2), 383-407.

Church, A. T. (1982). Sojoumer adjustment. Psychological Bulletin, 19, 540-572.

Clarke, C., \& Hammer, M. R. (1995). Predictors of Japanese and American managers' job success, personal adjustment, and intercultural interaction effectiveness. Management International Review, 35(2), 153-170.

Cohen, M. D., March, J. G., \& Olsen, J. P. (1972). A garbage can model of organizational choice. Administrative Science Quarterly, 17, 1-25.

Cook, J., \& Wall, T. (1980). New work attitude measures of trust, organizational commitment and personal need non-fulfillment. Journal of Occupational Psychology, $\underline{53}, 39-52$.

Copeland, L., \& Griggs, L. (1985). Going international. New York: Random House.

Deshpande, S. P., \& Viswesvaran, C. (1991, August). The effectiveness of cross-cultural training: A meta-analysis. Paper presented at the Annual Meetings of the Academy of Management, Miami, FL.

Dowling, P. J., Schuler, R. S., \& Welch, D. E. (1994). International Dimensions of Human Resource Management (2nd ed.). Belmont: Wadsworth.

Dun \& Bradstreet Corporation. (1996a). Directory of American Corporate Families and International Affiliates (Vol. III). Dun \& Bradstreet Information Services.

Dun \& Bradstreet Corporation. (1996b). Reference Book of Corporate Managements. Dun \& Bradstreet Information Services.

Duncan, R. B. (1974). Modifications in decision structure in adapting to the environment: Some implications for organizational learning. Decision Sciences, 705-725.

Dunning, J. H. (1988). The eclectic paradigm of international production: A restatement and some possible extensions. Journal of International Business Studies, 19, 1.

Earley, P. C. (1987). Intercultural training for managers: A comparison of documentary and interpersonal methods. Academy of Management Journal, 30(4), 685-698.

Fagre, N., \& Wells, L. T. Jr. (1982). Bargaining power of multinationals and host governments. Journal of International Business Studies, 13(3), 9-23. 
Feldman, D. C., \& Thomas, D. C. (1992). Career management issues facing expatriates. Journal of International Business Studies, 23 (2), 271-292.

Feldman, D. C., \& Tompson, H. B. (1993). Expatriation, repatriation, and domestic geographical relocation: An empirical investigation of adjustment to new job assignments. Journal of International Business Studies, 24(3), 507-529.

Fiol, C. M., \& Lyles, M. A. (1985). Organizational learning Academy of Management Review, 10(4), 803-813.

Gaylord, M. (1979). Relocation and the corporate family. Social Work, May, 186-191.

Gomez-Mejia, L. \& Balkin, D. G. (1987). Determinants of managerial satisfaction with the expatriation and repatriation process. Journal of Management Development, 6 , 7-17.

Gregersen, H. B. (1992). Commitments to a parent company and a local work unit during repatriation. Personnel Psychology, 45, 29-53.

Gregersen, H. B., \& Black, J. S. (1992). Antecedents to commitment to a parent company and a foreign operation. Academy of Management Journal, 35(1), 65-90.

Guzzo, R. A, Noonan, K. A., \& Elron, E. (1994). Expatriate managers and the psychological contract. Journal of Applied Psychology, 70(4), 617-626.

Haire, J. F., Anderson, R. E., Tatham, R. L., \& Black, W. C. (1992). Multivariate data analysis with readings. (3rd ed.). New York: Macmillan.

Harvey, M. G. (1983). The return side of foreign assignments: Dealing with the repatriation dilemma. Columbia Journal of World Business, 18, 53-59.

Harvey, M. G. (1985). The executive family: An overlooked variable in international assignments. Columbia Journal of World Business, 20, 84-92.

Hedberg, B. L. (1981). How organizations learn and unlearn. In P. C. Nystrom and W. H. Starbuck (Eds.) Handbook of Organizational Design (Vol. 1), York, England: Oxford University Press.

Heenan, D. A., \& Perlmutter, H. (1979). Multinational organizational development. Reading, MA: Addison Wesley.

Hendry, C. (1996). Continuities in human resource processes in internationalization and domestic business management. Journal of Management Studies, $33(4), 475-494$. 
Henry, E. R. (1965). What business can learn from Peace Corps selection and training. Personnel, 42, 17-25.

Hitt, M. A., Hoskisson, R E., \& Ireland, R D. (1994). A mid-range theory of the interactive effects of international and product diversification on innovation and performance. Journal of Management, 20, 297-326.

Hodgetts, R. M. (1993). Modern human relations at work. (5th ed.). Hinsdale, IL: Dryden Press.

Hodgetts, R. M., \& Kuratko, D. F. (1991). Management. (3rd ed.). San Diego, CA: Harcourt Brace Jovanovich.

Hrebiniak, L. G., \& Alutto, J. A. (1972). Personal and role-related factors in the development of organizational commitment. Administrative Science Quarterly, 17, 555-572.

Johanson, J., \& Vahine, J. E. (1977). The internationalization process of the firm - A model of knowledge development and increasing foreign market commitments. Journal of International Business Studies, $\underline{8}$ (Spring/Summer), 22-32.

Johanson, J., \& Weidersheim-Paul, F. (1975). The internationalization of the firm - Four Swedish cases. Journal of Management Studies, 12(3), 305-322.

Kahn, R. L., Wolfe, D. M., Quinn, R. P., \& Snoek, J. D. (1964). Organizational stress. New York: Wiley.

Karasek, R. (1979). Job demands, job decision, latitude, and mental strain: Implications for job redesign. Administrative Science Quarterly, 2, 215-308.

Kim, D. H. (1993). The link between individual and organizational learning. Sloan Management Review, Fall, 37-50.

Kobrin, S. (1988). Expatriate reduction and strategic control in American multinational corporations. Human Resource Management, 27(1), 63-76.

Landis, D., \& Brislin, R. W. (1983). Handbook of intercultural training (Vol. 1). New York: Pergamon Press.

Lecraw, D. J. (1984). Bargaining power, ownership, and profitability of transnational corporations in developing countries. Journal of International Business Studies, 15 (2), $27-43$.

Lei, D., Hitt, M. A., \& Bettis, R. (1996). Dynamic core competencies through meta-learning and strategic context. Journal of Management, 22(4), 549-569. 
Levitt, B., \& March, J. G. (1988). Organizational learning. In W. R. Scott \& J. Blake (Eds.) Annual Review of Sociology (Vol. 14, pp. 319-340). Palo Alto, CA: Annual Reviews.

Locke, E. A. (1976). The nature and causes of job satisfaction. In M. C. Dunnette (Ed.). Handbook of Industrial and Organizational Psychology (pp. 1297-1349).

Luthans, F., McCaul, H. S., \& Dodd, N. (1985). Organizational commitment: A comparison of U.S., Japanese, and Korean employees. Academy of Management Journal, 28, 213218.

March, J. G., \& Olsen, J. P. (1975). The uncertainty of the past: Organizational learning under ambiguity. European Journal of Political Research, 3, 147-171.

March, J. G., \& Simon, H. A. (1958). Organizations. New York: Wiley.

Marsic, V. J., \& Watkins, K. E.. (1990). Informal and incidental learning in the workplace. London and New York: Routledge.

Mendenhall, M., Dunbar, E., \& Oddou, G. R. (1987). Expatriate selection, training and careerpathing: A review and critique. Human Resource Management, 26(3), 331-349.

Mendenhall, M., \& Oddou, G. R. (1985). The dimensions of expatriate acculturation: A review. Academy of Management Review, 10(1), 39-47.

Mendenhall, M., \& Oddou, G. R. (1986). Acculturation profiles of expatriate managers: Implications for cross-cultural training programs. Columbia Journal of World Business, Winter, 73-79.

Miles, R. H. (1982). Coffin nails and corporate strategies. Englewood Cliffs, NJ: Prentice Hall.

Miller, D. (1990). The Icarus paradox: How exceptional companies bring about their own downfall. New York: HarperCollins.

Miller, D. (1996). A preliminary typology of organizational learning: Synthesizing the literature. Journal of Management, 22(3), 485-505.

Miller, E. L. (1975). The job satisfaction of expatriate American managers: A function of regional location and previous international work experience. Journal of International Business Studies, $\underline{6}, 65-73$.

Milliman, J., Von Glinow, M. A., \& Nathan, M. (1991). Organizational life cycles and strategic international human resource management in multinational companies: Implications for congruence theory. Academy of Management Review, 16(2), 318-339. 
Mintzberg, H. (1989). Mintzberg on management. New York: Free Press.

Mowday, R. T., Porter, L. W., \& Steers, R. M. (1982). Employee-organization linkages: The psychology of commitment, absenteeism, and turnover. New York: Academic Press.

Mowday, R. T., Steers, R. M., \& Porter, L. W. (1979). The measurement of organizational commitment. Journal of Vocational Behavior, 14, 224-247.

Naumann, E. (1993). Organizational predictors of expatriate job satisfaction. Journal of International Business Studies, 24(1), 61-80.

Nicholson, N. (1984). A theory of work role transitions. Administrative Science Quarterly, 29, 172-191.

Oberg, K. (1960). Culture shock: Adjustment to new cultural environment. Practical Anthropologist, $7,492-499$.

O'Boyle, T. (1989, December 11). Grappling with the expatriate issue. The Wall Street Journal, p. B1.

Political Risk Services, Inc. (1996). Country Comparisons. Syracuse, NY: Political Risk Services.

Porter, L. W., Steers, R. M., Mowday, R. T., \& Boulian, P. (1974). Organizational commitment, job satisfaction and turnover among psychiatric technicians. Journal of Applied Psychology, 59, 603-609.

Porter, M. E. 1990. The competitive advantage of nations. New York: The Free Press.

Prahalad, C. K., \& Hamel, G. (1990). The core competence of the corporation. Harvard Business Review, May/June, 79-91.

Rizzo, J. R., House, R. H., \& Lirtzman, S. (1970). Role conflict and ambiguity in complex organizations. Administrative Science Quarterly, 2, 150-163.

Ronen, S., \& Shenkar, O. (1985). Clustering countries on attitudinal dimensions: A review and synthesis. Academy of Management Review, 10(3), 435-454.

Rosenzweig, P. M. (1994). The new "American challenge": Foreign multinationals in the United States. California Management Review, Spring, 107-123. 
Ruygrok, W., \& van Tulder, R. (1993). The ideology of interdependence. Doctoral Dissertation, Department of Political Science, University of Amsterdam, Amsterdam, The Netherlands.

Schein, E. (1992). Organizational culture and leadership (2nd ed.). San Francisco, CA: JosseyBass.

Shenkar, O. (1992). The national/corporate culture matrix in international joint ventures. Paper presented at the Annual Meetings of the Academy of International Business, Brussels, Belgium.

Smith, A, \& Zeithaml, C. P. (1993). The international expansion process: A model and empirical evidence. Proceedings of the Annual Academy of Management, 152-156.

Starbuck, W. H. (1965). Organizational growth and development. In J. G. March (Ed.). Handbook of Organizations (pp. 451-533). Chicago: Rand McNally.

Steers, R M.,\& Mowday, R. T. (1981). Employee turnover and post-decision accommodation processes. Research in Organizational Behavior, $\underline{3}, 235-282$.

Stening, B. W., \& Hammer, M. R. (1992). Cultural baggage and the adaption of expatriate American and Japanese managers. Management International Review, 32(1), 77-89.

Stephens, G. K., \& Black, J. S. (1988). International transfers and dual-career couples. Paper presented at the Annual Meetings of the Academy of Management, Anaheim, California.

Stephens, G. K., \& Black, J. S. (1991). The impact of spouse's career-orientation during international transfers. Journal of Management Studies, $28(4), 417-428$.

Stewart, R (1982). A model for understanding managerial jobs and behaviors. Academy of Management Review, 7, 7-14.

Sullivan, D. (1994). Measuring the degree of internationalization of a firm. Journal of International Business Studies, 25(2), 325-342.

Torbiorn, I. (1982). Living abroad. New York: Wiley.

Tung, R. L. (1981). Selection and training of personnel for overseas assignments. Columbia Journal of World Business, Spring, 68-78.

Tung, R. L. (1982). Selection and training procedures of U.S., European, and Japanese multinationals. California Management Review, 25(1), 57-70. 
Ulrich, D., Von Glinow, M. A., \& Jick, T. (1993). High-impact learning: Building and diffusing learning capability. Organizational Dynamics, 22(2) 52-66.

United Nations. (1996). Human Development Report. Washington, D.C.: United Nations Development Program.

Van Maanen, J., \& Schein, E. (1979). Toward a theory of organizational socialization. In B. Staw (Ed.). Research in Organizational Behavior (Vol. 1, pp. 209-264) Greenwich: JAI Press.

Webster's II New Riverside University Dictionary. (1984). New York: Barley Books.

Weick, K. E. (1979). The Social Psychology of Organizing. (2nd ed.). Reading, MA: Addison Wesley.

Weiss, D. J., Dawis, R. V., England, G. W., \& Lofquist, L. H. (1967). Manual for the Minnesota Satisfaction Questionnaire (Minnesota Studies in Vocational Rehabilitation, 22). Minneapolis: Industrial Relations Center, University of Minnesota.

Zeira,Y., \& Banai, M. (1987). Selecting managers for foreign assignments. Management Decision, 25, 38-40. 


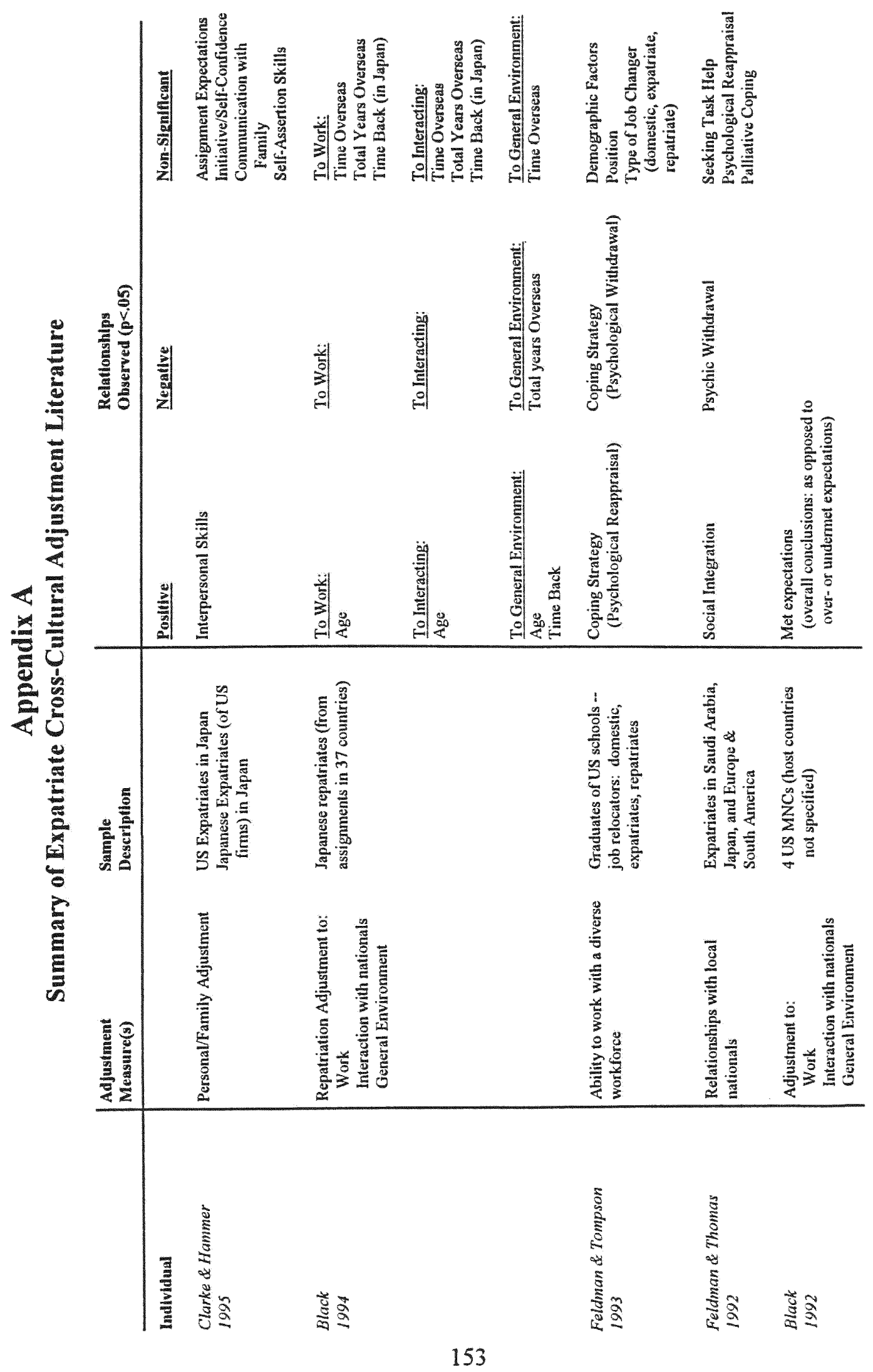




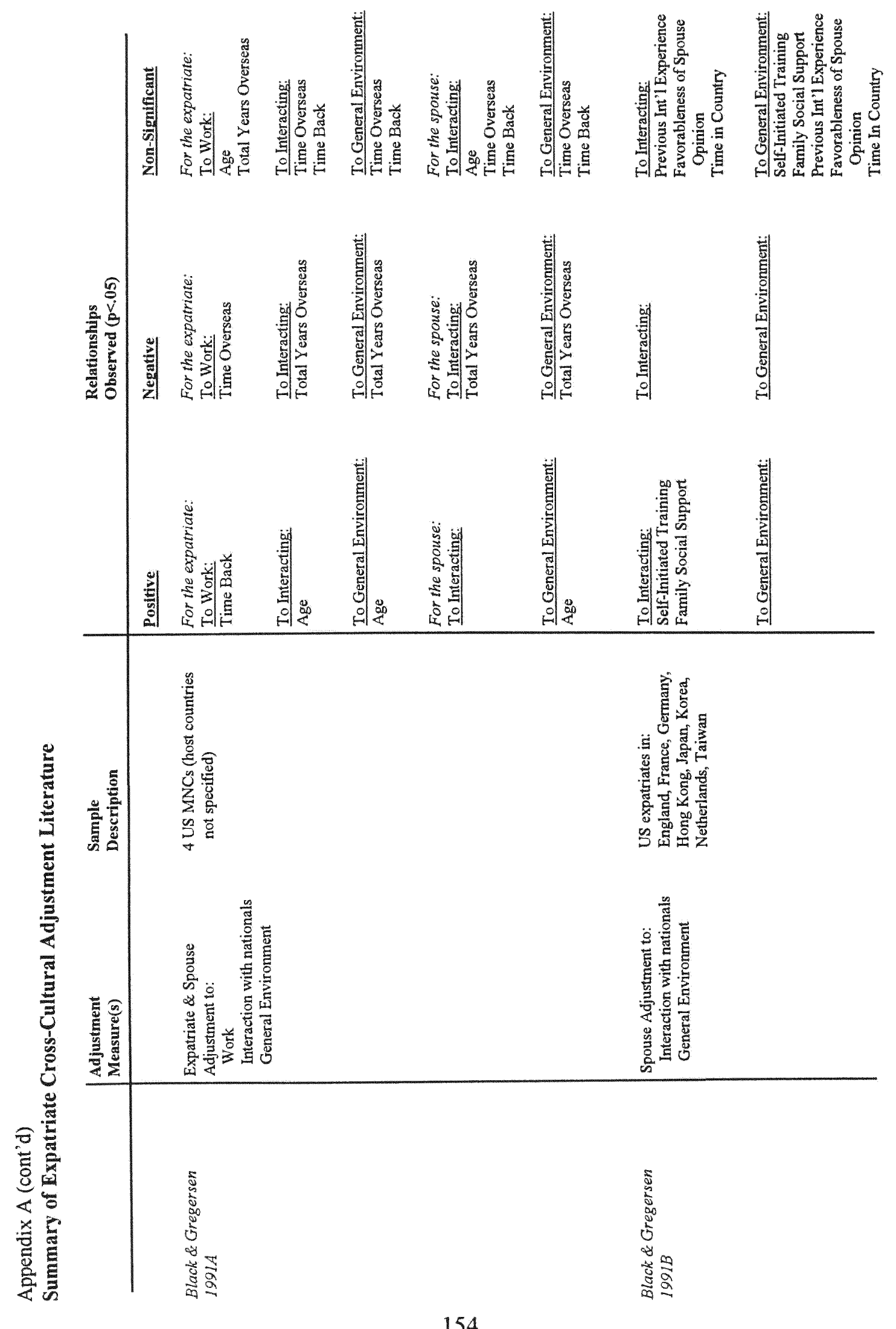




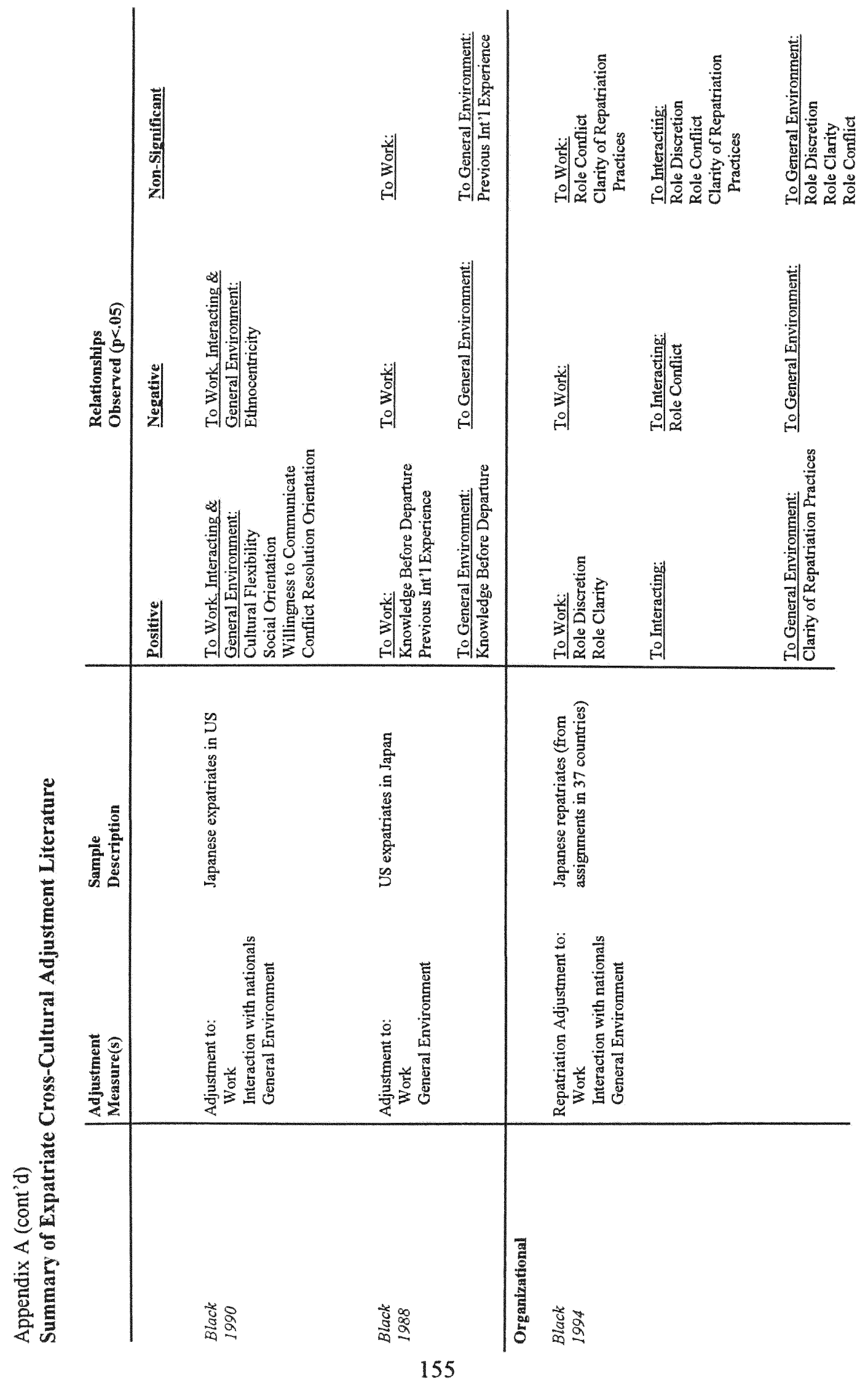




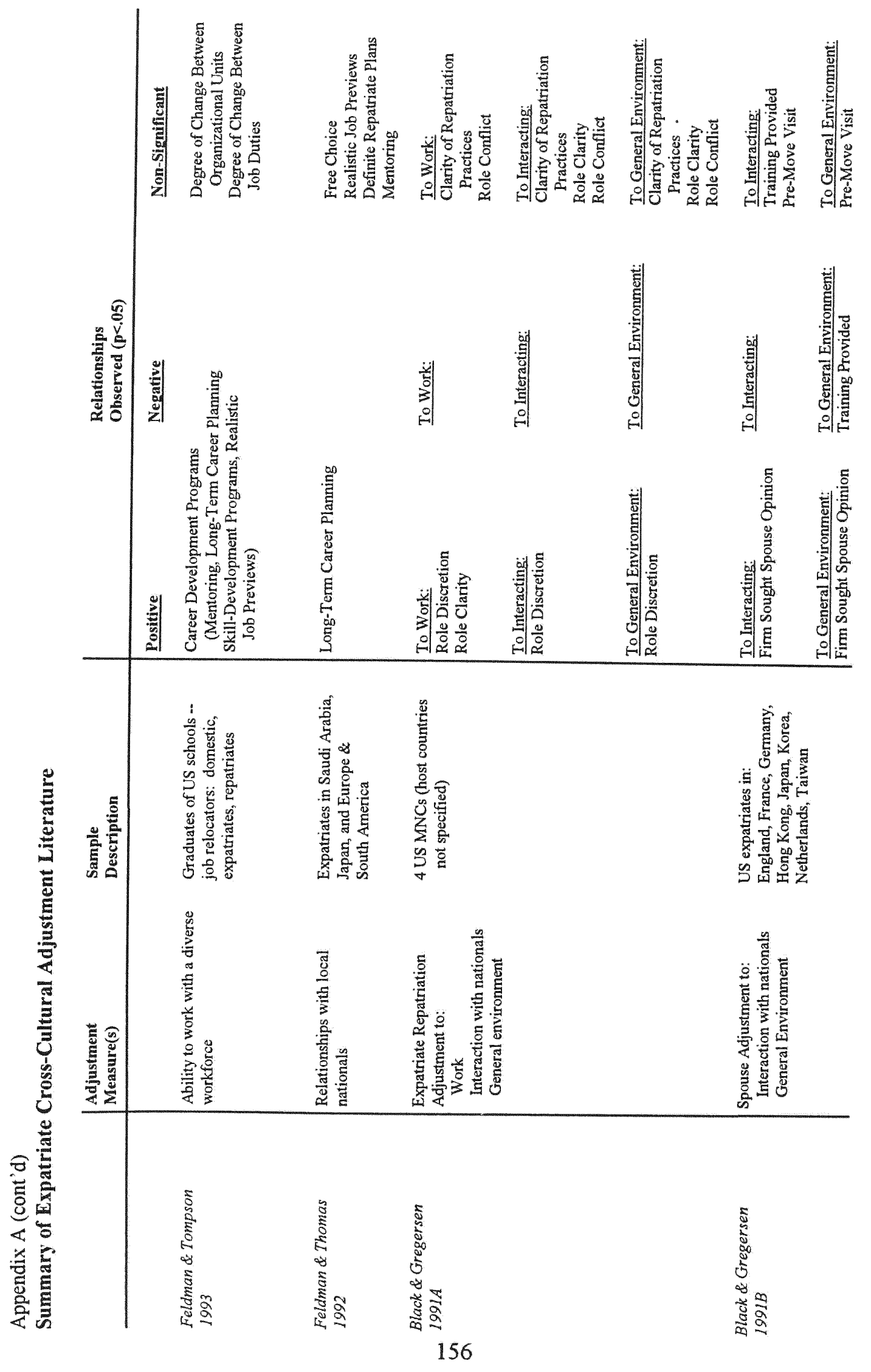




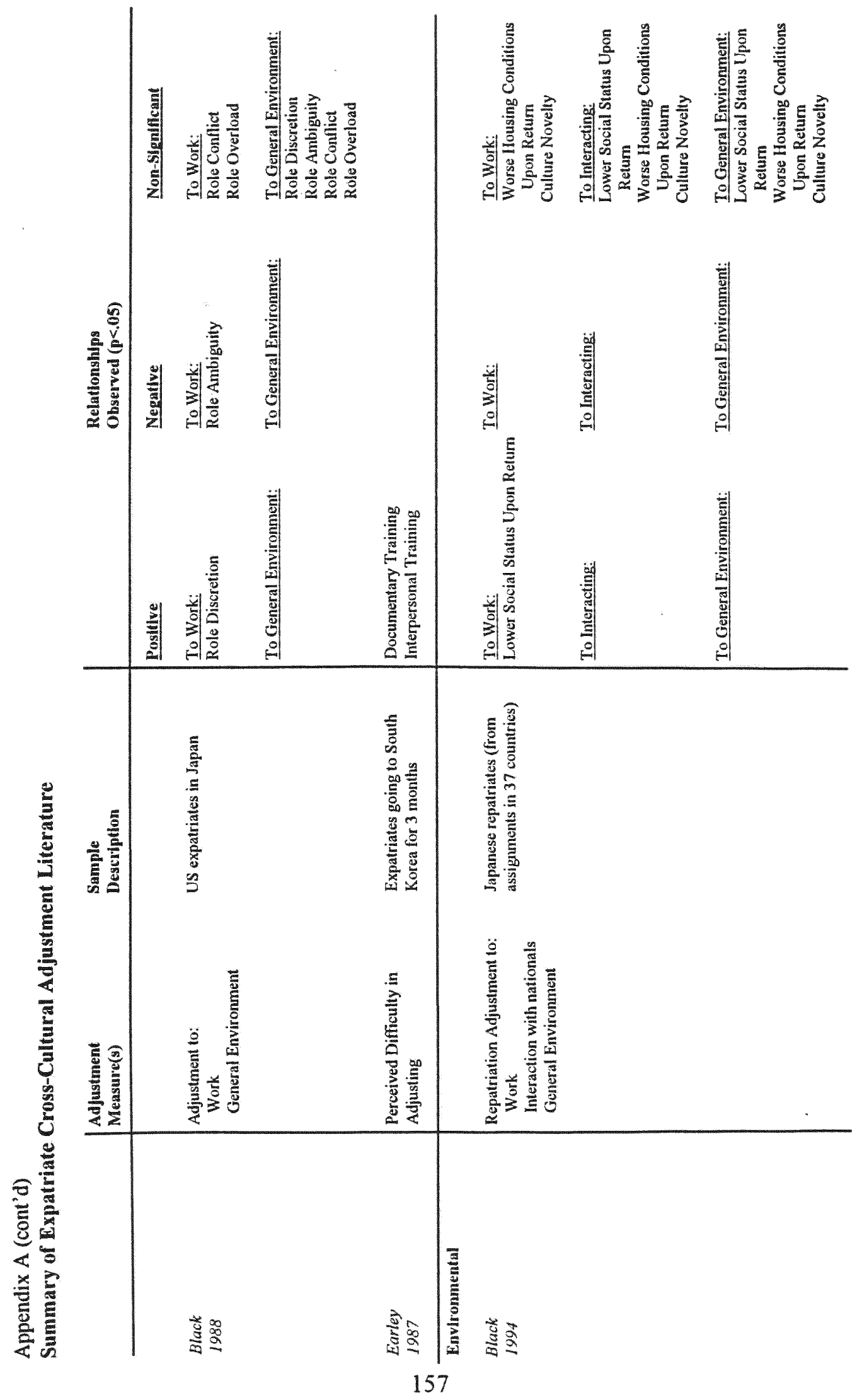




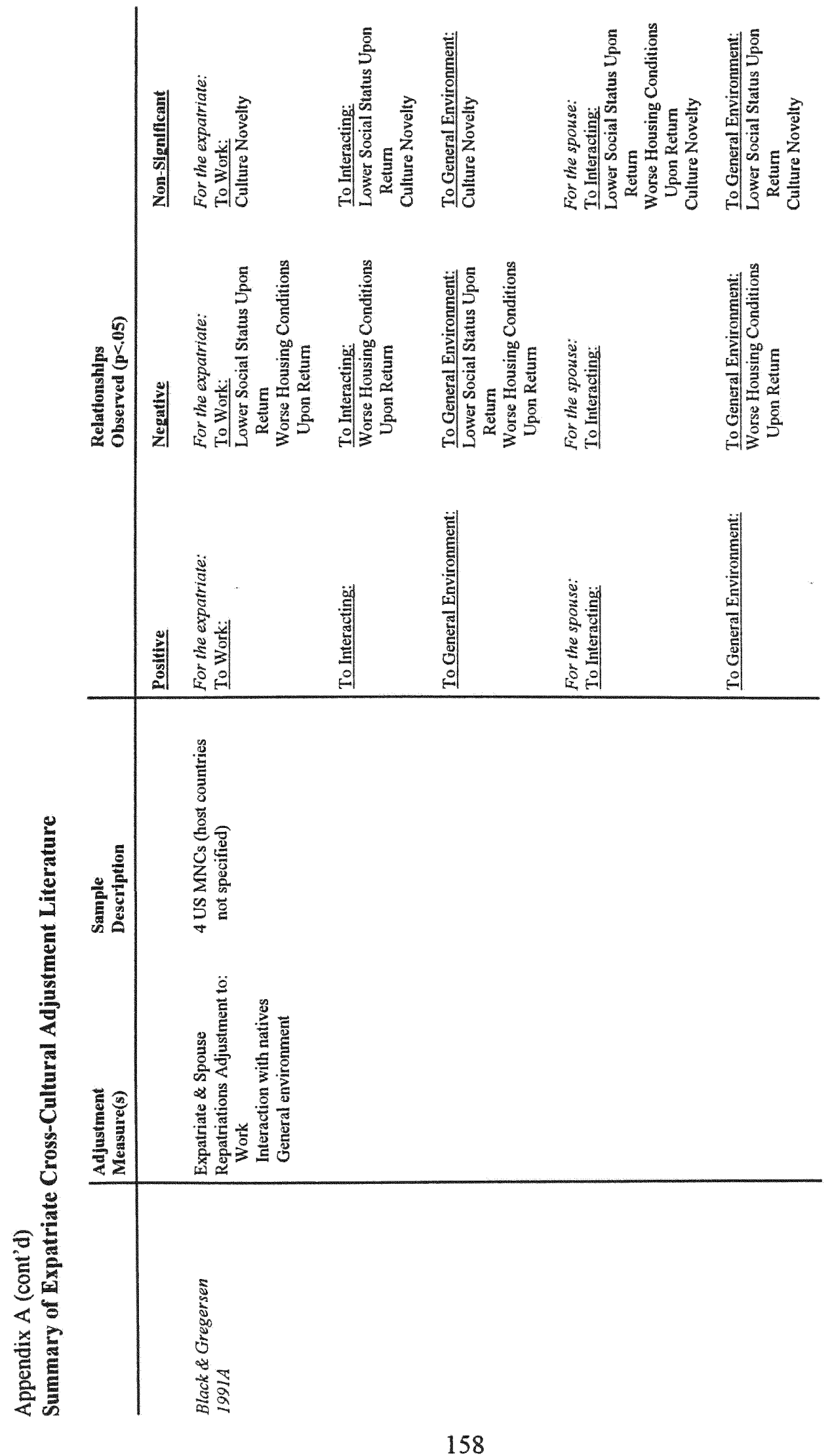




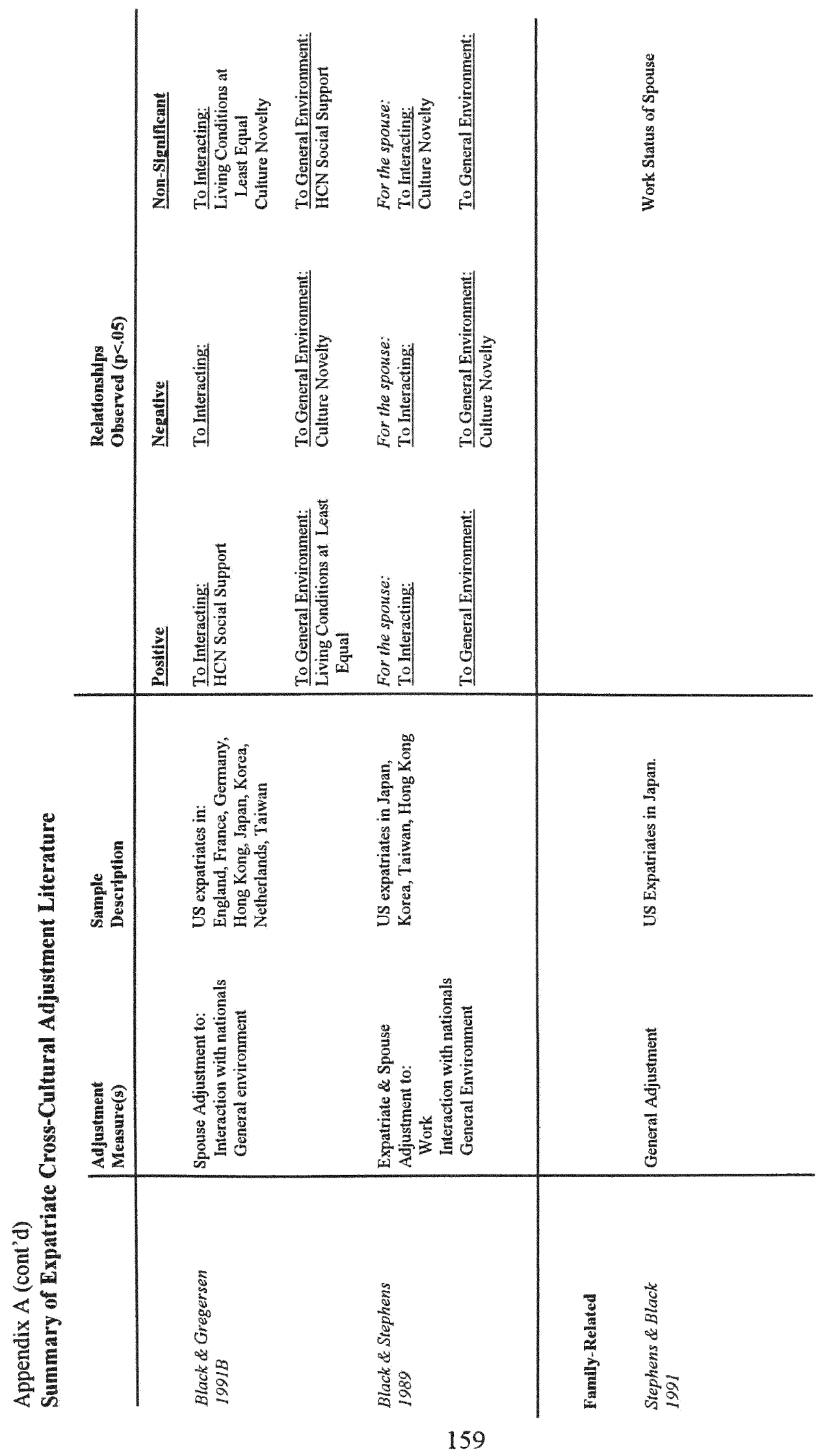




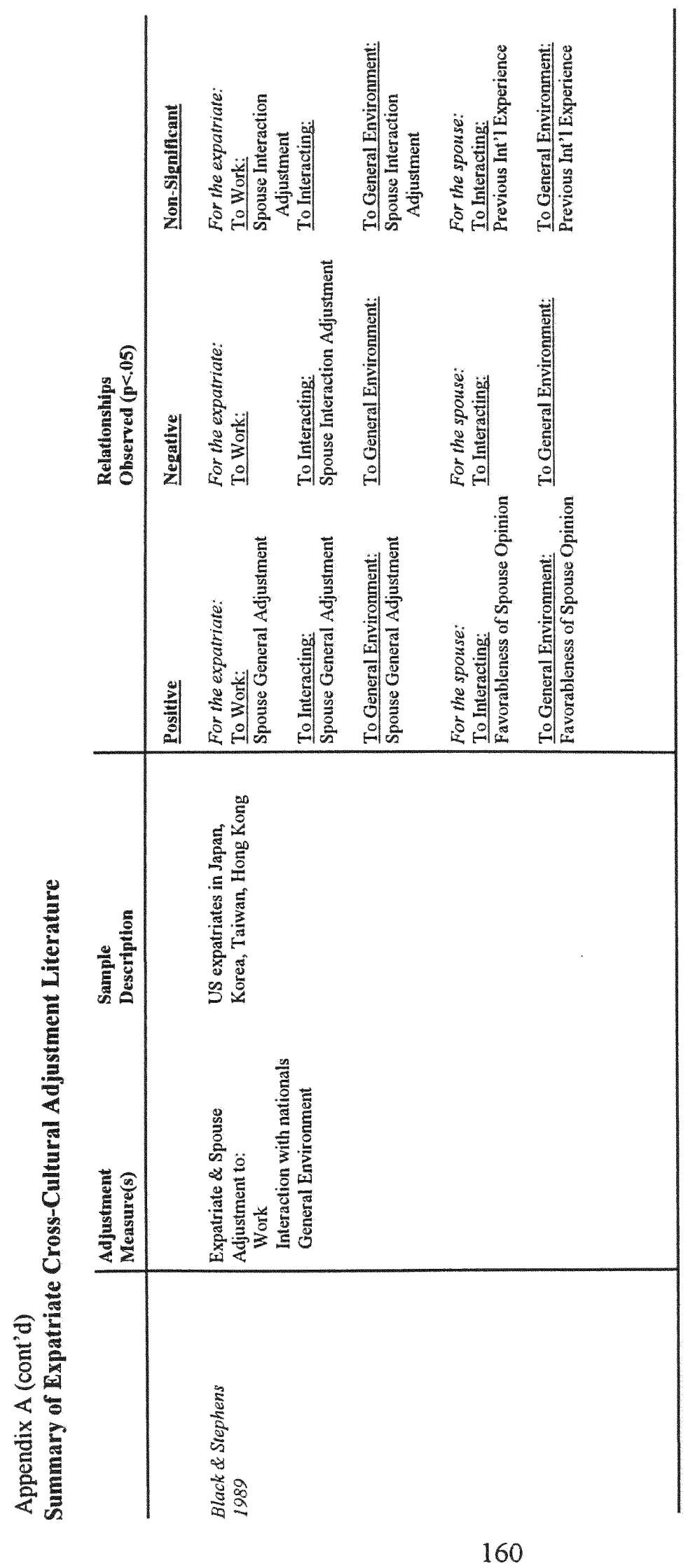




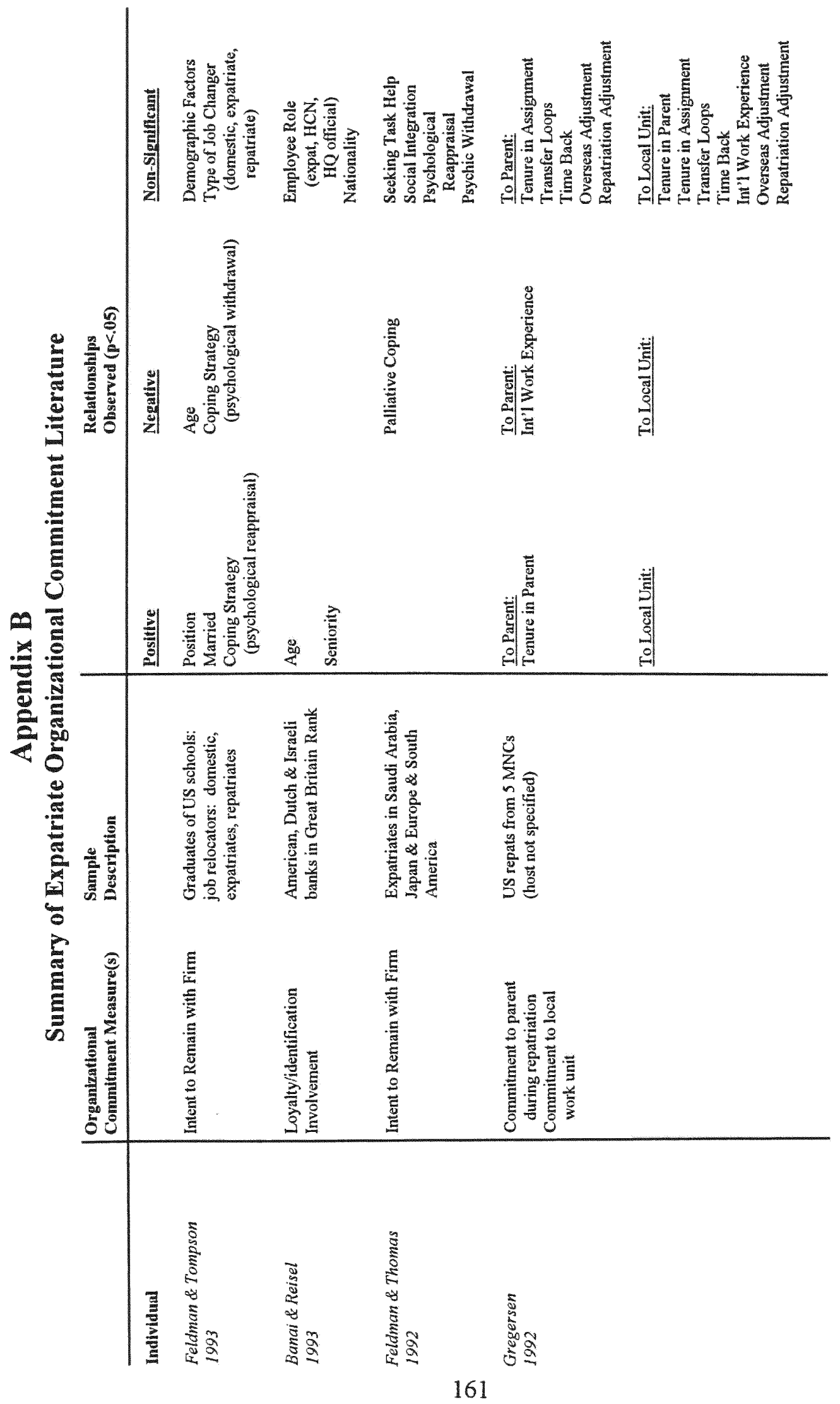




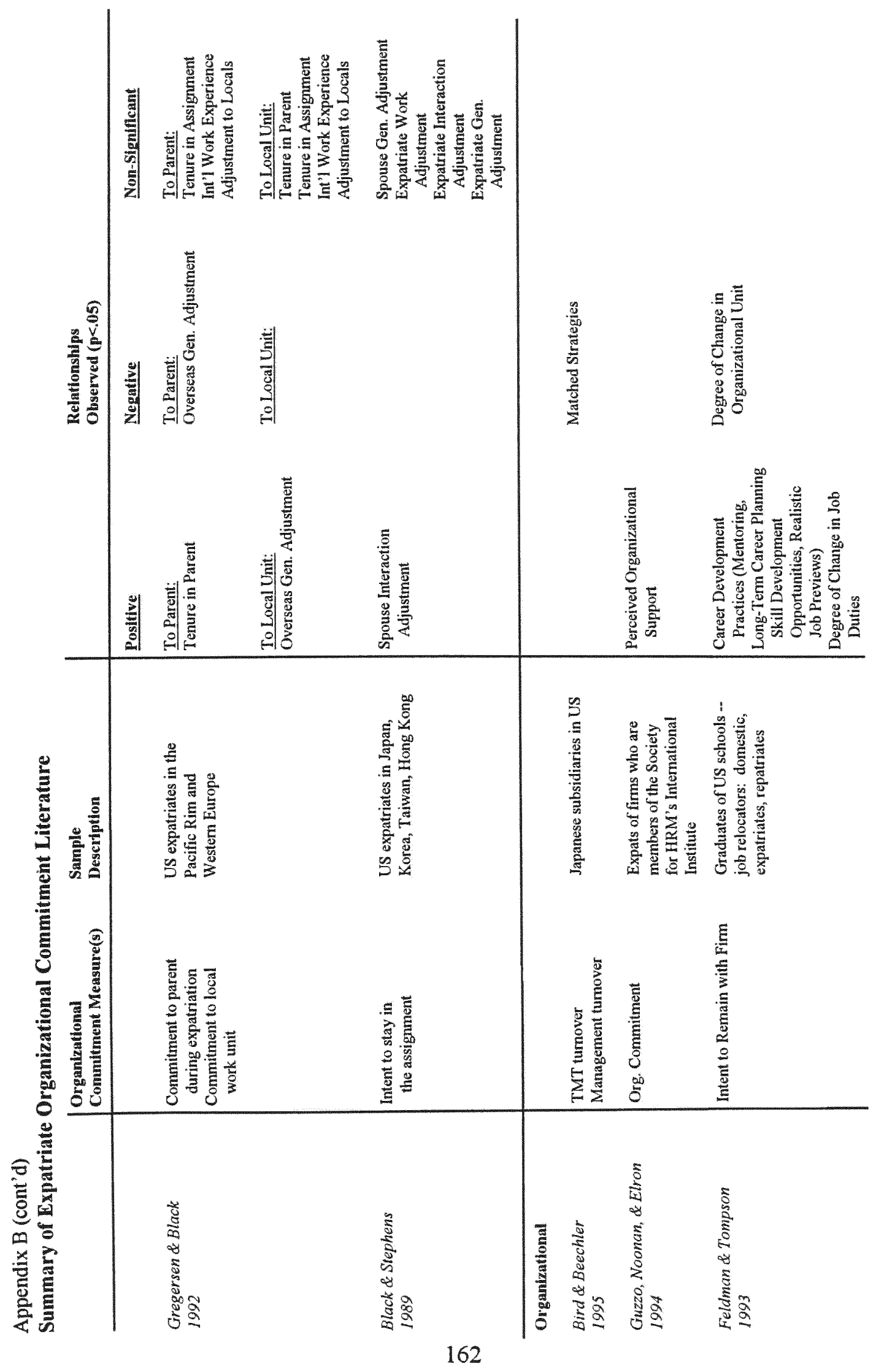




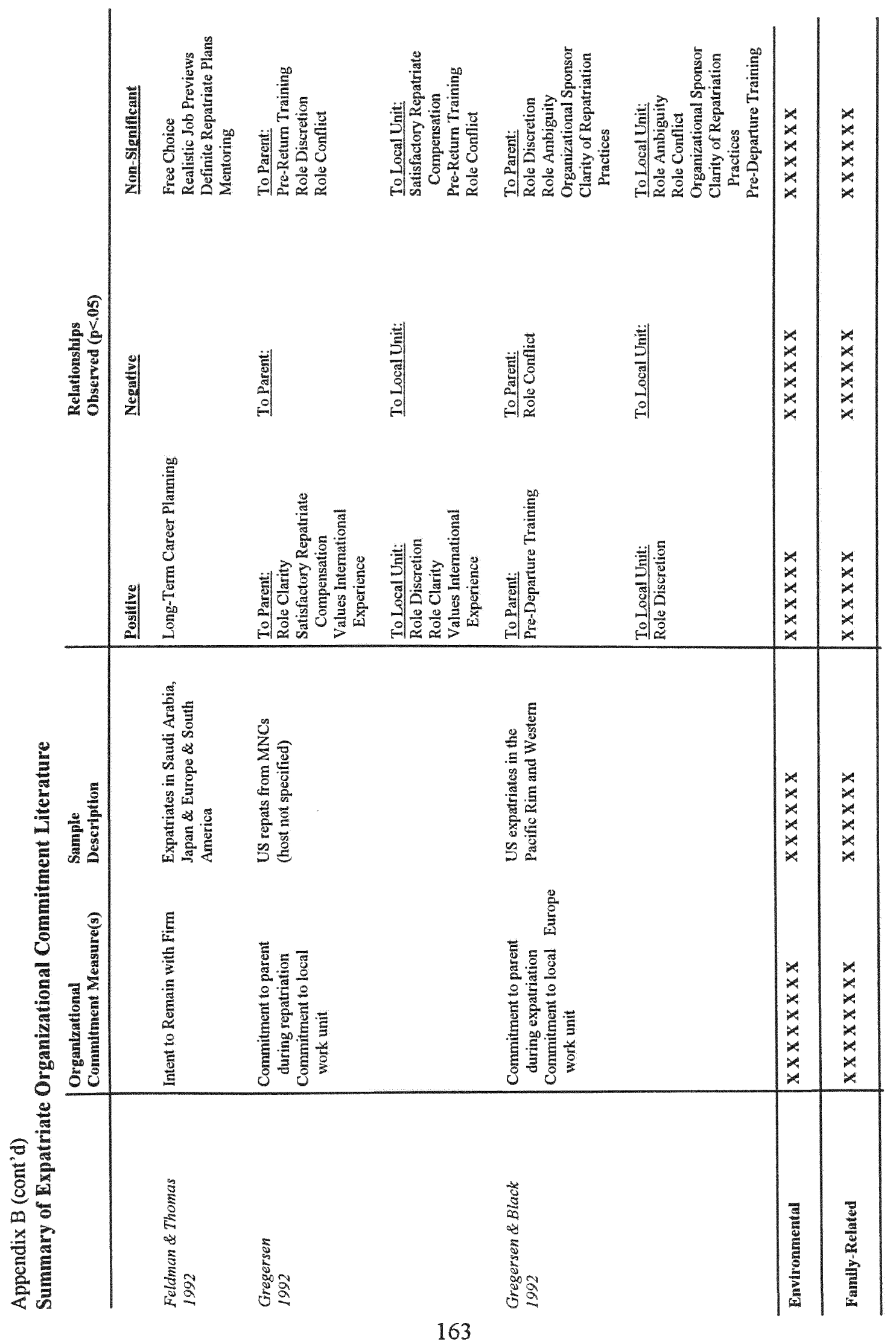




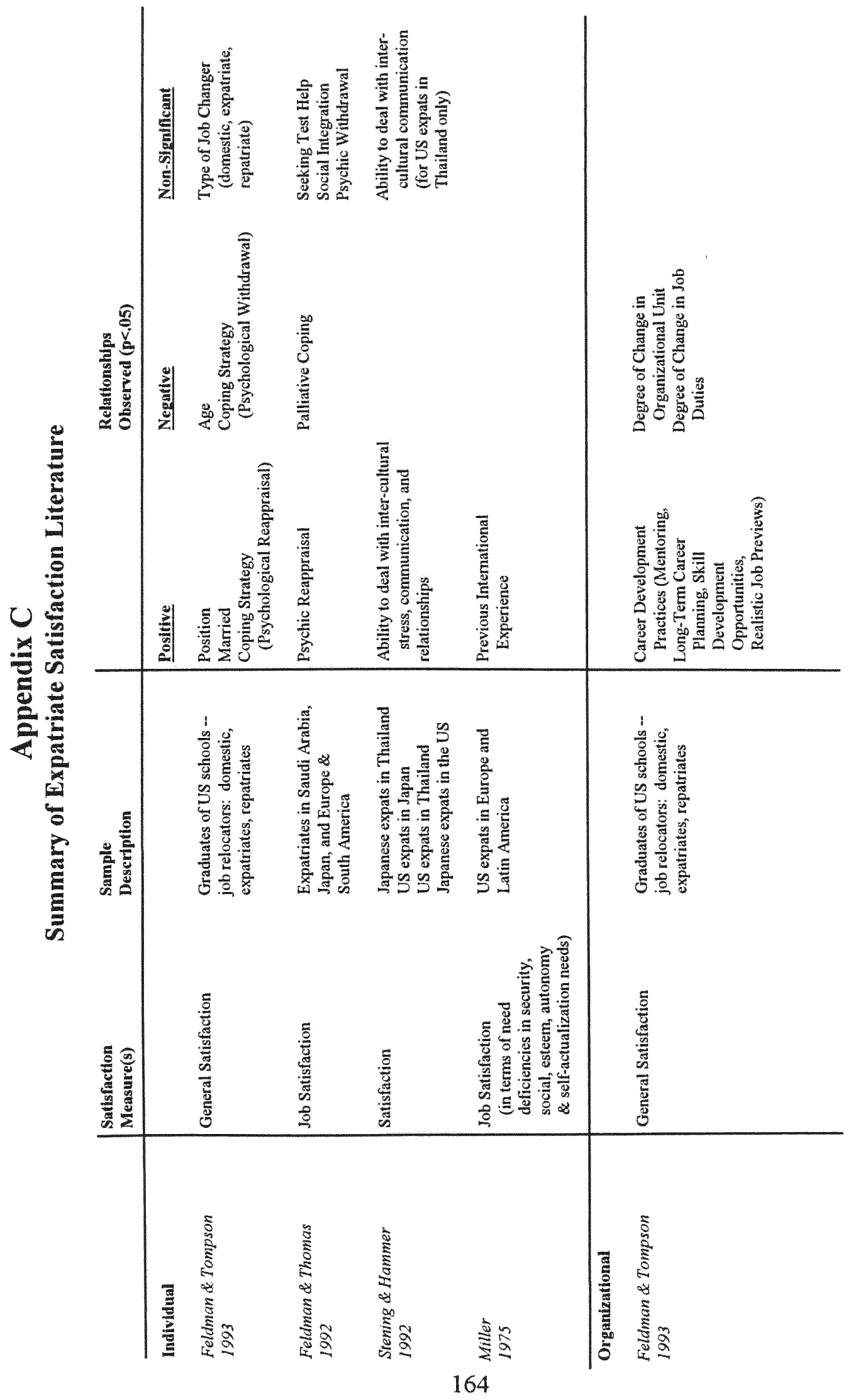




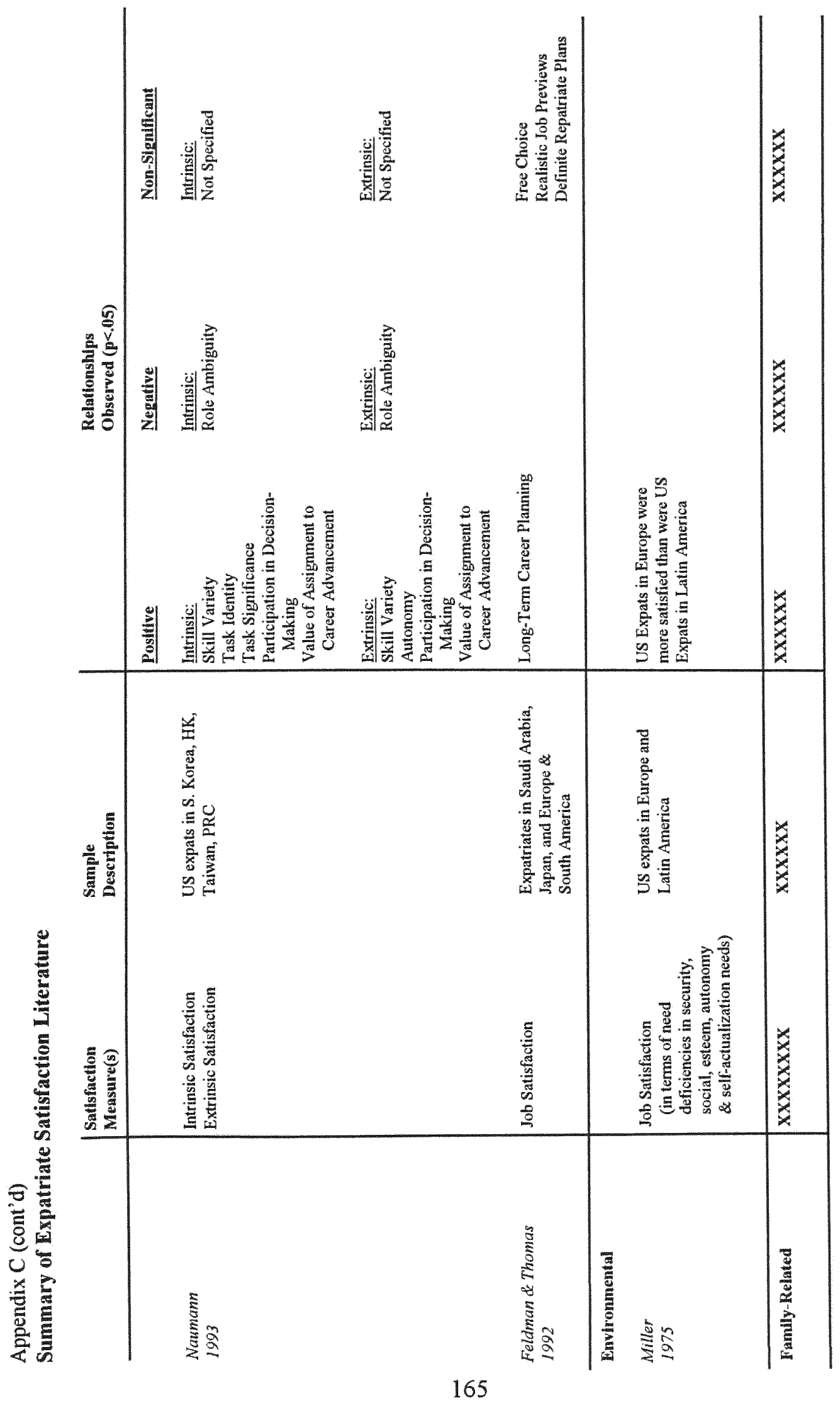




\section{APPENDIX D \\ Letter to HR Manager (limited participation)}

May 23, 1996

Ms. XXXXX

Vice President, Human Resources

ABC CORPORATION

XXXXXXXXXX

Dear Ms. XXXXX:

I am very pleased that you have decided to participate in this aspect of the project. Obtaining information from firms in the Computer/Office Equipment industry will provide the most applicable results for the industry as a whole.

In this package you will find a one-page questionnaire, labeled "H.R. Manager Survey", for you to complete. If you have any questions, please do not hesitate to contact me.

Phone: (954) 433-9234

Fax: (305) 348-3278

E-mail: Richardm@servax.fiu.edu

Ms. XXXXX, I would like to thank you for your assistance with this project. As I may have mentioned in our previous phone conversation, six weeks have been allocated to the collection of completed surveys. Therefore, may I ask that you return the questionnaire by July 20 ? I have enclosed a self-addressed, stamped envelope for this purpose. If you prefer to fax it to me, my fax number is provided above. In the ensuing months, I will prepare a report for you highlighting the results of the project and their value to firms in your industry. If at any time you decide that you would like to have your current expatriates participate by completing a questionnaire, please feel free to make copies from the one provided in the enclosed envelope, including the attached biodata card and cover letter. I will also be happy to forward any number of copies to you immediately. I assure you that at no time will the responses of this survey be used for any commercial purposes, nor will any of the individual respondents be identified.

Again, thank you very much, and I look forward to your responses and to our next correspondence.

Sincerely,

Meredith Downes

Florida International University 


\section{APPENDIX E}

\section{Letter to HR Manager (full participation)}

May 23, 1996

Ms. XXXXX

Vice President, Human Resources

ABC CORPORATION

XXXXXXXXXX

Dear Ms. XXXXX:

I am very pleased that you have decided to participate in this project. Obtaining information from firms in the Computer/Office Equipment industry will provide the most applicable results for the industry as a whole.

In this package you will find a one-page questionnaire, labeled "H.R. Manager Survey", for YOU to complete. You will also find an envelope containing the expatriate survey questionnaires (an adequate supply for your U.S. expatriate respondents), each accompanied by a demographic/biodata card and a cover letter. These are to be administered to your firm's expatriates that are currently on assignment abroad. The expatriate population of interest includes those who have been sent from the U.S. to work in another country. In the event that more surveys are needed, please let me know and I will forward them to you immediately.

Phone: (954) 433-9234

Fax: (305) 348-3278

E-mail: Richardm@servax.fiu.edu.

I assure you that at no time will the responses of this survey be used for any commercial purposes, nor will any of the individual respondents be identified.

Ms. XXXXX, I would like to thank you for your assistance with this project. I am confident that you will find the results beneficial to you. As indicated by the cover letter to each expatriate, I would like to receive the completed forms by July 20 . May I ask that you return the completed H.R. Manager Survey by that time as well? I have enclosed a self-addressed, stamped envelope for this purpose. If you prefer to fax it to me, my fax number is provided above. In the ensuing months, I will prepare a report for you highlighting the results of the project and their value to firms in your industry.

Again, thank you very much, and I look forward to your company's responses and to our next correspondence.

Sincerely,

Meredith Downes

Florida International University 


\section{APPENDIX F}

\section{H.R. MANAGER SURVEY}

1. What is your title with the organization?

2. For each country in which your organization has a subsidiary, please list that country below and then indicate the total number of professional-level employees used in that country's subsidiary. Of that population, please indicate the number that are U.S. expatriates and the number that are local nationals.

\section{COUNTRY}

1.

2.

3.

4.

5.

6.

7.

8.

9.

10.

11.

12.

13.

14.

15.

(please use the back of this paper if necessary)

.

.

5.

.

.

.

.

3.

4.

.
Total Number of Professional. Level Employees

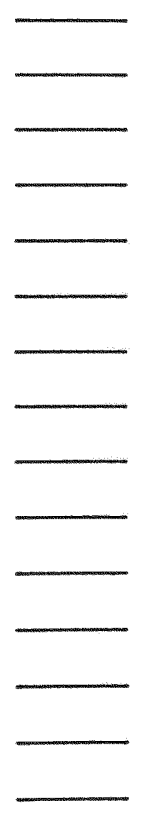

\section{Number of U.S. \\ Expatriates}

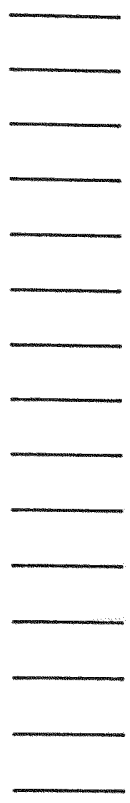

Number of Local Nationals

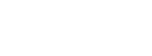




\title{
APPENDIX G
}

\section{Letter to Expatriates}

May 23, 1996

Dear Survey Respondent:

Your company has decided to participate in a research project conducted at Florida International University. The purpose of the project is to assess the expatriate experience both for the firm and for the individual on assignment abroad. More specifically, we are interested in the importance of certain elements to the overall outcomes of expatriate assignments. Therefore, your perceptions, as measured by the enclosed survey, are essential to this research. Your company has reviewed the outline for the project and sees potential benefits from participating.

Enclosed you will find the questionnaire survey, as well as a Demographic/Biodata card. It is equally important that both the questionnaire and the card be completed. It is approximated that this will take a total of 20-30 minutes.

As indicated above, this research is being conducted independent of your organization. Therefore, your responses will remain confidential by sending BOTH THE COMPLETED SURVEY AND THE BIODATA CARD to the following address:

\author{
Meredith Downes \\ Department of Management \& International Business \\ Florida International University \\ University Park \\ Miami, FL, USA 33199
}

I have enclosed a self-addressed envelope for this purpose. If you prefer to fax the completed forms to me, my fax number is provided below.

Recognizing possible delays in mail delivery time, as well as the fact that many people vacation around this time of your, six weeks have been allocated to the collection of completed surveys. Therefore, we would like to have your responses by July 20,1996 . If this date will pose a problem for you, or if you need any other assistance in completing these forms, pleas do not hesitate to contact me.

Phone: (954) 433-9234

Fax: (305) 348-3278

E-mail: Richardm@servax.fiu.edu

I sincerely thank you, in advance, for your assistance in this endeavor.

Sincerely,

Meredith Downes

Florida International University 


\section{APPENDIX H \\ Expatriate Survey (p. 1)}

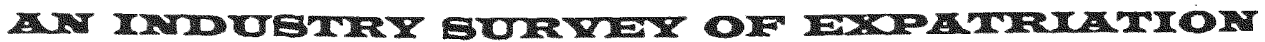

This survey is part of a research project designed to investigate expatriate policies in multinational firms and to assess the perceptions of expatriates regarding their international assiguments. Please answer all of the questions as they pertain to your current expatriate assignment.

1. In what country are you currently assigned?

2. Number of years that your company has had a subsidiary in this country

3. Number of years working for this company

Are these consecutive years?

4. What is your age?

5. How many years have you spent (in your lifetime) working overseas (not including this assignment)?

For the statements below, ask yourself: "How satisfied am I with this aspect of my job?" and respond by circling the appropriate number:

1. Being able to keep busy all the time

2. The chance to work alone on the job

3. The chance to do different things from time to time

4. The chance to be "somebody" in the community

5. The way my boss handles his/her subordinates

6. The competence of my supervisor in making decisions

7. Being able to do things that don't go against my conscience

8. The way my job provides for steady employment

9. The chance to do things for other people

10. The chance to tell people what to do

11. The chance to do something that makes use of my abilities

12. The way company policies are put into practice

13. My pay and the amount of work I do

14. The chances for advancement on this job

15. The freedom to use my own judgment

16. The chance to try my own methods of doing the job

17. The working conditions

18. The way my co-workers get along with each other

19. The praise I get for doing a good job

20. The feeling of accomplishment I get from the job

\begin{tabular}{|c|c|c|c|c|}
\hline $\begin{array}{l}\text { Very } \\
\text { Sacistied }\end{array}$ & Sexisfied & $\begin{array}{l}\text { Decide is } \\
\text { Satisfied } \\
\text { or Nor }\end{array}$ & $\underset{\text { satistied }}{\text { Dis }}$ & $\begin{array}{c}\text { Yery } \\
\text { Dis } \\
\text { sasisfied }\end{array}$ \\
\hline 1 & 2 & 3 & 4 & 5 \\
\hline 1 & 2 & 3 & 4 & $s$ \\
\hline 1 & 2 & 3 & 4 & 5 \\
\hline 1 & 2 & 3 & 4 & 5 \\
\hline 1 & 2 & 3 & 4 & 5 \\
\hline 1 & 2 & 3 & 4 & 5 \\
\hline 1 & 2 & 3 & 4 & 5 \\
\hline 1 & 2 & 3 & 4 & 5 \\
\hline 1 & 2 & 3 & 4 & 5 \\
\hline 1 & 2 & 3 & 4 & 5 \\
\hline 1 & 2 & 3 & 4 & 5 \\
\hline 1 & 2 & 3 & 4 & 5 \\
\hline 1 & 2 & 3 & 4 & 5 \\
\hline 1 & 2 & 3 & 4 & 5 \\
\hline 1 & 2 & 3 & 4 & 5 \\
\hline 1 & 2 & 3 & 4 & 5 \\
\hline 1 & 2 & 3 & 4 & 5 \\
\hline 1 & 2 & 3 & 4 & 5 \\
\hline 1 & 2 & 3 & 4 & 5 \\
\hline 1 & 2 & 3 & 4 & 5 \\
\hline
\end{tabular}


Please rate the statements below by circling the appropriate number:

1. I feel certain about how much authority I have.

2. Clear, planned goals and objectives exist for my job.

3. I know that I have divided my time properly.

4. I know what my responsibilities are.

5. I know exactly what is expected of me.

6. Explanation is clear of what has to be done.

7. I have discretion as to what work gets done.

8. I have discretion as to how work gets done.

9. I have authority to decide what tasks to delegate.

10. I have freedom to choose what to become an expert in.

11. I have discretion as to what tasks subordinates do.

12. I have authority to decide what work gets shared.

13. I have freedorn to decide how much of a generalist or expert to become.

14. I have discretion as to what I am responsible for.

15. I am proud to tell people who I work for.

16. I sometimes feel like leaving this organization for good.

17. I am not willing to put myself out just to help this organization.

18. Even if this organization were not doing so well financially, I would be reluctant to change to another employer.

19. I feel myself to be a part of the organization.

\begin{tabular}{|c|c|c|c|c|}
\hline $\begin{array}{l}\text { Strovely } \\
\text { Agree }\end{array}$ & Agree & $\begin{array}{l}\text { Nether } \\
\text { Agree mor } \\
\text { DAssagree }\end{array}$ & Dtsagree & $\begin{array}{l}\text { Stromely } \\
\text { Dusagree }\end{array}$ \\
\hline 1 & 2 & 3 & 4 & 5 \\
\hline 1 & 2 & 3 & 4 & 5 \\
\hline 1 & 2 & 3 & 4 & 5 \\
\hline 1 & 2 & 3 & 4 & 5 \\
\hline 1 & 2 & 3 & 4 & 5 \\
\hline 1 & 2 & 3 & 4 & 5 \\
\hline 1 & 2 & 3 & 4 & 5 \\
\hline 1 & 2 & 3 & 4 & 5 \\
\hline 1 & 2 & 3 & 4 & 5 \\
\hline 1 & 2 & 3 & 4 & 5 \\
\hline 1 & 2 & 3 & 4 & 5 \\
\hline 1 & 2 & 3 & 4 & 5 \\
\hline 1 & 2 & 3 & 4 & 5 \\
\hline 1 & 2 & 3 & 4 & 5 \\
\hline 1 & 2 & 3 & 4 & 5 \\
\hline 1 & 2 & 3 & 4 & 5 \\
\hline 1 & 2 & 3 & 4 & 5 \\
\hline 1 & 2 & 3 & 4 & 5 \\
\hline 1 & 2. & 3 & 4 & 5 \\
\hline 1 & 2 & 3 & 4 & 5 \\
\hline 1 & 2 & 3 & 4 & 5 \\
\hline 1 & 2 & 3 & 4 & 5 \\
\hline 1 & 2 & 3 & 4 & 5 \\
\hline 1 & 2 & 3 & 4 & 5 \\
\hline 1 & 2 & 3 & 4 & 5 \\
\hline 1 & 2 & 3 & 4 & 5 \\
\hline 1 & 2 & 3 & 4 & 5 \\
\hline 1 & 2 & 3 & 4 & 5 \\
\hline 1 & 2. & 3 & 4 & 5 \\
\hline
\end{tabular}

20. In my work I like to feel I am making an effort not only for myself but for the organization.

21. The offer of some more money with another employer would not make me think seriously about changing my job.

22. I would not advise a close friend to join our staff.

23. To know that my own work had made a contribution to the good of the organization would please me.

24. I've kept in close touch with people in the home office, so I think the transition back home will be fairly smooth.

25. I'm in contact with my bosses and colleagues back home a lot, and pretty much know what's happening on the home front.

26. I have a mentor back home who is looking out for my best interests while I'm overseas.

27. There's someone in management I can count on to keep me visible and under consideration for good assignnents while l'm away.

28. I have a friend in management back home whom I can really trust and whom I can talk to honestly about my problems over here.

29. My mentor is keeping his/her eyes out for a good repatriate assignment for me. 
30. I'm not sure that accepting this overseas assignment will be good for my career in the long run.

31. I can see how the skills I'm developing in this assignment will be useful to me later in my career.

32. I probably could have moved up the corporate ladder faster if I had stayed in a domestic assignment.

33. In terms of my career path in this company, this exparriate assignment makes a lot of serse.

34. Sometimes I feel like this expatriate assignment might not be very good for my career.

35. I'm not sure how this particular overseas assignment is going to help me later in my carees. in my career.

37. This expatriate assignment was the logical next step in my career.

38. I know how this expatriate assignment fits into my overall career.

39. This exparriate assignment really positions me well to get a good job when I get back home.

40. All in all. this expatriate assignment will be good for my career in terms of advancement and career mobility.

41. I'd probably have a better chance of getting promoted soon if I weren't in a foreign assignment.

42. This exparriate assignment has helped me develop important skills that will be useful to me later in my career.

43. This expatriate assignment fits in logically with my career path.
36. This expatriate assignment is going to open up lots of doors for me

\begin{tabular}{|c|c|c|c|c|}
\hline $\begin{array}{c}\text { Stroagly } \\
\text { Agre }\end{array}$ & Agree & $\begin{array}{l}\text { Nebier } \\
\text { Agre ner } \\
\text { Dirngree }\end{array}$ & Diswgree & $\begin{array}{l}\text { Stroongly } \\
\text { Distagree }\end{array}$ \\
\hline 1 & 2 & 3 & 4 & 5 \\
\hline 1 & 2 & 3 & 4 & 5 \\
\hline 1 & 2 & 3 & 4 & 5 \\
\hline 1 & 2 & 3 & 4 & 5 \\
\hline 1 & 2 & 3 & 4 & 5 \\
\hline 1 & 2 & 3 & 4 & 5 \\
\hline 1 & 2 & 3 & 4 & 5 \\
\hline 1 & 2 & 3 & 4 & 5 \\
\hline 1 & 2 & 3 & 4 & 5 \\
\hline 1 & 2 & 3 & 4 & 5 \\
\hline 1 & 2 & 3 & 4 & 5 \\
\hline 1 & 2 & 3 & 4 & $s$ \\
\hline 1 & 2 & 3 & 4 & 5 \\
\hline 1 & 2 & 3 & 4 & 5 \\
\hline
\end{tabular}

Five types of expatriate training programs are listed below, together with a brief description of each Please indicate whether you or your spouse recerved each type of training by checking the appropriate box

Area Studies Programs

Environmental briefings to provide information on the host country's sociopolitical history, geography, economy, and culture.

\section{Culture Assimilator}

A series of short episodes briefly describing intercultural encounters that are critical to the interaction between member of different cultures.

\section{Sensitivity Training}

Programs for developing attitudinal flexibility so that expatriates can become aware of and eventually accept unfamiliar behaviors and value systems as valid ways of doing things in a different culture.

\section{Field Experiences}

These involve sending the candidate to the counury of assignment or to "microcultures" nearby (e.g. Indian reservations, urban black ghertos) prior to the actual assignment.

\section{Language Training}

Please indicate the number of months for which language training was provided at the company's expense.

\section{Expatriate}

Yes No

Spouse

No Yes No
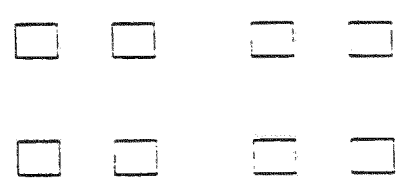

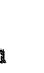

.

\section{.}




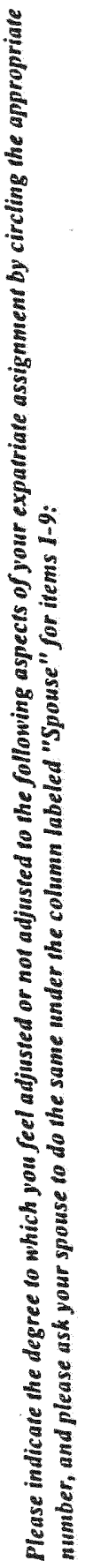

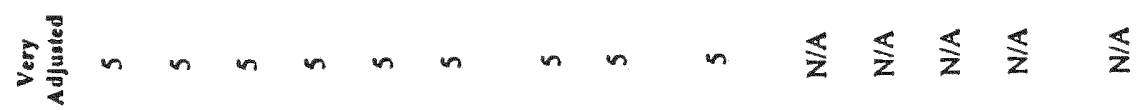

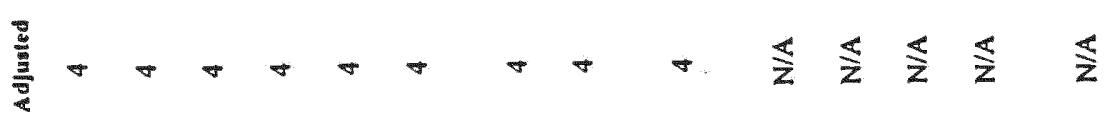

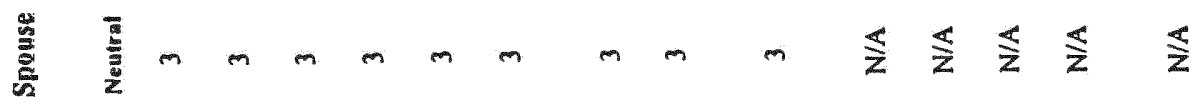

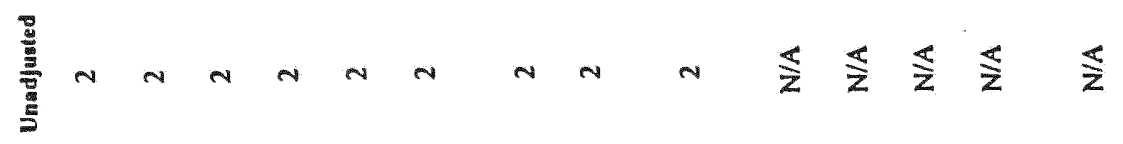

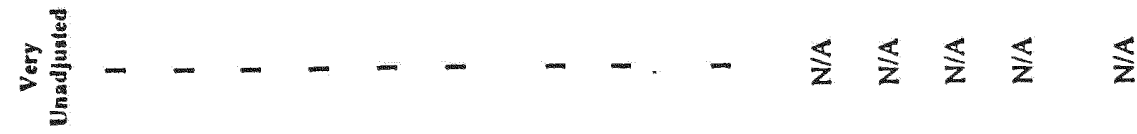

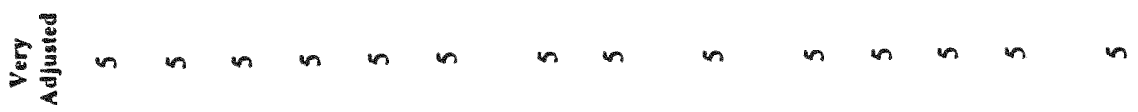

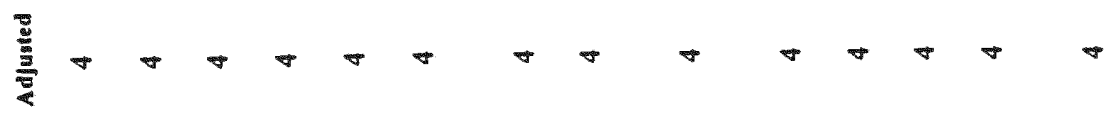
(1)

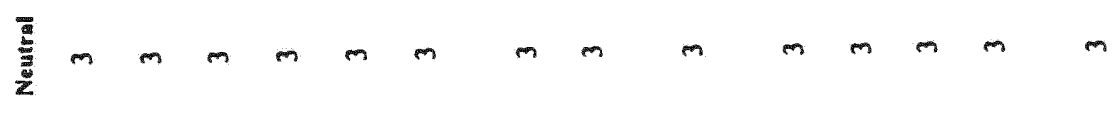

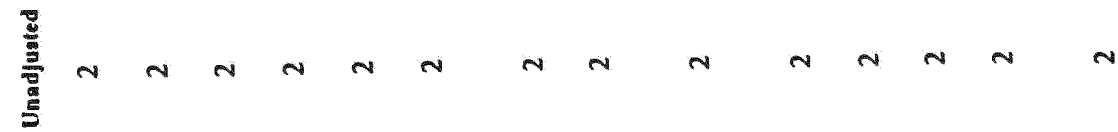

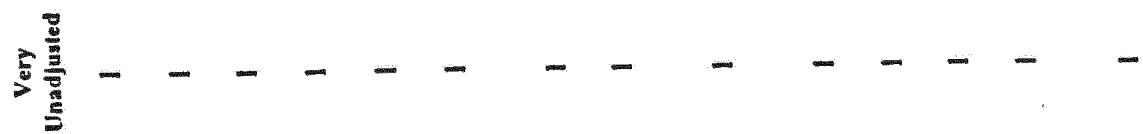

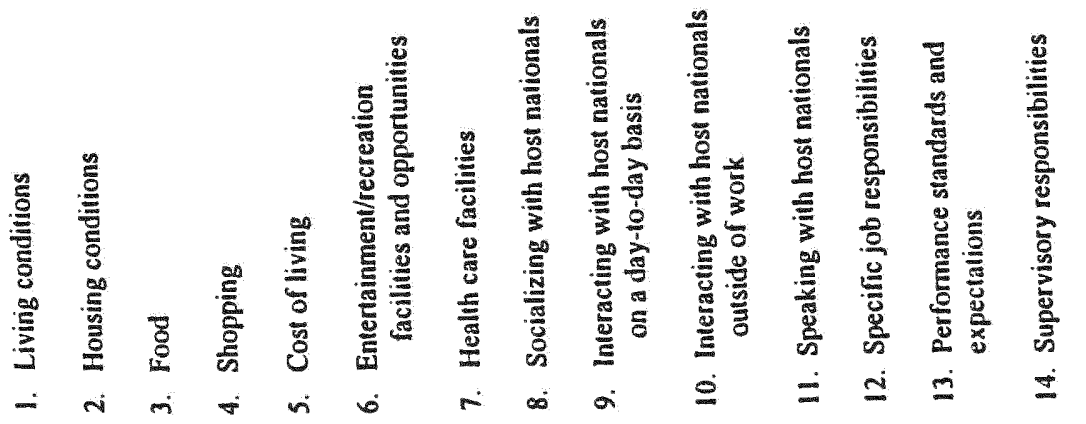




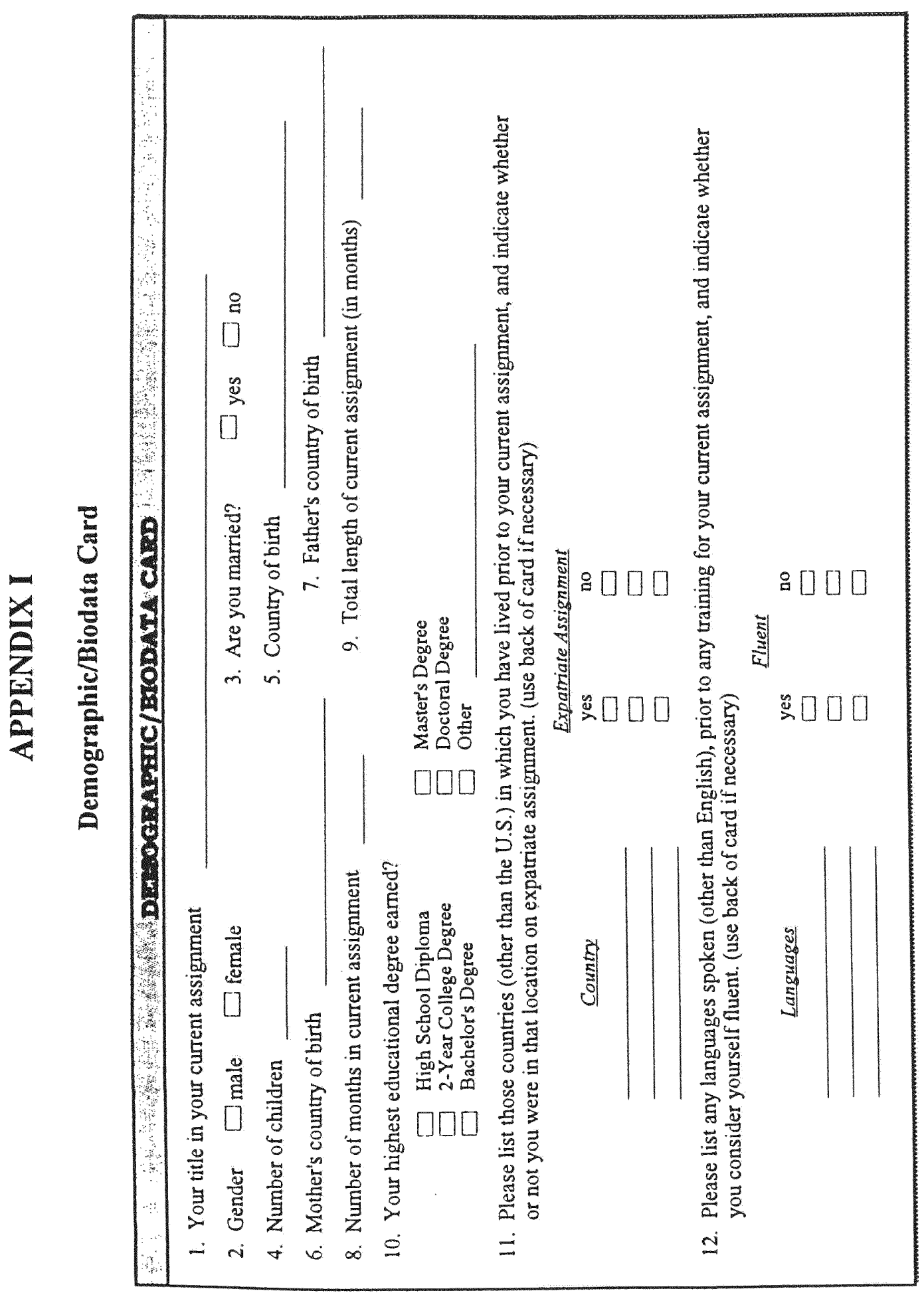




\section{APPENDIX J}

\section{Index of Abbreviations}

\begin{tabular}{|c|c|}
\hline $\mathrm{ADJ}$ & Expatriate Cross-Cultural Adjustment \\
\hline ADJSP & Spousal Cross-Cultural Adjustment \\
\hline AGE & Expatriate Age \\
\hline $\mathrm{CF}$ & Cultural Familiarity \\
\hline DOI & Degree of Internationalization \\
\hline EDUC & Expatriate Education Level \\
\hline FATA & Foreign Assets as a Percentage of Total Assets \\
\hline FSTS & Foreign Sales as a Percentage of Total Sales \\
\hline GEOG & Geographic Proximity \\
\hline HDI & Human Development Index \\
\hline IHRM & International Human Resource Management \\
\hline IND & Industry \\
\hline LT & Long-Term Career Planning \\
\hline MENT & Mentorshp Provisions \\
\hline MNC & Multinational Corporation \\
\hline $\mathrm{OC}$ & Expatriate Organizational Commitment \\
\hline OSTS & Overseas Subsidiaries to Total Subsidiaries \\
\hline OVER & Expatriate Overseas Experience \\
\hline PDIO & Psychic Dispersion of International Operations \\
\hline PROPEXP firm & Proportion of Expatriates in Firm \\
\hline
\end{tabular}


APPENDIX J (cont'd)

PROPEXP $_{\text {sub }} \quad$ Proportion of Expatriates in Subsidiary

RA

Role Ambiguity

$\mathrm{RD}$

Role Discretion

RISK

Degree of Host-Country Risk

SAT

Expatriate Job Satisfaction

SUB

Subsidiary Age

TEN

Expatriate Tenure with Firm

TMIE

Top Management International Experience

TREXP

Expatriate Training

TRSP

Spousal Training 
VITA

\section{MEREDITH DOWNES}

March 1, 1965

1987

1992

1997

1997
Born, Miami, Florida

B.S., Journalism

University of Florida

Gainesville, Florida

M.B.A.

Florida International University

Miami, Florida

Ph.D., Business Administration

Florida International University

Miami, Florida

Assistant Professor

Mlinois State University

Normal, Illinois

\section{PUBLICATIONS AND PRESENTATIONS}

Downes, M. (1994). [Review of General managers in action: Policies and strategies, by Francis Joseph Aguilar]. Organizational Dynamics, Fall, 77-78.

Downes, M. (1994). [Review of Making quality happen: How training can turn strategy into real improvement, by Ted Cocheu]. Organizational Dynamics, Summer, 7475.

Downes, M. (1995). Human resource practices in ASEAN: A comparative analysis.

Proceedings of the Annual Academy of International Business, Southeast USA, Orlando, FL.

Downes, M. (1996). SIHRM: Global staffing considerations. Journal of International Management, 2(1): 31-50.

Downes, M., \& Kroeck, K. G. (1994). Exploring occupational interests and employment opportunities in jobs with international dimensions. Paper presented at the Annual Meetings of the Academy of International Business Meetings, Boston, MA., and at the Graduate Students' Scholarly Forum, Florida International University, Miami, FL. 
Downes, M., \& Kroeck, K. G. (1996). Discrepancies between existing jobs and individual interests: An empirical application of Holland's model. Journal of Vocational Behavior, 48(1): 107-117.

Downes, M., \& Thomas, A. (1996). Expatriates as a tool for organizational learning as firms internationalize. Paper presented at the Annual Meetings of the Academy of International Business Meetings, Banff, Canada.

Downes, M., \& Thomas, A. (1997). An organizational learning approach to expatriate cross-cultural adjustment. Paper to be presented at the Annual Meetings of the Academy of Management, Boston, MA.

Downes, M., Zalka, L., Perry, S. R., Friday, S. S., Paul, K., Abratt, R., \& Curwen, P. (1996). Creating a tool for mass marketing: A three-country study. Proceedings of the Annual Academy of International Business, Southeast USA, New Orleans, LA.

Lowe, K., \& Downes, M. (1996). Willingness to accept international assignments: Does gender matter? Paper presented at the Graduate Students' Scholarly Forum, Florida International University, Miami, FL.

Lowe, K., Downes, M., \& Kroeck, K. G. (1996). Women's interests in international careers: Revisiting prior research with referent countries. Paper presented at the Annual Meetings of the Academy of Management, Cincinnati, $\mathrm{OH}$.

Zalka, L., Downes, M., \& Paul, K. (1997). Consumer sensitivity to corporate social performance in the Anglo cluster of countries. Proceedings of the Annual Eastern Academy of Management, Dublin, Ireland.

Zalka, L., Downes, M. , \& Paul, K. (1997). Measuring consumer sensitivity to corporate social performance: Which consumers care most? Journal of Global Marketing, 11(1), 29-48. 